\title{
¿Puede enseñarse el Derecho inglés en las universidades?
}

Albert Venn Dicey

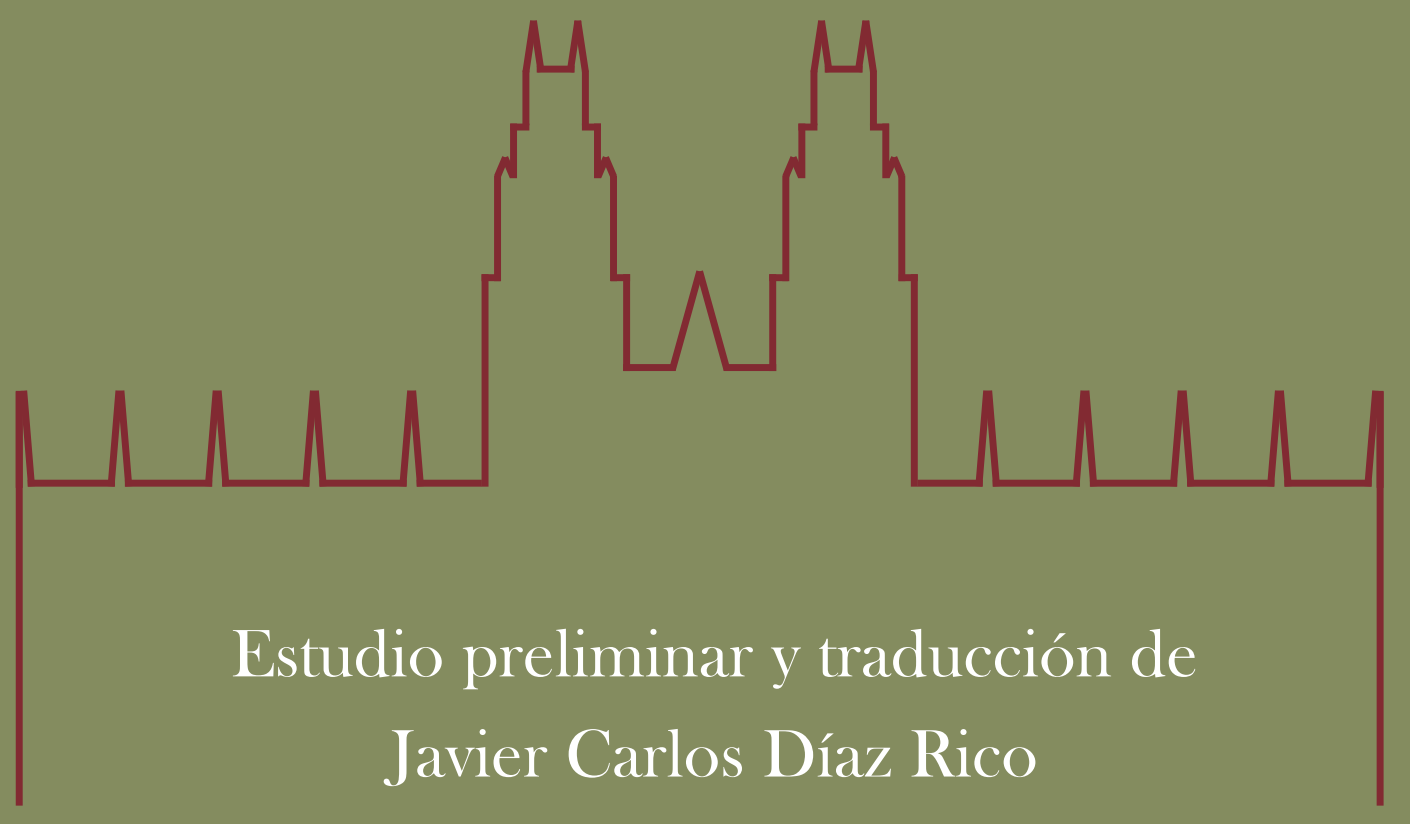



¿PUEDE ENSEÑARSE EL DERECHO INGLÉS

EN

LAS UNIVERSIDADES? 
The Figuerola Institute

Programme: Legal History

The Programme "Legal History" of the Figuerola Institute of Social Science History -a part of the Carlos III University of Madrid- is devoted to improve the overall knowledge on the history of law from different points of view -academically, culturally, socially, and institutionally- covering both ancient and modern eras. A number of experts from several countries have participated in the Programme, bringing in their specialized knowledge and dedication to the subject of their expertise.

To give a better visibility of its activities, the Programme has published in its Book Series a number of monographs on the different aspects of its academic discipline.

Publisher:

Carlos III University of Madrid

Book Series:

Legal History

Editorial Committee:

Manuel Ángel Bermejo Castrillo, Universidad Carlos III de Madrid

Catherine Fillon, Université Jean Moulin Lyon 3

Manuel Martínez Neira, Universidad Carlos III de Madrid

Carlos Petit, Universidad de Huelva

Cristina Vano, Università degli studi di Napoli Federico II

More information at www.uc3m.es/legal_history 
¿PUEDE ENSEÑARSE EL DERECHO INGLÉS EN LAS UNIVERSIDADES?

ALBERT VENN DICEY

Estudio preliminar y traducción de

Javier Carlos Díaz Rico

DYKINSON

2021 
Publicación financiada por FEDER/Junta de Andalucía-Consejería de Economía y Conocimiento/Proyecto “La memoria del jurista” (ref. UHU-1256527).

Historia del derecho, 93

ISSN: 2255-5137

(C) 2021 Javier Carlos Díaz Rico

Editorial Dykinson

c/ Meléndez Valdés, 61 - 28015 Madrid

Tlf. (+34) 915442846

E-mail: info@dykinson.com

http://www.dykinson.com

Preimpresión: TALLERONCE

ISBN: 978-84-1377-346-9

Depósito legal: M-4248-2021

Versión electrónica disponible en e-Archivo

http://hdl.handle.net/10016/31912

\section{(c) (i) (8) $\Theta$ \\ BY NC ND}

Licencia Creative Commons Atribución-NoComercial-SinDerivadas 3.o España 
ÍNDICE

Dicey y la enseñanza jurídica: Javier Carlos Díaz Rico

1. Dicey y la Cátedra Viner 9

2. Renovación de la enseñanza del derecho inglés (1846-1884) 11

3. Creación de literatura jurídica y codificación 30

4. Nota sobre la traducción 35

¿Puede enseñarse el derecho inglés en las universidades? 39

Can English law be taught at the Universities? 63

Apéndices

1. Principales sedes de la enseñanza jurídica (1847-1914) 85

2. Cronología de Albert Venn Dicey 86

3. Ante la Gresham University Commission (1892) 89

$\begin{array}{ll}\text { Bibliografía } & 113\end{array}$ 



\section{DICEY Y LA ENSEÑANZA JURÍDICA}

\section{Dicey y la CÁtedRa Viner}

Albert Venn Dicey (1835-1922) accedió a la Cátedra Viner de derecho inglés del All Souls College de la Universidad de Oxford en 1882. Lo hizo con 47 años y permaneció en ella otros 27, hasta 1909. Su lección de despedida tuvo por objeto los Comentarios de Blackstone, el primer titular de la Cátedra Viner, la más antigua de derecho inglés (fundada en 1758) ${ }^{1}$. Tras abandonarla, Dicey ocupó brevemente el cargo de reader en derecho internacional privado (1910-1913), disciplina de la cual fue uno de sus principales impulsores en Inglaterra. La cátedra que nos ocupa deriva su nombre del jurista inglés Charles Viner (1678-1756), cuyo testamento previó su creación².

Las dos biografías existentes sobre Dicey no otorgan un papel relevante a sus ideas sobre la enseñanza del derecho, a pesar haber sido uno de los aspectos cruciales de su elección a la cátedra ${ }^{3}$. Los estudios sobre Dicey están decididamente centrados en su Law of the Constitution ${ }^{4}$, y en menor medida en su Law and Opinion ${ }^{5}$, sin conceptualizar la primera obra como culminación de un programa de investigación comenzado décadas atrás, la "exposición clara y efectiva del derecho vigente”. La lección inaugural no se entiende sin la experiencia de la instrucción jurídica en los bufetes y el propio ejercicio posterior

1 A. V. Dicey, "Blackstone's Commentaries”, National Review 54 (1909), pp. 653-675. Reimpresa en The Cambridge Law Journal 4, 3 (1932), pp. 286-307.

2 Vid. la lección inaugural de otro Vinerian Professor, William S. Holdsworth, Charles Viner and the Abridgments of English Law, Londres, Stevens \& Sons, 1923.

3 Richard A. Cosgrove, The Rule of Law. Albert Venn Dicey. Victorian Jurist, Chapel Hill, The University of North Carolina Press, 1980, cap. 3, The restoration of the Vinerian Chair, pp. 45-65; Trowbridge H. Ford, Albert Venn Dicey. The Man and His Times, Chichester, Barry Rose Publishers Ltd., 1985, cap. 5, Apprenticeship in London, pp. 79-100. Vid. en español el reciente estudio, Héctor Domínguez Benito, "Historia de un manifiesto. Una introducción al derecho de la constitución de Albert Venn Dicey”, en A. V. Dicey, El derecho de la constitución, Valencia, Tirant lo Blanch, 2019, pp. 9-77.

4 A. V. Dicey, Lectures Introductory to the Study of the Law of the Constitution, Londres, Macmillan and Co., 1885.

5 A. V. Dicey, Lectures on the Relation between Law \& Public Opinion in England during the Nineteenth Century, Londres, Macmillan and Co., 1905.

6 A. V. Dicey, ¿Puede enseñarse el derecho inglés en las universidades?, infra, p. 57. 
de la abogacía por parte de Dicey. Al igual que en los casos de sus colegas de Oxford Pollock, Holland o Anson, aprendizaje en el bufete y ejercicio del derecho son dos elementos insalvables para explicar su pensamiento jurídico.

Esta lección inaugural permite asimismo calibrar el influjo en Dicey de los juristas que le precedieron. La literatura tradicional ha modelado tal influencia en dos vertientes, una analítica representada por John Austin y otra histórica representada por Henry S. Maine. Habitualmente se otorga un peso determinante a la primera, lo que conduce a la calificación de Dicey como jurista austiniano-analítico 7 . Las propuestas de Dicey en su lección inaugural cuestionan esta tradicional visión en favor de un entendimiento más complejo de su producción intelectual. Recientes aportaciones transitan esta vía, por ejemplo a propósito de la teoría constitucional del imperio defendida por Dicey, impregnada de una noción de civilización próxima a la defendida por Maine ${ }^{8}$.

El libro clásico sobre la Cátedra Viner o Vinerian Chair of English Law es el de Harold G. Hanbury, titular de la misma durante el periodo 1949-19649. Su título es sin embargo impreciso, pues si bien pueden encontrarse en él retratos de los distintos titulares de la cátedra y análisis de sus doctrinas, escasa información es ofrecida sobre las condiciones de la enseñanza del derecho presentes en cada periodo. Hasta cierto punto es paradójica esta ausencia, en una obra que denomina el acceso a la cátedra de Dicey "segunda fundación" de la misma. Estas carencias fueron remediadas primeramente por el profesor Frederick H. Lawson con su obra The Oxford Law School, cuya primera página centra adecuadamente el objeto de estudio: "el derecho fue enseñado por primera vez en Oxford hace muchos siglos, pero la formación jurídica [legal education] tal como la conocemos hoy tiene una historia de poco más de cien años, [...]"10. Así lo reconoció Dicey en su lección ${ }^{11}$. La presente intro-

7 Cfr. Ian Ward, Writing the Victorian Constitution, Cham, Springer International Publishing, 2018, p. 170. Hart en cambio no lo nombra: "[D]esde Austin desciende una línea de juristas analíticos ingleses: Amos, Clark, Markby, Hearn, Holland y Salmond [...]”, cfr. H. L. A. Hart, "Introducción” [1954], en John Austin, El objeto de la jurisprudencia (ed. Juan Ramón de Páramo), Madrid, 2002, pp. 5-15, p. 15.

8 Vid. Dylan Lino, "Albert Venn Dicey and the Constitutional Theory of Empire”, $O x$ ford Journal of Legal Studies 36, 4 (2016), pp. 751-780, p. 764.

9 Harold G. Hanbury, The Vinerian Chair and Legal Education, Oxford, Basil Blackwell, 1958.

10 Frederick H. Lawson, The Oxford Law School, 1850-1965, Oxford, Clarendon Press, 1968, p. 1.

11 Dicey, ¿Puede enseñarse el derecho inglés en las universidades?, infra, p. 60. 
ducción expondrá los inicios de esta formación en la Universidad de Oxford, contemplados desde la perspectiva de Dicey.

\section{RENOVACIÓN DE LA ENSEÑANZA DEL DERECHO INGLÉS (1846-1884)}

Dicey fue admitido el 26 de enero de 1863 en la corporación de barristers londinense Inner Temple, pero conviene remontarse unas décadas atrás para establecer cuál era la situación a la que se enfrentaban los juristas reformistas. El propio Dicey señala en su lección los años cuarenta y cincuenta del siglo XIX como el inicio de las reformas en la enseñanza del derecho ${ }^{12}$.

El 25 agosto de 1846 fue publicado el informe del Comité sobre Enseñanza Jurídica $^{13}$, nombrado por la Cámara de los Comunes el 8 de abril del mismo año. Éste se lamenta, comparando explícitamente en varias ocasiones la situación inglesa con la alemana, de que solamente haya en Oxford dos cátedras de derecho, "la cátedra de Civil Law, ocupada por el Dr. Phillimore, y la cátedra de Common Law, también llamada Vinerian Professorship, desempeñada por el Dr. Kenyon"14. Sobre esta última se afirma que el número de lecciones anuales es de veinticuatro y el de asistentes es de alrededor de treinta y ocho. No hay exámenes ni se confieren grados en Common Law, solamente en Civil Law. En Cambridge se encuentran otras dos cátedras jurídicas, The Regius Professorship of Civil Law y The Downing Professorship of Law, ocupadas por el Dr. Geldart y por Mr. Starkie respectivamente ${ }^{15}$.

El University College de Londres sale mejor parado de la investigación parlamentaria. Su situación se valora como más avanzada o "continental". Su reciente fundación por círculos benthamistas en 1826 contribuyó a ello. La de Jurisprudencia era una de sus facultades y se conferían anualmente grados de bachiller y de doctor en derecho, tras la superación de un examen. El estudiante podía escoger entre los Commentaries de Blackstone o los de Kent, y

12 Signo de un destacado "movimiento intelectual, o incluso revolución" en sus palabras, cfr. Dicey, ¿Puede enseñarse el derecho inglés en las universidades?, infra, p. 58.

13 House of Commons, Report from the Select Committee on Legal Education. Together with the Minutes of Evidence, Appendix and Index, Londres, 1846.

14 House of Commons, Report from the Select Committee on Legal Education, cit., p. iii. Joseph Phillimore (1775-1855) fue Regius Professor of Civil Law en Oxford durante el periodo 1809-1855.

15 Vid. Christopher Harvie, "From the Cleveland Commission to the Statutes of 1882 ", en Michael G. Brock (ed.), The History of the University of Oxford, Oxford, Clarendon Press, 2000, vol. 7, pp. 67-96. 
opcionalmente los Institutes de Rutherforth o los Principles of the Civil and Criminal Code de Bentham. La cátedra de derecho la ocupaba el profesor Andrew Amos con notable éxito (de cincuenta a ciento cincuenta asistentes), mientras que las lecciones de John Austin no lo tuvieron tanto debido a su "carácter abstracto", fracaso que condujo a su posterior dimisión.

El informe finaliza con 34 conclusiones, algunas muy expresivas de cómo se percibía la cuestión educativa en el derecho. Por ejemplo, la conclusión tercera:

"Puede por tanto declararse, como hecho general con pocas excepciones, que el estudiante, profesional y no profesional, es abandonado casi únicamente a sus esfuerzos personales, aplicación, y oportunidades, y que ninguna educación jurídica, digna de tal nombre, de naturaleza pública, puede encontrarse en este país"16.

La conclusión séptima deja constancia de las diferencias culturales con el resto de Europa:

"La formación jurídica del Continente se desarrolla casi exclusivamente en las Universidades, y las Universidades están reguladas bajo un sistema totalmente diferente del nuestro".

En 1852 las Inns of Court crean el Council for Legal Education, compuesto por cinco miembros designados por estas corporaciones, bajo la presidencia de Richard Bethell (1800-1873), posteriormente Lord Chancellor (Lord Westbury) en el gobierno de Palmerston ${ }^{17}$. Una de las iniciativas más destacadas de tal Consejo fue el establecimiento de cinco readerships, con la finalidad de "revivir" una enseñanza en decadencia desde el siglo XVII ${ }^{18}$. A este avance se sumaría la creación por las Inns del Council of Law Reporting en 1865 y la introducción en 1872 de un sistema obligatorio de exámenes para

16 House of Commons, Report from the Select Committee on Legal Education, cit., p. lvi.

17 En 1866 Westbury promovió la formación de una Royal Commission to Inquire into the Expediency of a Digest of Law, disuelta en 1870 sin resultados aparentes. Cfr. Fiona R. Burns, "Lord Westbury, Law Reform and Fusion”, The Journal of Legal History 29 (2008), pp. 1-37, p. 20.

18 Lawson, The Oxford Law School, cit., p. 2. El propio Austin ofreció lecciones de jurisprudence en el Inner Temple también con escaso éxito. Cfr. Wilfrid E. Rumble, Doing Austin Justice. The Reception of John Austin's Philosophy of Law in Nineteenth-Century England, Londres/Nueva York, Continuum, 2005, p. 19. 
el acceso a la profesión de barrister (call to the Bar). En la siguiente década se publicó un informe sobre la formación jurídica impartida en las Inns of Court $^{19}$. Cinco readers ejercían docencia en aquel momento ${ }^{20}$ : John G. Phillimore (constitutional law and legal history) ${ }^{21}$, Henry S. Maine (jurisprudence and civil law), Reginald Walpole (conveyancing), Herbert Broom (Common Law, citado por Dicey en la lección inagural) y William L. Birckbeck (equity). Las lecciones de Maine fruto de tal enseñanza dieron lugar a su obra más influyente: Ancient $L a w^{22}$.

En la siguiente década Dicey situó el avance inicial en la literatura jurídica inglesa, el objetivo final de su plan de reformas como veremos. Fue impulsado por un primer grupo de juristas, entre los que destacaron Thomas B. Macaulay (1800-1859), Henry S. Maine (1822-1888), James F. Stephen (1829-1894), y el desaparecido en 1859 John Austin, cuyas Lectures on Jurisprudence se publicaron entre 1861 y $1863^{23}$. Un segundo grupo -el de Dicey- introdujo en Oxford estas ideas renovadoras. Fueron principalmente Thomas E. Holland (1835-1926), James Bryce (1838-1922), William R. Anson (1843-1914) y Frederick Pollock (1845-1937). Estos dos últimos, calificados de amigos, son citados y celebrados en la lección inaugural, acentuándose la ruptura con juristas precedentes, escasamente científicos ${ }^{24}$. Sus largas trayectorias vitales ayudan a explicar su duradera influencia en el derecho inglés, también debida a su notable cohesión interna. Sus orígenes socioeconómicos eran los mismos y todos ellos se habían formado en Oxford o Cambridge, y en Eton o en la King's College School de Londres (el caso de Dicey). Por otro lado, el ámbito académico del derecho era bastante reducido en aquella época y los centros docentes escasos. Aunque el título de la lección se refiere sin pre-

19 House of Commons, Report of the Commissioners Appointed to Inquire into the Arrangements in the Inns of Court and Inns of Chancery, for Promoting the Study of the Law and Jurisprudence. Together with Appendices, Londres, 1855.

20 Report of the Commissioners Appointed to Inquire into the Arrangements in the Inns of Court, etc, cit., p. 11.

21 John George Phillimore (1808-1865) barrister de Lincoln's Inn, hijo del mencionado Joseph Phillimore.

22 Henry S. Maine, Ancient Law. Its Connection with the Early History of Society and its Relation to Modern Ideas, Londres, John Murray, 1861. En 1887 ya había alcanzado la $11^{\mathrm{a}}$ edición.

23 John Austin, Lectures on Jurisprudence. Or the Philosophy of Positive Law, Londres, John Murray, 1861-1863, 3 vols.

24 Dicey, ¿Puede enseñarse el derecho inglés en las universidades?, infra, p. 49 y 77. 
cisar a las universidades inglesas, Dicey sólo menciona a Cambridge y Oxford. La de Londres adquirió importancia más adelante, mientras que la producción de graduados del resto de universidades fue mínima durante esta época. Por ejemplo, el Owens College de Mánchester, donde Bryce y Dicey ocuparon cargos docentes en los años setenta, no alcanzó el estatus de universidad hasta el otorgamiento de la Royal Charter de 1880 , por la que se creó la Victoria University. Dicey fue lecturer en derecho durante el periodo 1872-1873 en el mencionado Owens College ${ }^{25}$.

El primer grupo de reformadores se caracterizó por su relativa heterogeneidad, pues incluyó tanto a profesores de universidad como a jueces y altos funcionarios. Tal fue caso de Macaulay, historiador y barrister que desarrolló una importante carrera política. De él dice Dicey que fue el creador de "un nuevo tipo de codificación” ${ }^{26}$, implantada por primera vez en el Código Penal Indio de 1860, elaborado por la comisión jurídica que presidión ${ }^{27}$. La carrera de Maine por el contrario estuvo más centrada en el derecho; ejerció el cargo de Regius Professor of Civil Law en la Universidad de Cambridge (18471854) y el de Corpus Professor of Jurisprudence de la Universidad de Oxford (1869-1877). Entre medias ocupó el cargo de consejero jurídico del Consejo Legislativo Imperial de la India (1862-1869). Una publicación suya de 1856 fue una de las primeras reflexiones sobre la relación entre el derecho romano y la enseñanza del derecho ${ }^{28}$, que impulsó en Inglaterra el "renacimiento" del estudio del derecho romano al que se refiere Dicey en su lección ${ }^{29}$.

25 Philip J. Hartog, The Owens College, Manchester, (Founded 1851). A Brief History of the College and Description of its Various Departments, Mánchester, J. E. Cornish, 1900, pp. 83-85.

26 Dicey, ¿Puede enseñarse el derecho inglés en las universidades?, infra, p. 78.

27 Cfr. W. Morgan y A. G. Macpherson (eds.), The Indian Penal Code (Act XLV of 1860). With Notes, Calcuta, G. C. Hay \& Co/Londres, Crescent Place, Blackfriars, 1863, p. v. Holland consideró tal código el instrumento legislativo más científico en lengua inglesa hasta el momento. Cfr. Thomas E. Holland, "Codification”, Edinburgh Review 127 (1867), pp. 347-376, p. 364 .

28 Henry S. Maine, "Roman Law and Legal Education” [1856], en Henry S. Maine, Village Communities, Londres, Henry Holt and Company, 1876. Para la decisiva influencia de Maine vid. Carlos Petit, "California y el Derecho Romano", nota de lectura a Max Radin, Cartas Romanísticas (1923-1950), Nápoles, Jovene, 2001, pp. xi-cxxiv, pp. lxvlxix.

29 Dicey, ¿Puede enseñarse el derecho inglés en las universidades?, infra, p. 52. Azcárate y Santiago Innerárity anunciaban este renacimiento en la nota "Al lector" de su traducción de los Estudios de derecho romano del juez Mackenzie. Cfr. Gumersindo Azcárate 
Su artículo comienza con una advertencia sobre la distinción entre derecho escrito y no escrito, que recorre a todos los autores del periodo ${ }^{30}$. El derecho inglés está escrito y puede encontrarse en los reports. La codificación sería por tanto la conversión del derecho escrito en derecho bien escrito ${ }^{31}$. Esta empresa, que es calificada como "uno de los más valiosos objetos de los empeños humanos", es sin embargo prematura a juicio de Maine. Si no puede producirse una buena ley en el momento actual, es inútil intentar producir un código. La causa principal son los problemas terminológicos, presentes tanto en leyes como en el derecho inglés en general, que surgen debido a la ausencia de un sistema de instrucción jurídica organizado ${ }^{32}$. La terminología legal -en su opinión- debe convertirse en una disciplina específica de la educación jurídica; con la ayuda del derecho romano, el vocabulario jurídico puede ser ampliamente mejorado. Aunque reconociendo que en la práctica es imposible, menciona el ideal de reducir todo el lenguaje jurídico a la condición de símbolos algebraicos, para de este modo producir uniformidad en su método de empleo e identidad en las inferencias necesarias para su interpretación. Especialmente nocivos son a su entender los Acts of Amendment aprobados por el Parlamento británico. En estos casos la persona que proyecta la alteración de la ley no está coordinada con su redactor original, lo cual origina importantes problemas interpretativos. Sin embargo el problema de la calidad técnica de las leyes se debe, más que a la persona concreta que las redacta, a la carencia de un sistema de instrucción jurídica "que asegure la consistencia y cohesión de un cuerpo de derecho". Esta instrucción es tan importante como el libre intercambio de precedentes en los tribunales o un entendimiento común por parte de los jueces. Por último denuncia Maine la ausencia del hábito de interpretar el derecho legislado como un todo. Se había llegado a la

y Santiago Innerárity, “Al lector”, en Lord [Thomas] Mackenzie, Estudios de derecho romano comparado en algunos puntos con el francés, el inglés y el escocés [1862], Madrid, Francisco Góngora, 1876, pp. v-viii, p. vi.

30 John Austin, "On the Uses of the Study of Jurisprudence", en John Austin, Lectures on Jurisprudence (ed. Sarah Austin), Londres, John Murray, 1863, vol. 3, pp. 345388, p. 351. Dicey, The Law of the Constitution, cit., p. 28. Blackstone denomina al Common Law lex non scripta "porque recibe su fuerza legal del largo e inmemorial uso", cfr. William Blackstone, Commentaries on the Laws of England, Oxford, Clarendon Press, 1765-1770, vol. 1, Introduction, section 3, Of the Laws of England, p. 63-64.

31 Cursiva del autor. Maine, Ancient Law, cit., p. 14: "[I]t is written case-law, and only different from code-law because it is written in a different way".

32 Maine, "Roman Law and Legal Education", cit., p. 348. 
práctica - insiste - de interpretar una ley de manera aislada, lo cual conduce a que el Parlamento reaccione mediante la producción de leyes excesivamente detallistas. Uno de los orígenes de este defecto es la falta de un aparato de interpretación de normas, que sí posee en cambio el derecho romano ${ }^{33}$.

La progresiva circulación de proyectos de reforma, parlamentarios o privados, provocó que el proyecto codificador inspirado en Bentham decayese hacia los años cincuenta y fuera sustituido por otros más influidos por las corrientes alemanas. Un joven Dicey de 23 años se trasladó a la capital en 1858 solicitando su admisión en el Inner Temple, concedida en $1863^{34}$. En 1860 obtuvo la ansiada fellowship del Trinity College de Oxford tras el correspondiente examen. En este periodo de inmersión en la abogacía asistió a la publicación en 1861 de dos obras que influyeron poderosamente en el desarrollo de la ciencia jurídica inglesa: Lectures on Jurisprudence de John Austin y Ancient Law de Maine. Si bien Austin publicó The Province of Jurisprudence Determined en 1832 durante su etapa de profesor del University College de Londres, recibió escasa atención en aquellos años ${ }^{35}$. En 1861 su esposa Sarah Austin publicó una reimpresión de la obra (volumen 1) y dos años más tarde los volúmenes 2 y 3 . Este último contiene un interesante fragmento escrito entre 1828 y 1834 titulado Sobre la utilidad del estudio de la jurispruden$c{ }^{36}{ }^{36}$, con gran influjo de Savigny, cuyo Beruf había sido publicado en Inglaterra en $1831^{37}$. Austin transcribe en él un amplio pasaje del jurista alemán del que ahora solamente nos interesa una parte:

"Es, pues, evidente que la formación actual del jurista, -que consta de dos mitadesestá concebida de manera que la primera mitad (en la universidad) está dedicada a la base

33 Maine, "Roman Law and Legal Education", cit., p. 374.

34 Inner Temple Archives, signatura ADM 6.19.

35 Hart, "Introducción” [1954], en John Austin, El objeto de la jurisprudencia, cit., p. $5:$ "[...] nunca fue comentada en ninguna revista culta".

36 Austin, "On the Uses of the Study of Jurisprudence", en John Austin, Lectures on Jurisprudence (ed. Sarah Austin), cit. El escrito es una refundición de las lecciones inaugurales de Austin en la Universidad de Londres (1828) y en el Inner Temple (1834), cfr. Sarah Austin, "On the Uses of the Study of Jurisprudence”, nota preliminar a John Austin, Lectures on Jurisprudence (ed. Sarah Austin), cit., vol. 3, pp. 347-348, p. 347. La última edición española es: John Austin, Sobre la utilidad del estudio de la jurisprudencia, Santiago (Chile), Olejnik, 2018.

37 Friedrick Charles von Savigny, Of the Vocation of Our Age for Legislation and Jurisprudence, Londres, Littlewood \& Co, 1831, traducción de Abraham Hayward de la $2^{\mathrm{a}}$ edición de 1828. 
científica, y, en cambio, la segunda tiene por cometido el conocimiento del Código civil y del procedimiento prusiano, así como el manejo práctico de los mismos" ${ }^{38}$.

La afinidad con la propuesta de Dicey (Oxford y chambers) no puede ser más patente. Más adelante comprobaremos que importantes argumentos de nuestro recién catedrático ya los adelantó Austin en su escrito ${ }^{39}$. Por lo demás, las Lectures de Austin se convirtieron, en esta segunda vida, en un exitosísimo manual gracias al interés despertado por las reformas jurídicas, gozando incluso de ediciones adaptadas para el estudiante ${ }^{40}$.

James Fitzjames Stephen presentó a Austin y a Maine como los dos únicos autores dignos de mención de la jurisprudencia inglesa, en un artículo de 1861 titulado así, English Jurisprudence ${ }^{41}$. Este barrister londinense resultó decisivo para la generación de juristas de Dicey, e influyó particularmente en este último, ya que era su primo materno (y hermano del escritor Leslie Stephen). Ocupó al igual que Maine el cargo de consejero jurídico del Consejo Legislativo de la India (1869-1872), y durante el periodo 1875-1879 fue reader en Common Law en las Inns of Court, antes de ser nombrado juez de la High Court ${ }^{42}$.

Mientras tanto Dicey continuaba con escaso éxito su ejercicio jurídico en Londres, en cuyo Working Men's College ejerció como profesor de lógica en

38 Friedrich Carl von Savigny, De la vocación de nuestra época para la legislación y la ciencia del Derecho, Universidad Carlos III de Madrid, 2015, p. 86. La otra larga cita de Austin al Beruf también interesa, la que comienza con: "[s]e ha indicado anteriormente que en nuestra ciencia todo el éxito descansa en la posesión de los principios rectores; pues bien: esta posesión es justamente la base de la talla de los juristas romanos". Idem, p. 28. El lector comprobará la omnipresencia de los principios jurídicos en la lección de Dicey.

39 Otro profesor de la jurisprudencia analítica, William Markby, adelanta en las cuatro páginas de la introducción de su manual el espíritu general de la lección de Dicey. William Markby, Elements of Law. Considered with Reference to Principles of General Jurisprudence, Oxford, Clarendon Press, 1871, Introduction, pp. ix-xii. Fue reader en derecho indio en la Universidad de Oxford durante el periodo 1878-1900.

40 Lectures on Jurisprudence alcanzó 13 impresiones durante el periodo 1875-1920. Cfr. Rumble, Doing Austin Justice, cit., p. 5. Hart, "Introducción” [1954], en John Austin, El objeto de la jurisprudencia, cit., p. 5: "[...] la influencia de Austin sobre el desarrollo de la disciplina en Inglaterra ha sido mayor que la de cualquier otro escritor".

41 James F. Stephen, "English Jurisprudence”, Edinburgh Review 114 (1861), pp. 456-486.

42 Stefan Collini, Public Moralists. Political Thought and Intellectual Life in Britain, 1850-1930, Oxford, Clarendon Press, 1991, p. 266-269. 
1866, disciplina muy ligada a su primera producción jurídica. Fruto de estos iniciales años en la abogacía es el artículo de 1867 Legal Etiquette $^{43}$, un agudo análisis sociológico de la profesión jurídica centrado en los barristers, con inspiración en los filósofos radicales. En él denuncia las restricciones al libre comercio producidas por el cuerpo de normas que gobiernan la profesión, cuyo carácter más nocivo es quizás la dificultad de su conocimiento, aspecto del Common Law tradicionalmente criticado por la escuela de Bentham. En 1869 fue contratado por John D. Coleridge (1820-1894), importante jurista reformista al servicio del gobierno liberal de Gladstone, primero como Solicitor General y después como Attorney General. Trabajó con él hasta que Coleridge fue nombrado presidente del Court of Common Pleas en 1874, el cargo tradicionalmente precedente al de presidente del Queen's Bench (Lord Chief Justice of England), al que finalmente accedió en 1880. La inmersión de Dicey en el mundo judicial no disminuyó su interés por la reforma de la enseñanza jurídica, más bien le sugirió que la renovación de los hábitos de los abogados requería una previa educación racionalizada. Su postura sobre las diversas propuestas de reforma de la Universidad de Oxford se plasmó en un artículo de 1869, recensión de una obra del año anterior de Mark Pattison, rector del Lincoln College de Oxford, titulada Suggestions on Academical Organization ${ }^{44}$. El libro expone en primer término la necesidad de crear un cuerpo de profesores dedicado a la promoción de la ciencia. El principal escollo era que Oxford no ofrecía los incentivos necesarios para retener a los mejores juristas ${ }^{45}$. Además del bajo salario, la universidad no estaba diseñada de acuerdo con el concepto de profesión, ligado a la posibilidad de ascender y realizar una carrera. El lugar de los profesores especializados en las distintas disciplinas lo ocupaban los fellows, regidos generalmente por hábitos más medievales y clericales que científicos. Dicey proponía la sustitución de los

43 A. V. Dicey, "Legal Etiquette", The Fortnightly Review 7 (1867), pp. 169-179.

44 A. V. Dicey, "Suggestions on Academical Organization”, Fraser's Magazine 80 (1869), pp. 407-430. Mark Pattison, Suggestions on Academical Organisation with Especial Reference to Oxford, Edimburgo, 1868. Otro plan de reforma lo propuso Goldwin Smith, The Reorganization of the University of Oxford, Oxford/Londres, James Parker and Co., 1868.

45 La lección inaugural de Maitland también se ocupa de la conflictiva relación entre ejercicio y estudio del derecho. Cfr. Frederic W. Maitland, Why the History of English Law is Not Written, Londres, Cambridge University Press, 1888, pp. 16-20. Fue pronunciada el 13 de octubre de 1888 en la Arts School, Universidad de Cambridge, año en que fue nombrado Downing Professor of the Laws of England. 
colleges por facultades: teología, derecho (incluyendo historia), medicina, matemáticas y filología. La formación en Oxford la describe como literaria en vez de científica, lo que obstaculizaba el estudio riguroso de los principios de las diferentes ramas de conocimiento. Aunque los planes de Dicey no se materializaron, en 1870 fue creada la Honour School of Jurisprudence de la Universidad de Oxford, que posibilitó la separación del estudio de la historia y del derecho. La examinación para la obtención del grado de Bachelor of Civil Law (B.C.L.), introducida en 1851, se reforzó hasta el punto de que comenzó a discutirse si debía convalidarse la examinación de acceso a la abogacía a los estudiantes que la hubiesen superado ${ }^{46}$.

En ese año de 1870 publica Dicey su primer tratado: Rules for the Selection of the Parties to an Action ${ }^{47}$. El capítulo introductorio explica que su finalidad es reducir (to reduce or digest) a un conjunto de normas jurídicas el derecho que regula la actuación de las partes en un proceso, disciplina denominada en inglés the law of parties. Siguiendo este plan concibe ciento dieciocho normas, que a su vez son matizadas por reglas subordinadas y por excepciones. Las fuentes normativas empleadas son esencialmente sentencias y autores de notoria reputación, el abultado índice de casos muestra su gran dominio de los reports ${ }^{48}$. El carácter del libro es pedagógico, a la vez que orientado a los ejercientes. Se remarca como una de sus principales ventajas que el interesado en cierto punto jurídico puede acudir a la norma en cuestión para informarse acerca de las sentencias o leyes correspondientes. Lo anterior no supone -a su juicio- que la obra pierda el carácter de "especulativa", pues se contrapone a trabajos "prácticos" de autores como Mr. Chitty, Mr. Broom, y Mr. Justice Lush, en los que se trata de manera general la práctica jurídica (the law of practice). Los autores referidos muestran el derecho de las partes procesales como una materia "subsidiaria", lo que les impide realizar un tratamiento sistemático de ella. El método de Dicey en cambio permite demostrar que en realidad toda la disciplina se basa en unos pocos principios jurídicos, idea que retomará en su lección inaugural pronunciada trece años más tarde. Tan importantes son para Dicey los principios, que se erigen incluso en una forma de resistencia del derecho frente al cambio. En el momento de la publicación de este tratado, diversas propuestas para una

46 Lawson, The Oxford Law School, cit., pp. 42-47.

47 A. V. Dicey, A Treatise on the Rules for the Selection of the Parties to an Action, Londres, William Maxell \& Son, 1870.

48 Dicey, Parties to an Action, cit., pp. ix-xxii. Son 14 páginas de casos a dos columnas. 
reforma del sistema judicial inglés estaban siendo discutidas. Las Judicature Acts de 1873 y 1875 significaron la fusión de las jurisdicciones del Common Law y la equity y la creación de dos nuevos tribunales, la High Court y la Court of Appeal ${ }^{49}$. Dicey confiaba en que el tratado conservaría gran parte de su importancia, pues muchas normas del Common Law mantendrán su validez, quizás bajo otra forma, por el hecho de estar fundadas en los "dictados de la justicia y el sentido común”.

El 16 de agosto de 1870 emprende Dicey junto a su expupilo de Oxford James Bryce su primer viaje a los Estados Unidos ${ }^{50}$. La experiencia resultó decisiva para su posterior carrera académica, como lo demuestran los escritos de apoyo de diversos profesores estadounidenses a su candidatura a la Cátedra Viner y a otros puestos docentes. Las cartas de 1882 escritas por Langdell, Holmes y Dwight ensalzan las cualidades profesionales y científicas de Dicey ${ }^{51}$. Dwight por ejemplo dirige grandes elogios a su siguiente tratado, Law of Domicil: "[...] la obra es eminentemente judicial. Es un modelo de talento en la sistemática (arrangement) y lucidez en la formulación. Podría formar fácilmente la base de un Código". Desde un punto de vista más general, el viaje forma parte de la empresa angloamericana de construcción de la ciencia jurídica: "[...] una empresa transatlántica, por lo menos en su periodo formativo (c. 1870-1914)" ${ }^{2}$. La mirada hacia Estados Unidos tenía dos razones muy claras para Dicey. Al contrario que en Inglaterra, los profesores de derecho gozaban de un alto estatus al otro lado del océano, como se ocupa de remarcar la lección inaugural. Por otro lado, el pasado común ayudaba a construir un discurso mítico de exaltación del Common Law, que en ocasiones tomaba tintes raciales, y se fundamentaba en el caso de Dicey, más visiblemente en sus últimos textos, en la existencia de un supuesto carácter

49 Ambos tribunales pertenecen a la Supreme Court of Judicature. El plan inicial desposeía a la Cámara de los Lores de su jurisdicción de última instancia.

50 Robert S. Rait, Memorials of Albert Venn Dicey. Being chiefly Letters and Diaries, Londres, Macmillan, 1925, capítulo 5, First visit to the United States, pp. 56-75. El autor transcribe algunos pasajes de los diarios de Dicey.

51 London Metropolitan Archives, signaturas A/NFC/108/017, A/NFC/108/018 y A/ NFC/108/o19 respectivamente. Las cartas indican que Dicey fue candidato a la cátedra Corpus de jurisprudencia en 1882.

52 David Sugarman, "A Special Relationship? American Influences on English Legal Education, c. 1870-1965”, International Journal of the Legal Profession 18 (2011), pp. 7-57, p. 10. 
nacional compartido ${ }^{53}$. Siguiendo el razonamiento afirmará que instituciones jurídicas claves como la rule of law son tan propias de Inglaterra como de los Estados Unidos.

Dicey conoció personalmente durante aquella estancia a importantes figuras académicas o del mundo del periodismo: Edwin L. Godkin, editor del periódico neoyorquino The Nation; Oliver W. Holmes; Goldwin Smith, oxoniense empleado por la Universidad de Cornell; Charles W. Eliot, presidente de la Universidad de Harvard durante el periodo 1869-1909. La experiencia enriqueció sus perspectivas acerca del progreso de la enseñanza del derecho $^{54}$. Particularmente le impresionó la asistencia a una sesión de un moot court, institución admirada en su lección inaugural. Siguiendo su ideario de free trade y sus anhelos vitales del momento, en tales eventos concebía Dicey un medio por el que un joven abogado podía ganar distinción, tornando así innecesaria la separación entre solicitors y barristers, que había sido abolida en los Estados Unidos pocos años atrás ${ }^{55}$. Su viaje le ofreció asimismo la oportunidad de aplicar el método comparativo a su persistente reflexión sobre las reglas de carácter no jurídico: "[...] rules rather of custom than of law"56. A pesar de que Dicey no lo admite expresamente en su obra, la teoría de Maine, según la cual el derecho evoluciona desde la costumbre al contrato en un sentido individualista y contrario al status, ejerce de guía de sus cavilaciones estadounidenses ${ }^{57}$. Es patente la observación de la sociedad estadounidense como más avanzada, más igualitaria en términos tocquevillianos, con menos diferencias de clase, profesiones más abiertas y libre de elementos aristocráticos. Una manifestación de esta apertura (easiness, loose) es la situación de la mujer estadounidense, tema que captó mucho la atención de nuestro autor. Se informó por ejemplo de que en algunos Estados de aquel país las mujeres tenían derecho a administrar libremente su patrimonio después de casadas. Dicey registra en sus diarios que las diferentes condiciones sociales en Inglaterra constituyen obstáculos al desarrollo individual. En estas descripciones

53 A. V. Dicey, "A Common Citizenship for the English Race", Contemporary Review 71 (1897), pp. 457-476. Vid. Richard A. Cosgrove, Our Lady the Common Law. An Anglo-American Legal Community, 1870-1930, Nueva York, New York University Press, 1987.

54 A. V. Dicey, "The Teaching of English Law at Harvard”, Contemporary Review 76 (1899), pp. 742-76o.

55 Rait, Memorials of Albert Venn Dicey, cit., p. 67.

56 Rait, Memorials of Albert Venn Dicey, cit., p. 72.

57 Maine, Ancient Law, cit., p. 170. 
acude a conceptos como start business, pursuit of own happiness, struggle for life, cercanos a corrientes radicales del momento, como las representadas por John S. Mill o Charles Darwin ${ }^{58}$. En general se aprecia entusiasmo por los Estados Unidos, "un Estado cuyos poderes se usan para proteger a los individuos en el proceso de alcanzar la felicidad a su manera" 59 . No obstante, también se aprecia un claro interés por la parte sombría de la democratización anunciada por Tocqueville, la igualación de la sociedad -“everybody has some education”, anota Dicey- y la aparición de la corrupción partidista. Tras la asistencia a la convención del partido demócrata de Rochester, Dicey se convence de la existencia de una fuerte disciplina en los partidos y de una mayor dificultad de participación política a título individual ${ }^{60}$. Aparecen asimismo otras ideas generalizadas sobre los Estados Unidos, como la baja formación de los empleados públicos, producida según Dicey por la confusión entre los conceptos de igualdad de derechos e igualdad de capacidades ${ }^{61}$.

$\mathrm{Al}$ retornar a Inglaterra James Bryce fue designado titular de la Regius Chair of Civil Law de Oxford, el primero del grupo en alcanzar la cátedra universitaria, que ocupó durante el periodo 1870-1893 ${ }^{62}$. Dicey continúa por su parte entre la abogacía y el periodismo. En 1871 escribe un artículo sobre la enseñanza del derecho que adelanta muchos de los argumentos de su lección inaugural ${ }^{63}$, una defensa del programa de reformas de la Legal Education Association, en la que ingresó en 1870 y cuyo presidente Roundell Palmer (1812-1895) se convirtió en Lord Chancellor (Lord Selbourne) en dos ocasiones bajo sendos gobiernos de Gladstone (1872-1874, 1880-1885). Entre sus propuestas se encontraba el establecimiento de exámenes obligatorios para el acceso a la abogacía y la creación de una universidad o escuela de derecho,

58 Vid. John S. Mill, On Liberty, Londres, John W. Parker and Son, 1859, cap. 3, Of Individuality, As One of The Elements of Well-Being, pp. 99-133.

59 Rait, Memorials of Albert Venn Dicey, cit., p. 72.

60 Cfr. Walter Bagehot, The English Constitution, $2^{\mathrm{a}}$ ed., Boston, Little, Brown, and Company, 1873 [1867], p. 219.

61 Cfr. Bagehot, The English Constitution, cit., p. 263.

62 Los periodos de desempeño de los cargos docentes de los catedráticos oxonienses han sido tomados de Lawson, The Oxford Law School, cit., apéndice 8. B, pp. 252-253. La lección inaugural de Bryce trató también la enseñanza del derecho y el mencionado renacimiento del derecho romano en Inglaterra, James Bryce, "The Academical Study of the Civil Law. An Inaugural Lecture”, en James Bryce, Studies in History and Jurisprudence, Oxford, Clarendon Press, 1901, vol. 2, pp. 860-886.

63 A. V. Dicey, "Legal Education”, Macmillan’s Magazine 25 (1871), pp. 115-127. 
que Dicey consideraba deseable debido al carácter más ornamental que científico de la enseñanza ofrecida por las Inns of Court ${ }^{64}$. Otro foco impulsor de reformas jurídicas y educativas fue la Law Amendment Society, cuya lección inaugural del curso 1872-73 fue pronunciada por Stephen, sobre la codificación del derecho inglés ${ }^{65}$. Su regreso de la India generó en él gran optimismo en este ámbito, pues su estancia había culminado un periodo de grandes éxitos: "[...] el derecho indio ha sido completamente codificado", proclama ${ }^{66}$. Además recalca que el estudio del derecho es la disciplina favorita en las universidades indias, el conocimiento de los códigos por parte de la población es sorprendente. En Inglaterra en cambio los abogados han convertido el derecho en algo cuyo estudio resulta repulsivo ${ }^{67}$.

En 1874, tras el paso de Coleridge a la magistratura, Dicey es contratado por John Holker (1828-1882), Solicitor General del gobierno conservador de Benjamin Disraeli. Las reflexiones de Dicey sobre la reforma judicial efectuada por la Judicature Act de 1873 se exponen en un artículo titulado Judicial Policy in England"68. Aunque no aborda directamente la enseñanza del derecho, muestra su llamativa concepción de la profesión jurídica, entendida como una entidad moral unitaria, compuesta por dos vertientes: la abogacía (the bar) y la magistratura (the bench). El artículo critica, desde una óptica tocquevilliana, la Judicature Act de 1873 y la County Courts Act de 1846 por operar cambios en el modelo judicial que socavan los factores sobre los que se basan las virtudes de la justicia inglesa. El tradicional juez inglés -según Dicey- es seleccionado entre sus compañeros por su capacidad y se rige por un código compartido, lo cual constituye la primera garantía de su imparcia-

64 Dicey, ¿Puede enseñarse el derecho inglés en las universidades?, infra, p. 41. Vid. Austin, "The Uses of the Study of Jurisprudence", cit., Necessity for a Law Faculty, pp. 371-375.

65 James F. Stephen, “Codification in India and in England”, The Law Magazine and Review (new series) 1 (1872), pp. 963-990. Esta conferencia pronunciada el 11 de noviembre de 1872 en la sesión de apertura de la Social Science Association también apareció en The Fortnightly Review 18 (1872), pp. 644-670. La asociación fue creada en 1857 por fusión de la Society for Promoting the Amendment of the Law, la National Reformatory Union y la Society for Promoting the Employment of Women.

66 Stephen, "Codification in India and in England", cit., p. 970.

67 Stephen, "Codification in India and in England", cit., p. 980: "English lawyers have thrown it into a shape which can only be described as studiously repulsive".

68 A. V. Dicey, "Judicial Policy in England” [abril, 1874], Macmillan's Magazine 29 (1873-1874), pp. 473-487. 
lidad ${ }^{69}$. La jerarquía tradicional, con importantes dosis de honor y dignidad, constitutiva de una profesión casi aristocrática, es debilitada por el sistema de tribunales locales, en los que un abogado de prestigio debe litigar ante un juez inferior - según la escala social de la profesión. La falta de honor del nuevo puesto necesita de la compensación de una alta remuneración; así frente a la tradicional independencia se crea la esperanza de la promoción; frente al poder limitado del antiguo juez, los cambios procesales aumentan su discrecionalidad; frente a la ausencia de distinciones entre magistrates y advocates (como una supuesta beneficiosa particularidad inglesa), se produce la ruptura de este hábitat jurídico autorregulado ${ }^{70}$.

El prestigio de Dicey aumenta durante este periodo. A su intensa actividad periodística se unen dos nuevas responsabilidades: una temporal y otra permanente. Por un lado, es designado examinador del Trinity Term (periodo de primavera) de 1875 en la escuela de derecho de Oxford ${ }^{71}$. Por el otro, es nombrado asesor junior de la Commission of Inland Revenue, departamento del gobierno dedicado a la recaudación de impuestos en el que trabajó hasta 1890. La pérdida de su condición de fellow del Trinity College debido a su casamiento en 1872 es compensada ahora con los ingresos provenientes de dicho cargo, que complementan a los que provienen de su actividad periodística. La ascendencia de Stephen sobre su primo queda probada por una recensión de Dicey de 1875 a la obra de Maine Early History of Institutions ${ }^{72}$, de gran interés para valorar las influencias respectivas de Austin y Maine en nuestro autor. A partir de este momento Dicey asume el empleo del término "método histórico", en referencia al tipo de estudio al que se dedica Maine, al que contrapone el estudio "lógico" de Austin ${ }^{73}$. Aunque se intentan reconci-

69 Dicey, "Judicial Policy in England”, cit., p. 479: “[...] chosen from his fellows for his capacity and character". Cfr. Maine, El derecho antiguo, cit., p. 52-53: "Los límites a la libertad aparente del pretor son precisamente los que sujetan también al juez inglés. [...], el pretor romano, como sucede al canciller de Inglaterra, estaba sujeto dentro de los límites marcados por las ideas y por los sentimientos que había recibido en la educación y por la fuerza de la opinión profesional, fuerza que sólo pueden apreciar bien los que la han experimentado por sí mismos”.

70 Dicey, "Judicial Policy in England”, cit., p. 477.

71 Vid. el texto de la examinación en Lawson, The Oxford Law School, cit., p. 198.

72 [A. V. Dicey] "Maine's Early History of Institutions", The Nation, 1875, 1 de abril, pp. 225-226. Henry S. Maine, Lectures on the Early History of Institutions, Londres, John Murray, 1875 .

73 Cfr. John S. Mill, “Austin on Jurisprudence”, Edinburgh Review 118 (1863, Ju- 
liar ambos métodos, se percibe una clara preferencia por Austin. La crítica a este autor se califica como la parte más defectuosa del libro de Maine, al que se imputan los defectos, por un lado, de elaborar teorías que no reposan en una base suficiente de hechos establecidos, y por otro, de omitir las fuentes o autoridades, lo que dificulta la separación de la parte factual de su obra respecto de la teórica. Son signos de un positivismo todavía fuerte en el futuro catedrático.

La creciente admiración de Dicey por la magistratura inglesa se percibe en otra recensión, esta vez al libro History of English Modern Law del barrister Roland K. Wilson ${ }^{74}$, en la que trata la posible codificación del derecho inglés. El análisis parte de la distinción entre forma y contenido del derecho, analizada a través de las ideas de Bentham y Austin. Si la mejora de la substancia del derecho inglés se considera una empresa exitosa (y se dan varios ejemplos de ello), la forma del derecho en cambio parece empeorar, pues el estilo de las leyes se ha deteriorado más que ha mejorado: “[...] un código inglés es todavía meramente un sueño de reformistas". La contraposición entre judicatura y Parlamento comienza a ocupar un lugar central en el pensamiento de Dicey, pues se comienza a achacar a la asamblea el fracaso de la empresa codificadora $^{75}$. En el fondo son las labores representativas del Parlamento las que parecen obstaculizar el avance, pues en el caso indio, donde los ingleses son "déspotas", la aprobación de códigos ha sido perfectamente posible. Además, la cuidadosa composición de normas en lenguaje preciso, la esencia de la codificación a su entender, no es asunto que interese a los electores. El Parlamento cumple bien su tarea principal, la representación de la opinión pública, pero no la secundaria de producir derecho ${ }^{76}$. El derecho creado por Lord Mansfield - afirma- puede en efecto compararse favorablemente con los resultados de los reformadores parlamentarios. El judge-made law tiene el mérito de ser creado por personas que conocen el sistema que intentan mejorar.

Durante los años setenta el avance de la literatura jurídica inglesa se debe

ly-October), pp. 439-482, pp. 442-443. Isabel Turégano Mansilla, Derecho y moral en John Austin, Madrid, Centro de Estudios Políticos y Constitucionales, 2001, p. 146-154.

74 [A. V. Dicey], “Modern English Law”, The Nation, 1876, 2 de noviembre, pp. 273274.

75 Cfr. James F. Stephen, Liberty, Equality, Fraternity, Nueva York, Holt and Williams, 1873, p. 248. En el mismo sentido Frederick Pollock, Essays in Jurisprudence and Ethics, Londres, Macmillan and Co., 1882, p. 242.

76 Cfr. Bagehot, The English Constitution, cit., p. 196. 
fundamentalmente a los digestos de Stephen. En 1876 completa el relativo a la prueba y al año siguiente el digesto del derecho penal inglés, que sirvió de base para el proyecto de Código Penal (Draft Code) que introdujo en el Parlamento la Comisión sobre el Código Penal (1878-1879) presidida por Colin Blackburn, de la que Stephen era miembro ${ }^{77}$. En 1883 publicó junto a su hijo Herbert Stephen otro digesto más, esta vez sobre el derecho procesal penal ${ }^{78}$. En un artículo de Stephen de 1877 se argumenta la importancia de este tipo de depuración del derecho, condición necesaria de una futura codificación ${ }^{79}$. Se trata de una fase de condensación y reordenación del material jurídico que podría "transfigurar" el derecho en un plazo de 15 a 20 años -defiende Stephen. Asimismo mejoraría la legislación del Parlamento, que cada vez es más abundante y desordenada. Sin este paso previo la codificación es imposible. Propone para su coordinación la creación de un consejo para la literatura jurídica, financiado por las Inns of Court y encargado de dirigir los trabajos realizados mediante la contratación de destacados juristas. La necesidad de crear una literatura jurídica inglesa comparable con la de otros países será fuertemente interiorizada por Dicey, quien la promoverá en varios pasajes de su lección inaugural. Junto a Stephen debe mencionarse a Pollock, autor de un Digest of the Law of Partnership en 1877, base de la Partnership Act de $1890^{80}$.

El movimiento de reforma universitaria alcanzó en 1877 un importante avance con la aprobación de la Universities of Oxford and Cambridge Act, ley que confirió poderes de reforma de los estatutos de las universidades y colleges a una comisión presidida por Roundell Palmer ${ }^{81}$. El preámbulo de dicha

77 Vid. AA.VV., Report of the Royal Commission Appointed to Consider the Law relating to Indictable Offences: with an Appendix containing a Draft Bill embodying the Suggestions of the Commissioners, Londres, G. E. Ayre y W. Spottiswoode, 1879. El proyecto pasó la segunda lectura parlamentaria, pero fue abandonado tras el acceso de Disraeli al Gobierno en 1880. Cfr. James F. Stephen, A History of the Criminal Law of England, Londres, Macmillan and Co., 1883, vol. 3, p. 349. Vid. José Sánchez Osés, "La codificación del Derecho penal en Inglaterra”, Anuario de Derecho Penal y Ciencias Penales, t. 9, fasc. 2 (1956), pp. 267-295, pp. 284-293.

78 A Digest of the Law of Evidence, Londres, Macmillan \& Co, 1876; A Digest of the Criminal Law. Crimes and Punishments, Londres, Macmillan \& Co., 1877; A Digest of the Law of Criminal Procedure in Indictable Offences, Londres, Macmillan \& Co, 1883.

79 James F. Stephen, "Improvement of the Law by Private Enterprise", The Nineteenth Century 4 (1877), pp. 198-218.

80 Frederick Pollock, A Digest of the Law of Partnership, Londres, Stevens \& Sons, 1877.

81 El resto de miembros fueron: John Thomas; Mountague Bernard (catedrático 
ley menciona entre sus objetivos, "permitir o requerir" a los colleges contribuir más abundantemente al presupuesto de la universidad con la finalidad de reforzar la enseñanza de algunas disciplinas que no se enseñan o se enseñan de manera inadecuada. El traspaso de competencias de los colleges a la universidad ayudó a convertirla en una institución de enseñanza, pues hasta ese momento era más bien un órgano examinador, como denunció James Bryce ${ }^{82}$.

En 1879 escribe Dicey su segundo tratado: The Law of Domicil ${ }^{83}$. Si el derecho romano gozó de un renovado interés durante estas décadas, el derecho internacional privado cumplió también la función de localizar principios universales en el material jurídico positivo de las diferentes sociedades ${ }^{84}$. El prefacio del libro indica los autores con los que Dicey se considera endeudado: Savigny ${ }^{85}$, Story, Robert J. Phillimore ${ }^{86}$ y John Westlake (1828-1913) $)^{87}$. La

Chichelle de derecho internacional); William R. Grove (físico y juez); James Bellamy; Matthew W. Ridley; Henry John Stephen Smith. Éste último, matemático, fue estudiante del Balliol College y tutor de Dicey. Cfr. [Anon], "Professor Dicey", Journal of the Society of Comparative Legislation (new series) 17, 1 (1917), pp. 1-4, p. 1. Vid. Montague Bernard, A Letter to the Right Hon. W. E. Gladstone on the Statutes of the University of Oxford Commission, Londres, Rivingtons, 1882.

82 James Bryce, "A Few Words on the Universities Bill", Fortnightly Review 25 (1876), pp. 771-776, p. 772. Los estatutos fueron a aprobados por el gobierno en 1882, vid. Statutes made for the University of Oxford, and for the Colleges and Halls therein, by the University of Oxford Commissioners, etc, Oxford, Clarendon Press, 1882.

83 A. V. Dicey, The Law of Domicil. As a Branch of the Law of England Stated in the Form of Rules, Londres, Stevens and Sons, 1879.

84 Cfr. Austin, "Sobre la utilidad del estudio de la jurisprudencia”, cit., p. 46: “[...] los principios comunes a sistemas más perfectos -o bien las numerosas analogías que se dan entre ellos- constituyen el objeto de una amplia ciencia [...]. [...], ha sido llamada jurisprudencia general o comparada, o bien filosofía -o principios generales- del derecho positivo. Michael Lobban, "Was There a Nineteenth Century 'English School of Jurisprudence'?”, The Journal of Legal History 16 (1995), pp. 34-62, p. 40.

85 La obra de Savigny citada es una traducción del octavo tomo de su Sistema de derecho romano actual, Savigny, Private International Law. A Treatise on the Conflict of Laws, and the Limits of their Operation in Respect of Place and Time, translated, with notes, by W. Guthrie, Edinburgo/Londres, T. \& T. Clark/Stevens \& Sons, 1869.

86 Robert Joseph Phillimore (1810-1885), tercer barrister de la saga familiar, hijo de Joseph Phillimore.

87 Las oposiciones a la cátedra de derecho internacional público y privado celebradas en 1934 informan de la autoridad de Dicey en este campo. El primer tema del sexto ejercicio fue "El conflicto de leyes en la escuela anglo-americana contemporánea". Archivo General de la Administración, Educación, 32/13523, legajo 9138-3. 
concepción del tratado es netamente positivista. Se efectúa la separación entre el derecho inglés y el derecho de otros Estados, con base en el concepto austiniano de soberanía: la "autoridad de nuestro Estado"88. Únicamente el primero tiene cabida en la obra, aunque se advierte que la cita de autoridades extranjeras y sentencias de tribunales foráneos es conveniente porque ejercen de facto influencia en las sentencias de los tribunales ingleses. Es el punto de conexión austiniano entre ciencia del derecho y derecho positivo, con el que Dicey estaba muy comprometido en esta época ${ }^{89}$. La delimitación del concepto estricto de derecho expulsa al derecho internacional público del mundo positivo por regular relaciones entre Estados, es decir, constituye moralidad internacional ${ }^{90}$. Por eso la denominación Private International Law es errónea a juicio de Dicey, pues no es internacional el objeto, sino inglés. La materia prima del tratado son tres elementos: legislación parlamentaria, sentencias e inferencias ${ }^{91}$. El resultado es un código ( $a$ code), que primeramente se presenta aislado (al inicio del libro) y posteriormente explicado, norma por norma.

El empleo del término "code" se equipara al de "digest", con el que describe también su tratado sobre Parties to Actions. La empresa es la misma, presentar una masa caótica en forma de normas sistemáticas: "[...] a mass of law can best be exhibited in the form of systematic rules" ${ }^{22}$. Respecto de su obra anterior, se menciona con contenido orgullo que fue citada por "jueces competentes", influyó en los jueces. La tercera mención surge a cuenta del concepto de incerteza del derecho, señalado por Dicey con el adjetivo "unsettled”. Aunque el primer objetivo de su tratado es explicar las normas jurídicas, exponer los fundamentos sobre los que descansan e incluso llamar la atención sobre la corrección de algunas de ellas, en algunos casos -advierte- no existe ninguna norma aplicable. Se manifiesta entonces la importancia de su pro-

88 Dicey, The Law of Domicil, cit., p. iv: "[...] which are not laws to us at all, since they do not rest on the authority of our own State". Cfr. Austin, Lectures on Jurisprudence, cit., vol. 1, lección 4, p. 127.

89 Afirma Austin que la legislación judicial es el producto conjunto de jueces y juristas privados que por su talento en el derecho han captado la atención de los jueces ("have gotten the ear of the judicial legislators”). Cfr. Austin, Lectures on Jurisprudence, cit., vol. 2, lección 38, p. 353 .

90 La afirmación se repite en la primera lección de su Law of the Constitution de 1885. Cfr. Dicey, The Law of the Constitution, cit., p. 23.

91 Dicey, The Law of Domicil, cit., p. iv: "[...] or inferences drawn from authoritative dicta or admitted principles".

92 Dicey, The Law of Domicil, cit., p. v. 
grama de investigación, ya que el jurista teórico ejerce el papel de inspirador del juez y sugiere, a través de inferencias ("conjectural inference") deducidas de principios establecidos ("from established principles"), la norma aplicable ${ }^{93}$. Su lección aludirá constantemente a la importancia de los principios jurídicos, necesarios para aportar soluciones a nuevas situaciones producidas por el cambio social, no resueltas por decisiones anteriores ${ }^{94}$. Maine escribió irónicamente sobre la cada vez más caduca imagen de unos jueces poseedores de un "cuerpo de derecho inglés completo, bien unido, bien ordenado, de una amplitud suficiente para contener los principios aplicables a cualquier combinación de circunstancias ${ }^{95}$ ".

Otro suceso destacable de este año es la publicación de los Principles of the English Law of Contract de William R. Anson, manual de referencia durante décadas de esta disciplina ${ }^{96}$. Anson ocupaba desde 1874 el cargo de Vinerian Reader en el All Souls College de Oxford. En 1881 se convirtió en su presidente (warden), el primero de dicho college en ser laico. A tal obra siguió el año siguiente el libro de Holland Elements of Jurisprudence ${ }^{97}$, que ofreció a Dicey la ocasión de certificar el acceso de la jurisprudencia inglesa a un estadio avanzado de cientificidad. Thomas E. Holland fue compañero de Dicey en el Balliol College de Oxford y pronto se reveló como un gran defensor del proyecto codificatorio. En 1874 accedió a la Chichele Chair of International Law de Oxford, que ocupó hasta 1911. Sus Elements perfeccionan a la vez que reemplazan la obra de Austin, pionero de la jurisprudence a juicio de Dicey. Sin embargo dos defectos hacían la obra deficiente para la instrucción de los estudiantes: su expresión oscura y su carácter fragmentario. El libro de Holland remedia estas desventajas; su estilo es admirable, su conocimiento del derecho mayor que el de Austin y su dominio del derecho romano completo. El artículo finaliza afirmando que la conexión entre lógica y derecho es el elemento que aporta interés a las teorías de la ciencia jurídica.

93 Cfr. Dicey, The Law of Domicil, cit., p. v.

94 Dicey, ¿Puede enseñarse el derecho inglés en las universidades?, infra, p. 47, Dicey, Law \& Opinion, cit., pp. 362-363.

95 Maine, El derecho antiguo, cit., p. 33.

96 William R. Anson, Principles of the English Law of Contract, Oxford, Clarendon Press, 1879. La $22^{\text {a }}$ edición a cargo de A. G. Guest es de 1964.

97 A. V. Dicey, “The Study of Jurisprudence”, The Law Magazine and Review (fourth series) 5 (1880), pp. 382-401. Thomas E. Holland, The Elements of Jurisprudence, Oxford, Clarendon Press, 1880. La $13^{\text {a }}$ edición es de 1924. Holland obtuvo el Swinney prize de 1894 por esta obra. 
Dicey se impuso en 1882 en la elección para la Cátedra Viner a Anson y a Frederick Pollock. La comisión de nombramiento la compusieron los siguientes individuos: el Canciller de la Universidad de Oxford (el marqués de Salisbury), el Lord Chief Justice de Inglaterra (Lord Coleridge), el Regius Professor of Civil Law de Oxford (James Bryce), y el Corpus Professor of Jurisprudence (vacante). El año siguiente el núcleo del grupo se completó con la provisión de esta última cátedra en la persona de Pollock, sucesor de Maine, en activo hasta $1903^{98}$. Fue además profesor de Common Law en las Inns of Court (1884-1890) y editor de los Law Reports durante el periodo 1895-1935. La escuela de Oxford se consolidó en 1884 con la fundación de la revista Law Quarterly Review, cuyo primer editor fue precisamente Pollock. Su número inaugural contiene contribuciones de todos los juristas mencionados, a excepción de Bryce, miembro del Parlamento en pleno ascenso de su carrera política en aquellos momentos ${ }^{99}$. Además de estos juristas también aparecen aportaciones de Stephen, Holmes, Maitland, Paul Vinogradoff, o de los romanistas Erwin Grueber y Edwin C. Clark, configurándose así uno de los espacios más relevantes de desarrollo de la ciencia jurídica inglesa ${ }^{100}$.

\section{CREACIÓN DE LITERATURA JURÍDiCA Y CODIFICACIÓN}

La lección inaugural de Dicey no aboga por la supresión de las pasantías en bufetes, sino por la consecución de un equilibrio entre este tipo de instrucción y la enseñanza académica ${ }^{101}$. Su estructura es muy característica de los

98 Su lección inaugural trató igualmente la enseñanza del derecho en las universidades. Pronunciada el 20 de octubre de 1883 en el Corpus Christi College, Universidad de Oxford, Frederick Pollock, "English Opportunities and Duties in the Historical and Comparative Study of Law. An Inaugural Lecture", en Frederick Pollock, Oxford Lectures and other Discourses, Londres, Macmillan, 1890. Sobre Pollock y la evolución del método comparado vid. Héctor Domínguez Benito, "Frederick Pollock en París, o la naturaleza conflictiva del derecho comparado”, Revista de Historia del Derecho 55 (2018), pp. 91126.

99 Vid. H. A. L. Fisher, James Bryce. Viscount Bryce of Dechmont, O. M, Londres, Macmillan, 1927, vol. 1, capítulo 11, Parliament, pp. 171-196.

100 Vid. AA.VV, Law Quarterly Review 1 (1885), 520 pp. La revista contaba con distribución en Londres y Oxford, y con agente en Boston, Massachusetts.

101 Será también el tema principal de su comparecencia en 1892 ante la Gresham University Commission. Vid. Apéndice 3, pp. 89-112. 
textos de Dicey, en los que se exponen los argumentos de las dos imaginarias partes cual antecedentes de una sentencia ${ }^{102}$.

Una primera introducción contiene una narración con pasajes decididamente sarcásticos sobre la situación de los bufetes ingleses y las dificultades que encuentran los pasantes que inician su instrucción jurídica en éstos. La expresión "misterios de su arte", en referencia a la autocomprensión que tenían de su profesión los ejercientes del derecho más tradicionales, sobresale y se contrapone a la de "ciencia", que aparece repetidas veces en su lección. El término vuelve a emplearse en la lección primera de Law of the Constitution $^{103}$, también con carga crítica, en este caso hacia la concepción de la constitución británica de Burke como algo misterioso. Posteriormente se enuncian las ventajas del sistema de enseñanza en bufetes (tres puntos), a las que siguen sus inconvenientes (otros tres puntos). Por último, se diserta sobre las oportunidades que ofrece la enseñanza académica del derecho (cuatro puntos) $)^{104}$. La lección exhibe una estrecha sincronización con la lección primera de su Law of the Constitution (1885) ${ }^{105}$. La correspondencia de Dicey con el editor Macmillan ofrece información al respecto ${ }^{106}$. Una carta del 22 de junio de 1883 se ocupa de los planes de publicación de la lección inaugural. La siguiente, de 9 de junio de 1884, ya contiene la propuesta de Dicey de publicar 500 copias de Law of the Constitution, que finalmente llegaron a 750. Entre medias discurrió el curso de lecciones en Oxford que dio lugar al libro. La obra se entiende mejor como una investigación integrada en el programa de renovación que Dicey expone en su lección inaugural.

El objetivo principal del discurso de Dicey es favorecer la legitimación de los profesores, los únicos sujetos capaces de crear una literatura jurídica imprescindible para abordar una futura codificación del derecho inglés. El mo-

102 Vid. especialmente A. V. Dicey, England's Case against Home Rule, Londres, John Murray, 1886.

103 Dicey, The Law of the Constitution, cit., p. 4. Cfr. Austin "Sobre la utilidad del estudio de la jurisprudencia”, cit., p. 51.

10443 años después formulará cierto compromiso entre el sistema de enseñanza por lecciones y por tutores, A. V. Dicey, "Law-Teaching, Oral and Written", en Herbert H. Henson (ed.), A Memoir of the Right Honourable Sir William Anson, Oxford, Clarendon Press, 1920, pp. 84-101, p. 89.

105 Dicey, The Law of the Constitution, cit., lección 1, The True Nature of Constitutional Law, pp. 1-34.

106 British Library, Western Manuscripts, Macmillan Papers, Add MS 55084, documentos 5,6 para la primera carta y 7, 8 para la segunda. 
vimiento de reformas jurídicas comenzado en los años cuarenta y cincuenta había generado una sólida oposición por parte de los líderes de las corporaciones profesionales, cuyas posturas trata de reconciliar el recién catedráti$\mathrm{co}^{107}$. Cuatro elementos subyacen en su propuesta, siendo el primero el carácter científico del derecho: "[...] puede ser tratado como cualquier otra ciencia de una manera clara, racional, e interesante”. Ello garantiza la posibilidad de formulación de un digesto (segundo elemento):

"El primer deber de un profesor competente es el de dejar claro a sí mismo y a sus discípulos la idea de que el derecho puede ser reformulado en forma de un digesto consistente en un conjunto de normas y excepciones [...]"108.

El tercer elemento es el procedimiento juzgado idóneo para lograr tal codificación ${ }^{109}$. Ésta se concibe como una empresa neutral y técnica, adjetivos que describen el ideal del profesor. La lección comienza enfatizando estos valores: "[m]i objetivo en esta lección es describir, hasta donde alcancen mis capacidades, y con la máxima imparcialidad [...]”. La lección primera de Law of the Constitution reiterará este compromiso, contra el partidis$\mathrm{mo}^{110}$. No menciona la lección otros fines distintos a la codificación, como podrían ser la reforma social o la mejora de la substancia jurídica. Como expuso Dicey en artículos anteriores, estos elementos podrían interferir en el proceso precodificatorio ${ }^{111}$. Además, la reforma material del derecho se percibe como una tarea casi finalizada, que se había realizado mediante la derogación de las "leyes malas". Sin embargo, la formulación de buenas leyes es una labor distinta, el proyecto de codificación es ante todo una tarea terminológica: "[...] hasta que la terminología jurídica no haya sido revisada o establecida [...], Inglaterra nunca tendrá un código digno de los méritos del derecho inglés”. Las habilidades lógicas son la herramienta básica de

107 Vid. Raymond Cocks, Foundations of the Modern Bar, Londres, Sweet \& Maxwell, 1983 .

108 Dicey, ¿Puede enseñarse el derecho inglés en las universidades?, infra, p. 54.

109 David Sugarman, "Making Respected Gentlemen out of Law Professors. A Commentary on Albert Venn Dicey, Can English Law Be Taught at the Universities (1883)", en Isabella Löhr, Matthias Middell y Hannes Siegrist (eds.), Kultur und Beruf in Europa, Stuttgart, 2011, vol. 2, pp. 161-168.

110 Dicey, The Law of the Constitution, cit., p. 4: "[...] his duty is neither to attack nor to defend the constitution".

111 Vid. [Dicey], "Modern English Law”, cit., p. 274. 
esta empresa, la extracción mediante inferencias de los principios propios de la ciencia jurídica.

El cuarto elemento subyacente, no explícitamente expuesto, es la duración del proyecto. No se especifica el plazo de finalización del proceso de codificación porque depende de los esfuerzos de los profesores: "puede por medio de aplicación e inteligencia completarse gradualmente a través de todo el dominio del derecho inglés". Para el éxito de la empresa es necesario reformar los hábitos de los juristas, cuyo vicio principal es la tendencia a procurar una atención desmedida a las excepciones y anomalías del derecho, sacrificando los principios ${ }^{112}$. El origen de este defecto es que el derecho inglés está construido sobre casos: "cada caso incluido en un report constituye el registro de alguna excepción a una regla general"113. La acumulación de comentarios sobre las decisiones judiciales desprovista de un orden previo y de unos principios generales causa verdadero horror a los juristas del círculo de Dicey ${ }^{114}$.

La institución de los reports ocupa un espacio central en la lección. Es quizás el punto en el que más claramente Dicey abandona la supuesta neutralidad del profesor y entra en el terreno de las valoraciones o incluso de las emociones. Al fin y al cabo, esta nueva generación de profesores de derecho adquirió gran parte de los valores, códigos y etiquetas de los ejercientes, ya fuesen jueces o abogados, de la legal profession en definitiva ${ }^{115}$. A modo de ejemplo, Dicey coloca en la portada de su lección inaugural la precisión "barrister-at-law", profesión que efectivamente desempeñaba como asesor de los comisionados del Inland Revenue. En la edición octava de Law of the Constitution (1915), veinticinco años después de haber cesado su vinculación con la Board of Inland Revenue, colocará la etiqueta "of the Inner Temple" 116.

112 Cfr. A. V. Dicey, "Sir George Bramwell and the English Bench", The Nation, 15 de diciembre, 1881 , pp. 468-470, p. 470. Para la importancia del concepto de hábito de la época cfr. Collini, Public Moralists, cit., p. 98.

113 Dicey, ¿Puede enseñarse el derecho inglés en las universidades?, infra, p. 49.

114 Anota Pollock en una nota al pie de sus Ensayos sobre jurisprudencia y ética: “[...] en mi opinión, en la que creo no ser el único, el volumen de nuestras actuales series de Law Reports autorizados es por lo menos el doble de lo que deberían ser. Se debe ejercer un control mucho más estricto por parte del editor general y de los jueces”. Cfr. Frederick Pollock, Essays in Jurisprudence and Ethics, cit., p. 243.

115 David Sugarman, "Legal Theory, the Common Law Mind and the Making of the Text-Book Tradition”, en William Twining (ed.), Legal Theory and Common Law, Oxford, Blackwell, 1986, pp. 26-61, p. 33.

116 Otro ejemplo lo aporta David Sugarman. Es la dedicatoria del libro de Pollock 
Los reports se describen como "los más nobles monumentos" a la sensatez, a la justicia, al buen juicio (sound sense), etc. Alabarlos es ensalzar a sus creadores. La admiración por los jueces Mansfield, Campbell o Eldon es patente. También por los estadounidenses Story y Holmes y por el escocés Lord Stair. La expresión "sound sense" aparece repetidamente en la lección, conceptualizada como la principal virtud de la magistratura; la contraposición con el Parlamento y los partidos políticos es evidente. Aunque no aparezcan críticas expresas al uno y a los otros, poco adecuadas para la solemnidad de una lección inaugural, su trayectoria periodística anterior prueba que la aversión existía desde hacía años. No debe olvidarse la situación política del momento. Una primera extensión del sufragio había sido aprobada mediante la Second Reform Act de 1867 y se discutía una ulterior extensión, aprobada poco después mediante la Third Reform Act de 1884. Paralelamente se asistía al reconocimiento jurídico de los sindicatos (Trade Union Act 1871) ${ }^{117}$. En 1905 Dicey situaría retrospectivamente el inicio de periodo colectivista en 1865, año de la muerte -en el cargo-de Palmerston ${ }^{118}$.

Quizás estas amenazas al individualismo victoriano sean la clave para entender la enigmática expresión de "código natural". Empleada en una única ocasión, Dicey no explica la razón del adjetivo. A juzgar por su ubicación, dentro del punto cuarto del ámbito de la enseñanza académica del derecho, tras su defensa de la institución de los reports, su significado podría ser el de codificación pura y sin interferencia partidista, realizada por el jurista técnico ${ }^{119}$.

Principles of Contract a su maestro Nathaniel Lindley, juez de la Court of Common Pleas. Cfr. Sugarman, "Legal Theory, the Common Law Mind and the Making of the Text-Book Tradition”, cit., p. 36. Cfr. también Collini, Public Moralists, cit., p. 205.

117 Trade Union Act de 1871, sección 2: "The purposes of any trade union shall not, by reason merely that they are in restraint of trade, be deemed to be unlawful so as to render any member of such trade union liable to criminal prosecution for conspiracy or otherwise”. Cfr. Víctor Saucedo, "La doble vida de la conspiración inglesa”, Indret. Revista para el Análisis del Derecho 1 (2019), pp. 1-23, p. 9.

118 Dicey, Law \& Opinion, cit., p. 121.

119 Austin, Sobre la utilidad del estudio de la jurisprudencia, cit., p. 49 “[...], me imagino, por un sistema "natural", un sistema tan apropiado, tan evidentemente apropiado, que todo tratadista inteligente de un cuerpo de derecho lo ha de adoptar naturalmente o de por sí". Este "sistema natural" es en inglés "a natural arrangement”. Cfr. Austin, "On the Uses of the Study of Jurisprudence”, cit., p. 353: “[...] I presume, by a natural arrangement, an arrangement so commodious, and so highly and obviously commodious, that any judicious methodizer of a body of law would naturally (or of course) adopt it". 


\section{Nota SOBRE La TRAdUCCIÓN}

El texto traducido ha sido el publicado por Macmillan, consultado en la British Library ${ }^{120}$. La reciente edición de Law of the Constitution de J. W. F. Allison incluye asimismo la lección inaugural en un apéndice ${ }^{121}$; otra señal del cambio de perspectiva en el estudio de Dicey. El origen oral del texto es claro, el lenguaje es inmediato, lleno de expresiones de estilo directo, en ocasiones cargado de ironía. El uso de las mayúsculas se ha adaptado a las reglas actuales (p. ej. Universities) al igual que el de las comillas, situadas previamente a los signos de puntuación.

Los términos más reiterados pertenecen naturalmente al campo semántico de la educación. El principal de la lección, el adjetivo professorial, ha sido traducido como "profesoral". Su uso constante es lógico en un discurso cuyo objetivo es afirmar la autonomía y necesidad de estos profesionales. Consta asimismo el término professoriate (profesorado). La otra palabra esencial es lecture, que aquí se traduce, como se ha hecho generalmente ${ }^{122}$, como "lección”. Su derivación referida a la persona que la imparte es lecturer. Por último quedaría el sustantivo lectureship, cargo docente de establecimientos educativos, junto a otros como professorship o readership ${ }^{123}$. La ambigüedad de las posibles traducciones aconseja mantener el término inglés de estos cargos docentes. En una sociedad altamente estratificada, cada cargo conlleva una carga diferente de honor o respeto.

Continuemos con el lenguaje del mundo de la abogacía. Bufete de abogados es en inglés chamber, realizar una pasantía to read in chambers, y prepararse para el acceso a la abogacía (the bar) to read for the bar. Generalmente estos bufetes estaban dirigidos por algunos de los siguientes profesionales: draftsman, pleader o conveyancer, términos que la traducción mantiene en inglés ${ }^{124}$. El término lawyer se ha traducido como jurista o abogado, depen-

120 Dicey, Can English Law be Taught at the Universities?, Londres, Macmillan, 1883.

121 A. V. Dicey, The Law of the Constitution (J. W. F. Allison ed.), Oxford, Oxford University Press, 2013, apéndice 1, pp. 489-503.

122 A. V. Dicey, Lecciones sobre la relación entre derecho y opinión pública en Inglaterra durante el siglo XIX, Albolote (Granada), Comares, 2007.

123 Vid. Lawson, The Oxford Law School, cit., apéndice 2. D, pp. 198-211. Lawson equipara el cargo de readership al de profesor asociado (associate professor), Ibid, p. 63.

124 Los pleaders, expertos en derecho procesal, eran los verdaderos maestros del Common Law según Dicey. Cfr. Dicey, ¿Puede enseñarse el derecho inglés en las universidades?, infra, p. 52. 
diendo del contexto, mientras que barrister, solicitor y attorney no se han traducido. El barrister-at-law (derivación de bar) pertenecía a la categoría más elevada de la profesión, con competencia exclusiva para litigar ante los tribunales superiores. La lección inaugural muestra esta superioridad del barrister respecto al attorney, que se describe como una figura más ocupada en la relación con el cliente que en la elucidación de la cuestión jurídica crucial de un caso $^{125}$. Los términos judge y magistrate, empleados por Dicey como sinónimos ${ }^{126}$, se traducen como juez y magistrado. Finalmente se menciona la figura del counsel, de sentido muy amplio, traducida como asesor.

Desde un punto de vista más general algunos conceptos requieren una somera mención, pues nos acercan a la empresa de construcción de la ciencia jurídica en la que Dicey estaba inmerso en aquellos años. Uno de los elementos principales de su programa, compartido con los otros, es la creación de un vocabulario jurídico científico. Legal science se traduce aquí como "ciencia jurídica"; legal conceptions como "conceptos jurídicos"; rules of law como "normas jurídicas"; whole field of law como "ordenamiento jurídico". El adjetivo legal requiere especial referencia, pues se traduce como "jurídico", mejor que como "legal". El propio término law en ocasiones se ha traducido como "ley", lo que ha producido algunas confusiones ${ }^{127}$. Por ejemplo, la edición francesa de Law of the Constitution tradujo rule of law por règne de la loi ${ }^{128}$. Otra conocida traducción indica que "se llama constitución a la estructura de una sociedad política organizada a través y por la ley”129. Posada, dubitativo,

125 Cfr. Dicey, ¿Puede enseñarse el derecho inglés en las universidades?, infra, p. 43. La primera Royal Charter (1831) de la Law Society muestra esta graduación entre juristas: The Society of Attorneys, Solicitors, Proctors and others not Being Barristers, Practising in the Courts of Law and Equity of the United Kingdom. Cfr. Harry Kirk, Portrait of a Profession. A History of the Solicitor's Profession, 1100 to the Present Day, Londres, Oyez Publishing, 1976, p. 42: “[...] in 1863 there were 4630 barristers". Cfr. "Barrister", Encyclopædia Britannica, 1911, vol. 3.

126 Cfr. Dicey, “Judicial Policy in England” [abril, 1874], Macmillan’s Magazine 29 (1873-1874), pp. 473-487, p. 477.

127 Bartolomé Clavero, "Imperio de la ley y rule of law: léxico jurídico y tópica constitucional”, Quaderni Fiorentini 25 (1996), pp. 287-346, p. 288, p. 292.

128 Cfr. A. V. Dicey, Introduction a l'étude du droit de la constitution (ed. André Batut y Gaston Jèze), París, V. Giard \& E. Brière, 1902, seconde partie, Le règne de la loi. La edición española de Law and Opinion traduce como "la autoridad de la ley", cfr. Dicey, Lecciones sobre la relación entre derecho y opinión pública, cit., p. 185.

129 Cfr. James Bryce, Constituciones flexibles y rígidas (ed. Pablo Lucas Verdú), Madrid, Centro de Estudios Constitucionales, 1988, p. 20, aunque la nueva edición sustituye 
empleó los dos sustantivos: "[...] subordinación al derecho, supremacía de la ley, como dice Dicey" ${ }^{130}$. La reincidencia en traducciones indirectas facilitó la confusión, como en el caso de El derecho antiguo ${ }^{131}$. En el inglés de la época de Dicey el término "ley" aparece de tres formas: act, statute o enactment ${ }^{132}$. Éste último término a su vez puede emplearse de otra forma para referirse al derecho de creación judicial: enactments of judicial legislation ${ }^{133}$, aunque Dicey prefirió posteriormente el término judge-made law ${ }^{134}$. Jurisprudence se traduce por jurisprudencia, que tiene el sentido de ciencia jurídica ${ }^{135}$.

Los términos digest y code son empleados por Dicey como sinónimos ${ }^{136}$. En ocasiones se adjetivan y derivan en unauthorised digest o legislative code, dependiendo de si han sido aprobados como leyes por el Parlamento o no. La traducción registra digesto y código en cada caso, si bien su sentido no equivale exactamente a los términos españoles ${ }^{137}$. Debe tenerse en cuenta que el grupo de juristas al que pertenecía Dicey estaba creando un nuevo género jurídico, diferente del abridgement $t^{138}$, de los comentarios ${ }^{139}$, de los esbozos (outlines en la lección inaugural), o de obras como el Digest de Fisher (más bien un diccionario jurídico en opinión de Dicey). El género evolucionaría a principios del siglo XX hacia digestos más generales, como

ley por derecho, cfr. James Bryce, Constituciones flexibles y rígidas (ed. Pablo Lucas Murillo de la Cueva), Madrid, Centro de Estudios Políticos y Constitucionales, 2015, p. 19.

130 Cfr. Adolfo Posada, El régimen municipal de la ciudad moderna, $3^{\mathrm{a}}$ ed., Madrid, Librería General de Victoriano Suárez, 1926, p. 223. Vid. también Adolfo Posada, Tratado de derecho político, Madrid, Librería de Victoriano Suárez, 1894, vol. 2, p. 181.

131 Cfr. Ramón Cotarelo, "Introducción”, en Henry S. Maine, El derecho antiguo. Su conexión con la historia temprana de la sociedad y su relación con las ideas modernas, Valencia, Tirant, 2014, pp. 9-46, pp. 40-41.

132 Dicey, Can English Law be Taught at the Universities?, infra, p. 75.

133 Dicey, Can English Law be Taught at the Universities?, infra, p. 77.

134 Cfr. Dicey, The Law of the Constitution, cit., p. 32.

135 Roland Epstein, Fernando Picchi y Bruna Di Sabato, West's Law \& Commercial Dictionary. Dizionario giuridico e commerciale inglese-italiano, francese, spagnolo, tedesco, italiano-inglese, Bologna/St. Paul (Minnesota), Zanichelli/West, 1988, p. 879: Jurisprudenz, Rechstphilosophie, Rechstwissenschaft; ciencia jurídica, jurisprudencia; science juridique, jurisprudence; filosofía del diritto, teoría generale del diritto.

136 Cfr. Dicey, The Law of the Constitution, cit., p. 26.

137 Dicey, ¿Puede enseñarse el derecho inglés en las universidades?, infra, p. 58.

138 Charles Viner, A General Abridgment of Law and Equity. Alphabetically Digested under Proper Titles, with Notes and References to the Whole, Aldershot, 1742-53, 23 vols.

139 Blackstone, Commentaries on the Laws of England, cit. 
el digesto del derecho civil inglés elaborado por la siguiente generación de juristas de Oxford ${ }^{140}$.

Por último, dos conceptos clásicos del Common Law han sido mantenidos en su lengua original: report ${ }^{141}$ y statute-book ${ }^{142}$. Su conocimiento general quizás haga contraproducente una traducción que en otra época se creyó conveniente. El primero de ellos deriva en reporter, el profesional dedicado a su confección. No se traducen los nombres de cargos y tribunales: Chief Justice, Lord Chancellor, Attorney General, Solicitor General, fellow, etc. Los datos sobre los juristas citados han sido compuestos con ayuda de las siguientes obras: Dictionary of Legal Biography, Biographical Dictionary of the Common Law y Yale Biographical Dictionary of American Law ${ }^{143}$.

140 Edward Jenks et al., A Digest of English Civil Law, Londres, Butterworth, 19051917.

141 Cfr. Henry S. Maine, El derecho antiguo, considerado en sus relaciones con la historia de la sociedad primitiva y con las instituciones modernas. Parte general, Madrid, Tipográfica del Hospicio, 1893, p. 32: "repertorios de jurisprudencia". La misma traducción es ofrecida por el West’s Law \& Commercial Dictionary. Cfr. Roland Epstein, Fernando Picchi y Bruna Di Sabato, West's Law \& Commercial Dictionary, cit., p. 914: Entscheidungssammlungen, recueils de jurisprudence, raccolte di giurisprudenza.

142 Fue traducido por Posada como "Anuario de los Estatutos", cfr. Walter Bagehot, La constitución inglesa, Madrid, 1902, p. 6.

143 A. B. Schofield, Dictionary of Legal Biography, 1845-1945, Chichester, Barry Rose Law Publishers, 1998; A. W. B. Simpson, Biographical Dictionary of the Common Law, Londres/ St. Paul (Minnesota), Butterworths/Mason Pub. Co, 1984; Roger K. Newman, The Yale Biographical Dictionary of American Law, New Haven, Yale University Press, 2009. 


\title{
¿PUEDE ENSEÑARSE EL DERECHO INGLÉS
}

EN

\section{LAS UNIVERSIDADES?}

\section{LECCIÓN INAUGURAL,}

Pronunciada en el All Souls College, el 21 de Abril de 1883,

POR

\begin{abstract}
A. V. DICEY, B.C.L., Hon. LL.D., BARRISTER-AT-LAW,
\end{abstract}

VINERIAN PROFESSOR DE DERECHO INGLÉS EN LA UNIVERSIDAD DE OXFORD, Y FELLOW DEL ALL SOULS COLLEGE.

Londres:

MACMILLAN AND CO.

1883.

Precio un chelín. 

Si la cuestión de si el derecho inglés puede ser enseñado en las universidades pudiese ser presentada en forma de caso a un cuerpo de eminentes asesores, no hay ninguna duda de cuál sería su respuesta. Contestarían unánimemente y sin dudar, que el derecho inglés debe ser aprendido y no puede ser enseñado, y que el único lugar donde puede ser aprendido es en los tribunales de justicia y en los bufetes de abogados. El barrister que mantiene o piensa que los misterios de su arte solamente pueden ser aprendidos por medio de la práctica tiene, debe ser justamente reconocido, un argumento de peso en apoyo de su convicción. Puede contar con la práctica uniforme de varias generaciones. Instrucción directa o docencia no han recibido los abogados ingleses hasta hace veinticinco años, e incluso actualmente las lecciones pronunciadas por distinguidos profesores en la Sala del Temple o en Lincoln's Inn son el ornamento más que la parte esencial de la enseñanza del derecho. El conocimiento del derecho, como lo ha sido durante siglos, es adquirido por medio del ejercicio real ante los tribunales o por la práctica imitativa erróneamente llamada "reading" in chambers. Mi objetivo en esta lección es describir, hasta donde alcancen mis capacidades, y con la máxima imparcialidad, los notables méritos, y los no menores patentes defectos, del actual sistema de estudio del derecho, y mostrar cuál es el espacio que este sistema deja abierto a una enseñanza profesoral y académica.

El método dominante de instrucción mediante pasantías en bufetes pertenece de tal modo a nuestra vida cotidiana que, al igual que otras instituciones inglesas, sus peculiaridades difícilmente nos asombran; no obstante es ciertamente un método de instrucción que asombraría a un extranjero por ser algo extraño, por no decir inexplicable. Sus características más destacadas son descritas perfectamente por los escritos dejados (se dice) por un eminente abogado sobre la instrucción que con el tiempo le conduciría a la presidencia de la Cámara de los Lores. "El primer día que fui al bufete redacté algunos escritos; me fueron devueltos con cada palabra alterada excepto los nombres del demandante y demandado, junto con la petición de mi pleader de que en el futuro dejase un espacio entre las líneas de mis borradores. Este requerimiento fue toda la enseñanza sobre el derecho que recibí". Su señoría no quería decir, por supuesto, que no hubiese aprendido nada en el bufete; se refería a que su instrucción consistió únicamente en ver cómo el pleader con quien se instruía realmente litigaba o asesoraba. La experiencia de su 
señoría no fue de ningún modo singular. Cuando un estudiante que está preparando su acceso a la abogacía entra en el bufete de un barrister, el acuerdo alcanzado entre el llamado discípulo y su llamado tutor es más bien singular. El discípulo no se compromete a aprender, y el tutor de ninguna manera lo hace a enseñar. Nuestro estudiante paga cien guineas, y el barrister se compromete a que su discípulo pueda ver todo el trabajo que se desarrolla en el bufete, y a que tenga la oportunidad de probar con sus propias manos tal trabajo. Ésta es la verdadera y mayor ventaja adquirida por el estudiante. La enseñanza obtenida (si hay alguna) es cuestión del azar. Muchos abogados excelentes no tienen ningún talento como docentes. Muchos barristers que podrían ser admirables profesores tienen tal cantidad de trabajo que no disponen del tiempo, en el caso de que tuvieran la inclinación, de instruir a sus discípulos. Nuestro joven que se prepara para la abogacía puede recibir, y frecuentemente lo hace, inmensa ayuda del tutor en cuyo bufete trabaja, o de sus compañeros condiscípulos con los que conversa, pero todo a lo que tiene derecho es a ver y a redactar los documentos que llegan día tras día. Si quiere aprender algo, debe lograrlo por su cuenta. La tarea no es fácil. El joven que ha adquirido el privilegio de leer los papeles que están sobre la mesa de la sala de los discípulos, se encuentra en un primer momento inmerso en un laberinto de perplejidades. Puede o no haber leído algún libro elemental de derecho. Sus lecturas pueden, o más frecuentemente, pueden no ser apropiadas para el trabajo que discurre ante sus ojos. Con toda probabilidad, ignora los términos básicos de la cuestión jurídica que debe considerar. Lee documentos, por ejemplo, sobre el contrato de flete, mientras intenta encontrar en Maclachlan ${ }^{1}$ qué es un contrato de flete. Intenta establecer la cuestión de si Brown puede demandar a Jones sobre la base de una letra de cambio, al mismo tiempo que intenta discernir a partir de Byles la diferencia entre aceptante y librador ${ }^{2}$. Queda sumergido en los recovecos del seguro marítimo, a la vez que perplejo por una vaga confusión entre los términos barratry y bottomry, a la vez que intenta dominar en Arnould la diferencia entre "particular" y "general" average ${ }^{3}$. Algunas circunstancias aumentan considera-

1 David Maclachlan, barrister del Middle Temple, publicó en 1862 A Treatise on the Law of Merchant Shipping.

2 John B. Byles (1801-1884), special pleader y juez del Court of Common Pleas de 1858 a 1873, publicó en 1829 A Practical Compendium on the Laws of Bills of Exchange.

3 Joseph Arnould (1813-1886), barrister del Middle Temple, fue juez de la Corte Superior de Bombay de 1862 a 1869. 
blemente la perplejidad de nuestro principiante. Si tiene la fortuna de entrar en un "buen bufete", los documentos que estudia un día han desaparecido al día siguiente. Los papeles que empieza a leer el lunes se refieren a una letra de cambio; el martes continúa con unos documentos sobre constitución de obligaciones sobre derechos reales. El miércoles intenta comprender un contrato de seguro; el jueves se enfrasca en el empeño por desentrañar la responsabilidad de una compañía de ferrocarriles por el transporte de bienes, por redactar una contestación a una demanda o una prueba pericial. Es asaltado en cualquier momento por dificultades que un mínimo conocimiento jurídico disiparían rápidamente; poco después se sumerge con todos sus sentidos en un caso destinado a asombrar a la Cámara de los Lores. Difícilmente conoce cuáles son los libros a los que debe acudir para buscar orientación, y cuando encuentra el libro adecuado raramente tiene la habilidad necesaria para usarlo. El Digesto de Fisher ${ }^{4}$ - una especie de diccionario legal- el inestimable amigo de aquellos que han aprendido cómo consultar el oráculo, es tan útil para el principiante como podría serlo Liddell y Scott para un estudiante de grado que no estuviese muy versado en el alfabeto griego y no supiese nada de gramática griega ${ }^{5}$. A todo esto se añade que un caso remitido por un attorney tiene una apariencia muy diferente a la del mismo caso una vez depurado de todas las cuestiones irrelevantes por un reporter, o cuando constituye el objeto de un comentario en un libro de texto. Para nuestro estudiante es una desconcertante y en ocasiones mal compuesta narrativa, cuya cuestión no acierta a percibir y de cuyos términos solo comprende la mitad. Antes de poder decidir la sencilla cuestión de si A. puede demandar a B., debe determinar cuáles son los hechos relevantes del caso en cuestión, y es casi seguro que cometerá uno de los dos errores opuestos - o bien no percibe que muchos detalles de gran interés para las partes o para sus attorneys, actos que se han producido años antes de que la disputa comenzara, o cartas escritas meses después de que el proceso comenzara, como la ingratitud del demandante, la monstruosa falta de honestidad del demandado, y asuntos similares, no tienen nada que ver con la decisión, que finalmente se limita a probar si cierta

4 Robert A. Fisher (¿-1879). La obra mencionada es A Digest of the Reported Decisions of the Courts of Common Law, Bankruptcy, Probate, Admiralty, and Divorce (1870).

5 Lexicón griego publicado en 1843 por Henry G. Liddell (decano de Christ Church, Oxford) y Robert Scott. La alusión a la filología no es casual, cfr. Stefan Collini, Donald Winch y John W. Burrow, That Noble Science of Politics. A Study in Nineteenth-Century Intellectual History, Cambridge, Cambridge University Press, 1983, p. 211. 
comunicación constituye propiamente un contrato; o por otro lado nuestro principiante, debido a que nueve décimas partes de las circunstancias sobre las que fijó su atención son irrelevantes, omite considerar la décima, sobre la que todo el asunto depende. En resumen, se le pone a hacer ladrillos sin paja, o más bien sin que se le haya dicho nunca cómo se hacen ladrillos. Lo extraño de la cuestión es que a pesar de todo, y a su debido tiempo, principalmente por un proceso de imitación, consigue hacer ladrillos bastantes decentes. Y es que este duro método de aprendizaje por contacto con la práctica real, si bien no exactamente efectivo, tiene algunos méritos inestimables. Hay por lo menos tres cosas de gran valor que pueden ser aprendidas, en su caso, en un tribunal o en un bufete, y que no pueden ser aprendidas en otro lugar.

Primera. - El mecanismo de la práctica jurídica, como la redacción de las escrituras, la formulación de las demandas, la argumentación de los casos, y otros asuntos similares, debe ser aprendido en los bufetes o en los tribunales. Cuenta la tradición que en cierta época un asesor, más conocido como novelista que como abogado, complementaba (se dice) la insuficiencia de su práctica con la fertilidad de su imaginación. Sus discípulos, se afirma, redactaban declaraciones simuladas, respondidas con demandas ficticias, o inventaban excepciones procesales ilusorias. Pero este ejemplo de prácticas imaginativas ganó más notoriedad que éxito, y su imitación no es recomendable. En las escuelas de derecho de los Estados Unidos, y en los moot court, que han sido replicados con los resultados más felices por lo menos en una de las Inns of Court, mucho es enseñado y aprendido por medio de discusiones dirigidas por estudiantes y jóvenes barristers en presencia de experimentados abogados, con toda la solemnidad propia de los procesos ante los tribunales. Pero por razones obvias este modo de instrucción no puede ser practicado con resultados favorables en Oxford o Cambridge.

Segundo. - Solamente en los bufetes o mediante la práctica real puede ser adquirido el inestimable hábito de distinguir de entre una masa de detalles los hechos relevantes de un caso, y de aplicar a los hechos de la vida los principios del derecho apropiados. Hacer esto, como he indicado antes, es la tarea más difícil de las que deben ser realizadas por un estudiante en un bufete. Pero a pesar de que la dificultad es aumentada innecesariamente por los defectos de un sistema que incita a los principiantes a tratar con hechos antes de haber dominado los principios, no hay parte alguna del sistema de pasantías que sea la mitad de provechosa como la necesidad que éstas imponen a un joven de considerar el derecho en relación con los actos de la vida cotidiana. 
Tercero. - La capacidad de formar opiniones coherentes es una cualidad que sólo puede adquirirse con la práctica. Un abogado instruido de suficiente erudición y capacidad de trabajo puede generalmente reducir las posibles soluciones de un caso dado a una entre dos opiniones plausibles. Haber convertido un complejo y dudoso problema en una elección limitada a dos posibles puntos de vista no es un logro trivial. Pero la verdadera dificultad estriba en determinar cuál de esos dos puntos de vista opuestos es (según la jerga de la abogacía) la "mejor opinión", o en otras palabras, la que finalmente se revelará como la correcta cuando sea sometida al verdadero test del experimento legal -la decisión de los jueces. En la consecución de este logro se encuentra el criterio de la habilidad jurídica superior. Abogados de igual conocimiento, de igual capacidad de trabajo, incluso desde muchos puntos de vista de igual talento, en nada difieren tanto como en la aptitud de formarse opiniones sensatas. Todos nosotros conocemos hombres de profundo conocimiento, de infinito ingenio, de sutileza inagotable, cuyas opiniones únicamente tienen un defecto: que nunca coinciden con la sentencia de la Cámara de los Lores. Por otro lado, hay hombres cuyas opiniones están revestidas de infinita autoridad, porque tales opiniones son conocidas por la cualidad de tornarse verdaderas. Esta cualidad de la sensatez es por supuesto principalmente el resultado del buen juicio. Pero el buen juicio puede ser cultivado, y no es exactamente lo mismo que la capacidad de estimar cuál será la visión judicial del buen juicio. La experiencia y la práctica pueden ayudar mucho a situar en armonía la mente de un hombre con la opinión judicial. La cualidad de la sensatez no es un fruto que pueda ser proporcionado por lecciones.

En resumen, los méritos del sistema actual pueden ser sintetizados por la palabra "realidad". Coloca al estudiante en contacto con los negocios reales y actuales, y fomenta en él cualidades que no pueden ser producidas por ninguna enseñanza teórica, por excelente que sea. Buena disposición, habilidad técnica, juicio sensato, la capacidad de extraer las características esenciales de un caso a partir de una masa de confusos detalles, el hábito de aplicar a los acontecimientos sociales las normas jurídicas vigentes, son cualidades que deben ser adquiridas, en la medida en que no son dones de la naturaleza, mediante la práctica, y sólo mediante ella. Y un joven confundiría completamente sus intereses si, con el objeto de asistir a las lecciones del profesor más elocuente y erudito, sacrificase la ventaja de practicar en un bufete, lugar que con todas sus singularidades, ha instruido generación tras generación a grandes juristas. Pero admitir, o más propiamente proclamar, que de la práctica 
en bufetes puede adquirirse algo, algo de gran valor, que ningún otro método de instrucción puede sustituir, es algo muy diferente a admitir que un aprendizaje sobre la marcha ${ }^{6}$, bajo el cual un joven que se prepara para el acceso a la abogacía se sumerge en detalles y es abandonado a su suerte en la búsqueda de los principios jurídicos, es un sistema perfecto, o exento de defectos que conducen a graves males. Está muy bien oír que un sistema que ha producido a Mansfield, Eldon, Campbell y Westbury, está fuera de crítica7. Pero el sentido común rechaza este argumento ad verecundiam. Se puede demostrar que la enseñanza del derecho tiene graves defectos, y que las circunstancias de la vida actual han hecho que tales defectos tengan mayor peso que el que tenían hace cincuenta años.

He expuesto sin reservas las inmensas ventajas de la práctica en los bufetes. Los defectos inherentes del sistema son patentes tras una simple descripción del método de estudio que emplea un discípulo de un barrister o pleader. Estas deficiencias son tres. El conocimiento adquirido en los bufetes es fragmentario, asistemático y derrochador de tiempo y trabajo.

Primero. - El conocimiento adquirido en los bufetes es fragmentario, porque el sistema actual conduce inevitablemente a un dominio totalmente incompleto de los principios jurídicos.

El estudiante, tras su instrucción, puede haber adquirido muchos conocimientos sobre campos específicos del derecho en los que su maestro destaca, como el derecho de seguros, de patentes, o de las sociedades por acciones. Pero no conoce nada de ninguna otra cosa. De los principios generales que inspiran el ordenamiento jurídico conoce probablemente menos que nada, ya que ha aprendido a dudar de si tales principios existen. Sin embargo, ninguna forma de escepticismo tiene menos fundamento o es más nociva para la consecución de la eminencia jurídica. Quien estudie con inteligencia los tomos actuales de los Reports se convencerá rápidamente de que los asuntos de principio más que los asuntos de detalle son el verdadero objeto de perplejidad de abogados y jueces. ¿Es un matrimonio contraído en Inglaterra por un

6 La expresión traducida es "a hand-to-mouth system of learning”. Aparece en la obra del año anterior de Pollock, muy recomendada en The Law of the Constitution. Cfr. Frederick Pollock, Essays in Jurisprudence and Ethics, cit., ensayo 9, The Science of CaseLaw, p. 238.

7 Lord Mansfield (1705-1793) fue Chief Justice de 1756 a 1788; Lord Eldon (17511838), Lord Chancellor de 1801 a 1806; Lord Campbell (1779-1861), Chief Justice de 1850 a 1859; Lord Westbury (1800-1873), Lord Chancellor de 1861 a 1865 y promotor del Committee for the Inns. 
residente en Escocia un matrimonio inglés o escocés? ¿Puede una sentencia obtenida mediante fraude en un país extranjero ser ejecutada en Inglaterra? ¿Cuál es la exacta responsabilidad (si la hay) de un marido por los contratos celebrados por su esposa? ¿Qué significa "reunión constitucionalmente legítima”? ¿Cuál es la relación con el derecho de expresión del dogma según el cual el cristianismo es parte del derecho del país? Estas cuestiones y muchas otras similares han asombrado recientemente a nuestros tribunales. Cada una plantea cuestiones de principio; algunas tocan los verdaderos fundamentos del derecho. Sería inútil suponer que estos interrogantes pueden ser tratados por hombres que nunca han estado acostumbrados a trazar las aplicaciones de máximas generales ni siquiera en las minucias de la práctica diaria.

Segundo. - El conocimiento adquirido en bufetes es asistemático, ya que nada hay en el modo en que se aprende el derecho que induzca al estudio de éste como un todo.

Pocos son los abogados que han intentado alguna vez adquirir el dominio de las doctrinas elementales tanto del Common Law como de la equity, aunque fuese en una única disciplina jurídica. Menos son todavía los hombres que han captado los cánones que impregnan y gobiernan el ordenamiento jurídico inglés. Tras haber reflexionado sobre la naturaleza de la instrucción en bufetes, apenas necesitamos investigar la causa de esta estrecha concepción del conocimiento jurídico que frecuentemente resulta ser la parte débil de hombres que, dotados de gran habilidad, han ejercido la abogacía durante años con una incansable asiduidad.

Tercero. - El conocimiento adquirido en los bufetes es derrochador de tiempo y trabajo. El defecto más grave del sistema actual es, que por conllevar un desperdicio de esfuerzo, priva al estudiante de la mitad de los beneficios que debería obtener de la invaluable experiencia que puede ser adquirida a través de la observación de la práctica.

De nuevo los hechos hablan por sí mismos. Si un estudiante dedica toda su atención a la práctica que se desarrolla ante sus ojos, no tendrá tiempo para leer libros. Si se sumerge en una lectura atenta de los tratados y reports, no tendrá tiempo de estudiar los escritos procesales. Ni tampoco es conveniente el exceso de lectura para una persona desprovista de método de estudio, y sin guía ninguna sobre los libros que merecen su atención. De esta manera los propios asuntos que discurren ante sus ojos pierden la mitad de su carácter instructivo, y el discípulo, al abandonar el bufete, lo hace con la sensación de haber desperdiciado una gran oportunidad a causa del trabajo mal orientado. 
Dos consideraciones sugeridas por una visión general de los defectos inherentes al modo de enseñanza del derecho predominante son de especial importancia.

La primera de estas observaciones es que un estudiante, a pesar de que sea aplicado y teniendo en cuenta las circunstancias actuales, no puede compensar mediante un estudio asiduo de las obras jurídicas las deficiencias de la formación en bufetes. Ello se debe a que la literatura jurídica, hasta el inicio de la reforma ocurrida unos veinticinco o treinta años atrás, reproducía y estereotipaba todos los grandes defectos de la instrucción jurídica. Nuestras mejores obras, como los Leading Cases de Smith ${ }^{8}$, en el fondo constituyen una mera acumulación de notas sobre puntos aislados de curioso más que de útil aprendizaje. Son deficientes bajo cualquier concepción general, en la comprensión de los principios, en cualquier idea sobre el método. Los autores que han aprendido su oficio a partir de la práctica nunca han aspirado a un análisis o definición precisos de las ideas jurídicas. Por consiguiente los términos técnicos del derecho son tan malos como cualquier tecnicismo puede serlo; son técnicos sin ser precisos, o, en el caso de ser aparentemente populares, están cargados de ambigüedad. Intenten definir, según las autoridades recibidas, términos tales como "chose in action", "propiedad personal", "contrato nulo", "acuerdo tácito", y no solo asentirán a mi crítica, sino que descubrirán la causa de toda esta desesperanzadora confusión. Generaciones de ejercientes no se han interesado por la definición, ni han entendido su naturaleza o su importancia. Tomemos por ejemplo el caso de un escritor cuyo libro fue hace veinte años la guía del estudiante para el derecho de los contratos. Mr. J. W. Smith comienza su tratado con un capítulo sobre "naturaleza y clasificación de los contratos". De la naturaleza del contrato no dice nada a sus lectores. Lo que sí dice es que los acuerdos consisten en contracts of record, contracts under seal y simple contracts. Primeramente sustituye la definición por la división, y después formula una división que, por su falta absoluta de carácter instructivo, puede ser comparada con el intento de clasificar animales dividiéndolos en dodos, leones y otros animales que no sean dodos o leones ${ }^{10}$. En verdad, la falta de significado de la clasificación de Mr.

8 John W. Smith (1809-1845), barrister del Inner Temple, publicó entre 1837 y 1840 A Selection of Leading Cases on Various Branches of the Law.

9 Cfr. Dicey, The Law of Domicil, cit., p. 37.

10 Nótese la aguda crítica de nuestro autor, que desliza que J. W. Smith no discierne entre derecho vigente y derecho en desuso (el dodo se extinguió en el siglo XVII). 
Smith puede ser completamente comprendida únicamente por aquellos que saben que el término "simple contract" es una mera expresión negativa, cuyo significado no es otro que cualquier contrato que no sea un contract of record ni tampoco un contract under seal ${ }^{11}$. La división, ciertamente daría ocasión para un largo comentario. Su característica más peculiar, que no debe pasar desapercibida, es que enfatiza los anómalos e inusuales acuerdos conocidos como contracts of record, los cuales (si es que constituyen contratos) son la última clase de acuerdos con los que es deseable perturbar la atención de los estudiantes. De los verdaderos elementos de un contrato - la oferta, la aceptación, la promesa - nuestro maestro no dice nada. Si se compara la estéril clasificación de J. W. Smith con el fructífero análisis que puede encontrase en los trabajos de mis amigos el Professor of Jurisprudence ${ }^{12}$ y Sir W. Anson, se percibirá lo grande que es la confusión introducida en una materia sencilla por un escritor que ha aprendido el derecho sin dominar sus principios. El crítico observará asimismo que J. W. Smith, junto con otros respetables escritores como Chitty ${ }^{13} \mathrm{o}$ Addison ${ }^{14}$, ilustra en cada página un defecto que hasta hace poco ha recorrido toda nuestra literatura jurídica, y ha infectado por falta de correctivo algunos hábitos intelectuales de los juristas ingleses. Este vicio es la tendencia a procurar una atención desmedida a las excepciones y anomalías, con el descuido de los mucho más importantes cánones y reglas a las que tales excepciones se refieren. La fuente original de este defecto puede hallarse en el hecho de que el derecho inglés está construido sobre casos, y en que cada caso incluido en un report constituye el registro de alguna excepción a una regla general. Por ello todos nosotros estamos obligados a emplear en buena medida lo que un eminente abogado ha denominado el "derecho dado por supuesto”. Este derecho dado por supuesto no es nada más que los

11 Austin, "Sobre la utilidad del estudio de la jurisprudencia", cit., p. 354: "[n]o es raro en escritores que se llaman y se piensan a sí mismos 'tratadistas', dar por supuesto que conocen la significación de estos términos, y que está tiene también que ser conocida por aquellos a quienes se dirigen".

12 El fructífero análisis puede encontrarse en Frederick Pollock, Principles of Contract at Law and in Equity, Londres, Stevens, 1876. Su índice de abreviaciones incluye autores continentales citados también por Dicey en su lección: Pothier, Savigny, Wangerow.

13 Joseph Chitty (1776-1841), special pleader, con numerosas obras pertenecientes al periodo 1799-1837. Sus hijos Joseph, Edward y Thomas también fueron reconocidos ejercientes.

14 Charles G. Addison (1810-1866), publicó entre 1845 y 1847 A Treatise on the Law of Contracts. 
principios de la ciencia jurídica deducidos a través de inferencias a partir de las excepciones registradas. Los libros de texto reproducen las excepciones y generalmente omiten dar cuenta de los principios.

La segunda observación es que si un estudiante no puede encontrar en la literatura los elementos de instrucción ausentes en el bufete, los vicios que deforman el actual sistema de enseñanza del derecho tienen mayores consecuencias en el momento actual que en los días de nuestros antepasados.

Hasta el comienzo del siglo actual, o hasta un periodo considerablemente posterior, era posible seguir un plan exhaustivo de aprendizaje del derecho. Los estudiantes que eran capaces de explorar el conjunto del mundo del derecho no requerían necesariamente un plan para dominar sus complejidades. En los tiempos de Coke todo el derecho inglés reducido a expresión escrita probablemente no excedía en volumen los treinta o cuarenta tomos de los actuales Law Reports. Un autor que escribía a finales del siglo pasado, cuyo objetivo era más bien magnificar que infravalorar la dificultad del aprendizaje de los principios jurídicos, afirma que "el derecho de este país incluyendo leyes aprobadas por la asamblea legislativa y decisiones de los tribunales supremos de justicia no son menos que cincuenta tomos en folios”. Y si Paley ${ }^{15}$, aunque poco tendente a estar mal informado, no puede ser citado como una autoridad en asuntos jurídicos, podemos confiar absolutamente en las afirmaciones de Mr. Wallace, quien en su trabajo sobre los Reporters escribe que hasta el año 1776, el número total de Reports en Inglaterra tanto en derecho como en equity excedía poco más de ciento cincuenta tomos ${ }^{16}$. Por consiguiente, un hombre con la asombrosa laboriosidad de Lord Campbell, habría podido incluso leer algo cercano a la extensión total del derecho. Añádase a lo anterior que en todo caso hace un siglo disciplinas jurídicas enteras como el derecho de sociedades, el derecho de los contratos, la regulación del contrato de mandato, las normas del llamado derecho internacional privado, el derecho de las sociedades por acciones, y similares, se hallaban hasta tiempos recientes muy poco desarrollados por no decir que eran inexistentes. Podemos ahora medir las dificultades crecientes que deben ser afrontadas por un

15 William Paley (1743-1805) fue uno de los filósofos más admirados por Dicey. Cfr. la primera lección de Law of the Constitution, que cita sus Principios de filosofía moral.

16 John W. Wallace (1815-1884) fue el séptimo reporter de la Corte Suprema de Estados Unidos durante el periodo 1863-1874. La obra mencionada es John W. Wallace, The Reporters. Chronologically Arranged. With Occasional Remarks upon their respective Merits, Philadelphia, I. R. Bailey, 1844. El cargo de reporter fue creado en los Estados Unidos por una ley de 1817 (sess. 2, c. 63). 
estudioso que emprenda un sistema de estudio exhaustivo derivadas de un incremento en el volumen de los Reports o de un crecimiento de los límites del mundo del derecho. Desde el acceso al trono de Jorge II (1714) hasta digamos 1830, los principios del derecho inglés permanecieron invariables, en lo que al Parlamento tocaba, tanto inalterados como inalterables en la prácti$\mathrm{ca}^{17}$. Lord Eldon habría propuesto antes una ley para abolir la monarquía que una medida como la Married Woman's Property Act de 1882. Todo esto es ahora diferente. Los Reports ascienden a una cantidad de entre 1.300 y 1.500 tomos, los Revised Statutes ${ }^{18}$, que comienzan en 1868 , ascienden a quince voluminosos tomos; los Reports aumentan a razón de diez tomos por año, el Statute-book se ensancha tras cada periodo parlamentario, y cada tomo contiene importantes innovaciones que en ocasiones parecen hacer temblar los cimientos de nuestro sistema jurídico.

Entretanto el abogado está obligado a consultar tanto Reports extranjeros como ingleses. En 1776 y durante algunos años posteriores no existió ningún Report americano ${ }^{19}$. Actualmente los Estados Unidos gozan o sufren por causa de cuatro mil tomos de Reports, y la biblioteca del Middle Temple contiene una masa de Reports americanos que excede sobradamente la cantidad total de la literatura inglesa correspondiente al momento en que América declaró su independencia. Un sistema exhaustivo de aprendizaje del derecho se ha convertido en términos estrictos en una imposibilidad; es una tradición del pasado. No se puede estudiar el derecho de la manera en que lo hacían Coke, Holt, Blackstone ${ }^{20}$, o incluso Campbell, del mismo modo que no se puede ejercer el comercio en Inglaterra con las naves que bastaban para los días de Isabel o incluso Jorge III.

Mientras que el estudiante moderno necesita más que sus antepasados una guía educacional, debido a un extraño giro de la fortuna ha perdido las guías en las que sus predecesores confiaban. Los pleaders tienen mal nombre; su arte es objeto de la mejor sátira jurídica, pero a ellos les debe el derecho y

17 Vid. Dicey, Law \& Public Opinion, cit., lección 5, The Period of Old Toryism or Legislative Quiescence, pp. 70-124.

18 En 1861 el Parlamento aprobó la primera Statute Law Revision Act. El Law Committee publicó en 1868 la primera edición de los Revised Statutes, obra en 18 volúmenes.

19 William Johnson (1769-1848) fue el primer reporter de la Corte Suprema de los Estados Unidos, nombrado en 1806. Cfr. Newman, The Yale Biographical Dictionary of American Law, cit., p. 314.

20 John Holt (1642-1709/10), fue presidente del King's Bench durante el periodo 1689-1709/10. 
los abogados una gran deuda de gratitud. La ciencia del pleading consistía en la cuidadosa distinción entre el derecho y los hechos. Discípulos instruidos en el bufete de un pleader fueron por ellos compelidos a seguir una rutina en la práctica para aprender los principios del derecho de maestros que nunca estaban ausentes de los tribunales, y que no podían distinguirse en el pleading sin alguna comprensión de los principios. El Common Law no ha producido en el último siglo un solo abogado eminente que no fuese instruido por un special pleader. El pleading ha sido abolido, y los pleaders - los verdaderos maestros del Common Law- pronto serán una raza olvidada ${ }^{21}$.

Reconocer las deficiencias y más aún las ventajas de las pasantías en bufetes es casi la misma cosa que determinar en qué medida puede el derecho ser enseñado en las universidades. La instrucción académica en Oxford debe ser la preparación adecuada para el ejercicio de los negocios en Londres; el ámbito propio de la actividad profesoral es compensar todos los defectos que pueden surgir directa o indirectamente de un sistema desequilibrado de instrucción jurídica. Es tarea de los profesores exponer el derecho como un sistema coherente - analizar y definir los conceptos jurídicos- reducir la masa de normas jurídicas a un conjunto ordenado de principios, y ayudar, estimular y guiar en la reforma o renovación de la literatura jurídica. Permítanme en algunos minutos trazar con cierto cuidado cada uno de estos ámbitos de la enseñanza académica.

1. En las universidades se puede enseñar a un estudiante a contemplar el derecho como una unidad y a considerar la relación de una parte del derecho inglés con otra. El renacimiento del estudio del derecho romano ha ayudado mucho en la tarea de ordenar la caótica masa del derecho inglés bajo algún

21 Fue abolido gradualmente por las Unification of Process Act 1832, Common Law Procedure Act 1852 y Judicature Acts 1873-75, cfr. Frederic W. Maitland, Equity. Also the Forms of Action at Common Law. Two Courses of Lectures (A. H. Chaytor y W. J. Whittaker eds.), Cambridge, Cambridge University Press, 1909, pp. 374-375. Fue Maine según Maitland quien formuló la idea de precedencia del derecho procesal sobre el substantivo, con crítica incluida al término Adjective Law empleado por Bentham. Cfr. Henry S. Maine, Dissertations on Early Law and Custom. Chiefly Selected from Lectures Delivered at Oxford, Londres, John Murray, 1883, capítulo 11, Classification of Legal Rules, p. 389: "[s]o great is the ascendency of the Law of Actions in the infancy of Courts of Justice, that substantive law has at first the look of being gradually 'secreted in the interstices of procedure'; and the early lawyer can only see the law through the envelope of its technical forms". Cfr. Ignacio Cremades Ugarte, "Introducción”, en Frederic W. Maitland, Las formas de acción en el Common Law, Madrid, Marcial Pons, 2005, pp. 9-30, pp. 9-11. 
tipo de forma, y a esta fuente debe indudablemente ser en parte atribuido el avance realizado por la literatura jurídica de los últimos veinte años en claridad y simetría. Pero no hay ninguna razón en la naturaleza de las cosas por la que el derecho inglés no deba ser exhibido como un modelo de ordenación clara y coherente de normas y conceptos jurídicos. No hay la más mínima razón por la cual no se deba proporcionar a los estudiantes, o mejor, por la que no deban ser enseñados a proveerse por sí mismos, de esbozos del derecho inglés tan notables como aquéllos pertenecientes al único sistema que puede reivindicar ser su rival. El que haya obtenido tal guía habrá logrado mucho más que simplemente aumentar su conocimiento. Habrá adquirido no solamente un método de estudio, sino también un esquema con el cual podrá parcelar, y a través de la división, retener el conocimiento que adquiera mediante la lectura o la práctica. Un joven que comienza a prepararse para el acceso a la abogacía que cuente con un conocimiento general de su materia como la que se obtiene a través de la enseñanza académica en Alemania, Francia, Escocia y Estados Unidos, aprenderá fácilmente por medio del estudio en bufetes o de la asistencia a procesos ante tribunales más derecho del poseído comúnmente por barristers de muchos años de ejercicio.

2. En las universidades puede ser enseñando lo que por la propia naturaleza de las cosas nunca puede ser aprendido en los bufetes -el hábito de analizar y definir conceptos jurídicos. Tal análisis no es la ocupación de hombres completamente dedicados a las necesidades cotidianas del ejercicio profesional, pero su importancia difícilmente podría ser sobrevalorada. Ningún juez competente negaría, me arriesgo a decir, que la mitad de las dificultades tanto del estudio del derecho como del ejercicio profesional surgen por la inexactitud y vaguedad de los términos jurídicos ${ }^{22}$. Todos sabemos cuánto se ha hecho por clarificar el derecho de los contratos gracias a un cuidadoso análisis del acuerdo. Cualquiera que haya dirigido su atención en esa dirección sabe que la teoría de la posesión de Savigny ha solucionado muchos rompecabezas del derecho inglés. Clarifica las normas en relación con la prescripción adquisitiva; esclarece asuntos tan aparentemente técnicos como la naturaleza de los actos que perturban la posesión y los principios que rigen las acciones interdictales, nos permite reducir a una unidad consistente el derecho del

22 “[...] inaccuracy and vagueness of legal terms”. Otro catedrático de Oxford empleó el mismo adjetivo décadas después: "open texture or vagueness...of the concepts”. Cfr. H. L. A. Hart, "Analytical Jurisprudence in Mid-Twentieth Century: A Reply to Professor Bodenheimer”, University of Pennsylvania Law Review 105 (1957), pp. 953-975, p. 957. 
domicilio, y curiosamente torna inteligible por lo menos una de las ambigüedades de esa ley tan estudiada -la décimo séptima sección del Statute of Frauds. No hay de hecho esfera más apropiada o beneficiosa para la actividad profesoral que la explicación, simplificación y análisis de la terminología jurídica. Se podría incluso predecir que hasta que la terminología jurídica no haya sido revisada o establecida, como lo ha sido en otros países bajo la influencia de la enseñanza profesoral, Inglaterra nunca tendrá un código digno de los méritos del derecho inglés.

3. En las universidades se puede enseñar, y difícilmente puede hacerse bajo las actuales circunstancias en otro lugar, el hábito de concebir el derecho como un conjunto de normas y excepciones, y de determinar cuidadosamente los límites exactos de principios establecidos. Este es el verdadero remedio de la fatal tendencia de recordar las excepciones y olvidar las normas obvias. El primer deber de un profesor competente es el de dejar claro a sí mismo y a sus discípulos la idea de que el derecho puede ser reformulado en la forma de un digesto consistente en un conjunto de normas y excepciones, y el de hacer sentir a sus oyentes que los principios generales, comunes y ordinarios son mucho más importantes que lo que es excepcional, anómalo o anormal.

Mediante un estudio adecuado y un pensamiento cuidadoso enteras disciplinas jurídicas pueden ser reducidas a un orden y presentadas bajo la forma de unos pocos principios que resumen el efecto de cientos de casos, y pueden ser así comprendidos y recordados, mientras que ninguna memoria puede ni siquiera retener los nombres de los casos de los que dichas reglas dependen. Tomemos un ejemplo de lo que estoy refiriendo. Dejemos que alguien intente componer en forma de normas y excepciones cierta proposición (como la que podría encontrarse en un código) sobre las diferentes clases de personas que pueden ser consideradas sujetos británicos. La tarea no presenta ninguna dificultad insuperable. Tres o cuatro leyes breves, no más de diez o doce casos, constituyen el material necesario. Pero cualquiera que siga mi propuesta advertirá que la tarea requiere tiempo y esfuerzo, y que cuando se ha realizado adecuadamente se tiene en la mente un conjunto de proposiciones sobre la adquisición y pérdida de la nacionalidad británica que convierte a uno en un experto permanente de una materia complicada. Descubrirá también que en algunos puntos el derecho de la nacionalidad se encuentra estrictamente hablando irresuelto. Sabrá dónde se hallan las verdaderas perplejidades, y cuando, como ha ocurrido recientemente, un caso recaiga en uno de los puntos debatidos, fácilmente comprenderá los efectos de la decisión y los 
retendrá en su memoria. Aprenderá además que los recovecos del derecho actual surgen históricamente a partir del conflicto y compromiso final entre dos teorías rivales de la obediencia ${ }^{23}$. Lo que puede lograrse en un campo específico de nuestra materia puede por medio de aplicación e inteligencia completarse gradualmente a través de todo el dominio del derecho inglés. Ningún profesor o conjunto de profesores de cierta facultad puede dentro de un tiempo finito reducir todo el derecho inglés a este tipo de código natural. Pero puede afirmarse con seguridad que nada de mayor valor puede ser enseñado a los estudiantes, tanto intelectualmente como desde la perspectiva del ejercicio profesional, que el hábito de concebir el derecho como un conjunto de normas; y también que una escuela de juristas caracterizada por este hábito mental reduciría gradualmente la entera masa caótica de principios legales a una forma clara, lógica, y simétrica. Llegamos, no obstante, a los confines del último y quizás más interesante ámbito de los esfuerzos profesorales.

4. En las universidades puede ser promovida, estimulada y guiada como en ningún otro lugar, la muy necesitada reforma, y casi diría creación de la literatura jurídica ${ }^{24}$.

Ningún país es tan rico como el nuestro en registros de decisiones judiciales. Mil quinientos tomos o más de Reports son los más nobles monumentos de los méritos substanciales de nuestro derecho a la sensatez, a la justicia, a la perspicacia, al poder intelectual, a la habilidad literaria de nuestros jueces. Un estante de la biblioteca del Temple sería sobradamente suficiente para contener todos los tomos dignos de nuestra literatura jurídica. No tenemos una historia general del derecho inglés que merezca tal nombre, no tenemos ni unos veinte tratados dignos de colocarse al lado de las producciones de los grandes juristas de otros países. Si bien la riqueza de nuestros Reports es un homenaje permanente a la grandeza de nuestros jueces, la pobreza de nuestra literatura jurídica es seguramente uno de los resultados de la inexistencia hasta años recientes de un profesorado del derecho. En los enseñantes académicos, en todo caso, recae naturalmente la tarea, tan llena de importancia como de interés, de contribuir a la reforma o renacimiento de la literatura jurídica, lo cual constituye uno de los fenómenos más destacados de los últimos treinta años. Si observamos las necesidades de nuestros estudiantes, es

23 La teoría romana y la feudal. Vid. John Westlake, A Treatise on Private International Law, Londres, W. Maxwell, 1858, capítulo 1, History of the Doctrine of Allegiance in England and France, pp. 5-14.

24 Cfr. Austin, "Sobre la utilidad del estudio de la jurisprudencia", cit., p. 74. 
de la máxima importancia proporcionar obras que les permitan contemplar el derecho como un estudio racional, que puede ser tratado como cualquier otra ciencia de una manera clara, racional, e interesante. Más de uno de mis colegas ha emprendido ya esta tarea con preeminente y reconocido éxito. $\mathrm{Si}$ los jóvenes aprendices son capaces de demostrar alguna gratitud, debe seguramente existir un amplio grupo de estudiantes que den gracias diariamente a Sir William Anson y al profesor Pollock por haberlos librado de la carga de la onerosa confusión de Addison, y del inútil esfuerzo impuesto por el intento de entender las fútiles sutilezas de J. W. Smith. Si bien es cierto que la absoluta necesidad del caso debe inspirar a todos los maestros el apremio por producir tratados dignos del derecho que cultivan, otro motivo puede buenamente conducir a enérgicos maestros hacia el camino de la autoría jurídica. Por medio de la enseñanza y de la literatura pueden influir mucho más de los que habitualmente se cree no sólo en la forma sino también en la substancia del derecho. Las normas jurídicas que se suponen tan inflexibles son de hecho la mayoría de las veces derecho de origen judicial, y nada es tan remarcable o inteligible como la facilidad con la que el derecho de origen judicial responde a la presión de las opiniones de autoridad. Atareados magistrados, que se ocupan de los casos que van llegando, toman sus principios de los escritores. Ciertos autores han modelado notoriamente incluso en tiempos recientes, se podría decir incluso que han creado, disciplinas enteras del derecho. La disciplina del pleading fue sistematizada hace cincuenta años y convertida en un arte por uno de los abogados de más consumada habilidad lógica ${ }^{25}$; el derecho de daños ha surgido, se dice, bajo la influencia de otro escritor todavía vivo. El vasto campo del llamado derecho internacional privado ha sido delineado en Inglaterra por medio de tres o cuatro normas derivadas de $\mathrm{Hu}$ ber, y de las doctrinas expuestas por Story en su Conflict of Laws $^{26}$. Pero en Inglaterra, como en cualquier lugar, el efecto producido por un solo escritor no es nada comparado con el que podría producir una escuela de maestros.

En esta lección, se observará, ninguna oposición se ha trazado entre las

25 Henry John Stephen (1787-1864), serjeant-at-law, publicó A Treatise on the Principles of Pleading in Civil Actions en 1824. Pariente de Dicey por línea materna, actualizó los Comentarios de Blackstone, Henry J. Stephen, New Commentaries of the Laws of England. Partly Founded in Blackstone, Londres, Henry Butterworth, 1841-45, 4 vols. 16 ${ }^{\mathrm{a}}$ ed. de 1914 editada por Edward Jenks.

26 Joseph Story (1779-1845) publicó en 1834 Commentaries on the Conflict of Laws, Foreign and Domestic, in Regard to Contracts, Rights, and Remedies, and especially in Regard to Marriages, Divorces, Wills, Successions, and Judgments. 
funciones de un profesor en tanto que docente y en tanto que investigador o autor. Ninguna se ha inferido porque no existe tal oposición. En verdad el proceso de enseñanza repetida de doctrinas elementales a un grupo necesariamente ignorante conlleva algún desperdicio de trabajo. La exposición (se dirá con razón) no es erudición. Pero este desperdicio de trabajo, por perjudicial que pueda ser, es o debe ser más que compensado mediante dos ventajas en la posición de un lecturer. Pronto advertirá que no puede explicar lo que ni él mismo entiende; las lecciones fáciles y lúcidas son el fruto de costosa lectura y larga, si no dolorosa, meditación. Asimismo la necesidad de hacer los pensamientos propios entendibles para uno mismo y para los demás es el correctivo más admirable de la pedantería, la hosquedad, la irrealidad, que ciertamente son los vicios de los denominados "paper lawyers", y que me aventuro a conjeturar son los defectos que en ocasiones infestan los estudios de profesores y juristas. En todo caso las cualidades que deben distinguir la enseñanza académica del derecho -el hábito de concebir nuestra materia como una unidad, el deseo de definir y (aunque con una mirada constante en las autoridades recibidas y en los hechos) simplificar las ideas y conceptos jurídicos, el esfuerzo por reducir el derecho a un conjunto de proposiciones que sean a la vez inteligibles y se hallen en correspondencia con las decisiones de los tribunales y las opiniones de los abogados ejercientes- estas cualidades son todas ellas fomentadas por la necesidad de una exposición clara y efectiva del derecho vigente, y son también características que pueden encontrarse en autores que desean producir obras monumentales de literatura jurídica. Es difícil imaginar que si en Inglaterra los libros de derecho hubiesen sido compuestos como en otros países, por juristas que escribieron con una mirada constante dirigida a una audiencia de estudiantes, hubiéramos contemplado el crecimiento de monstruosidades literarias tales como los Leading Cases de Smith, en la que montones sobre montones de notas son apilados por así decirlo en un estrato tras otro, erigidos sobre algún caso de ningún valor en sí mismo, enteramente aplastado bajo el peso de comentarios superpuestos; o que todos nosotros nos hayamos devanado los sesos a causa de las indescifrables enseñanzas de Lord St. Leonards ${ }^{27}$; o que sucesivas generaciones hayan visto una disciplina del derecho tras otra caer presa de la energía calamitosa de autores tan conocidos por su falta de perspicacia como por su portentosa y variopinta laboriosidad. Pero la inmensa influencia

27 Edward B. Sugden (1781-1875), Lord Chancellor en 1852 en el Gobierno de Lord Derby. 
ejercida sobre el derecho por escritores y maestros-ambos no necesitan ser distinguidos para nuestros actuales objetivos- puede ser probada mediante argumentos más fuertes que las consideraciones generales de los efectos de la exposición. En este asunto podríamos consultar las lecciones de una larga y variada experiencia. La gran demanda de una reforma en nuestra literatura jurídica es simplemente una parte de lo que puede ser razonablemente denominado un muy notable movimiento intelectual o revolución. Durante los últimos treinta años, tres hombres geniales han dado nuevos impulsos al estudio del derecho. Macaulay ha creado un nuevo tipo de codificación. Como historiador ciertamente no es el líder de ninguna escuela; como reformador y como codificador del derecho es el padre no solamente de códigos legislativos que posiblemente sobrevivirán a la memoria de su historia, sino de todos los digestos no oficiales, aunque inestimables, del derecho inglés como el Law of Bills of Exchange de Mr. Chalmers o el Digest of Criminal Law de Sir James Stephen, de los cuales uno ha recibido autoridad legislativa y el otro es probable que la reciba ${ }^{28}$. Austin ha dado nuevo impulso a la especulación jurídica, y ha influido en algunos escritores que no comparten sus puntos de vista, y que no adoptan explícitamente su sistema de análisis lógico, mucho más de lo que éstos perciben. Sir Henry Maine ha abierto un nuevo campo de investigación histórica, y junto a Austin ha reavivado el interés público por el derecho romano. De entre estos hombres dos eran profesores, y Macaulay, con su intenso amor por la explicación y su pasión por la ilustración, se aproximó más al tipo profesoral que a esa clase de barrister que brilla en las quarter sessions, en los circuitos judiciales, en el nisi prius o incluso en la Cámara de los Lores. Si se dice que la influencia de estos tres hombres únicamente ilustra indirectamente el efecto de la enseñanza profesoral, debemos ampliar nuestra visión para alcanzar una perspectiva más ancha. Los nombres de Pothier, Savigny, Wangerow, Mancini, o Bluntschli, son suficientes para recordarnos que las grandes obras de los juristas extranjeros, los tratados y códigos que han sido el resultado y la materialización de sus enseñanzas, fueron en muchos casos la elaboración más o menos inmediata de lecciones. Pero podemos observar un ámbito más cercano y examinar la condición jurídica de un país cuyo derecho recibe ciertamente mucha menos atención de la que merece.

Escocia, en lo relatico a los Reports, está dotada de menor riqueza que

28 Mackenzie D. Chalmers (1847-1927), jurista codificador del derecho mercantil, fue el inspirador de las siguientes leyes: Bills of Exchange Act 1882, Sale of Goods Act 1893, Marine Insurance Act 1906. Fue consejero jurídico del Consejo Legislativo de la India. 
Inglaterra, pero incluso una observación preliminar muestra que posee al menos tres o cuatro escritores institucionales que serían difíciles de igualar con autores ingleses del mismo mérito. Bajo petición he sido informado por la mayor autoridad viva en la historia del derecho de ese país que las mejores obras institucionales escocesas son en efecto producto de lecciones. Los Commentaries on the Definition and Punishment of Crime del Baron Hume ${ }^{29}$, los Principles of the Law of Scotland de John Erskine ${ }^{30}$, los Principles of the Law of Scotland de George Joseph Bell ${ }^{31}$, son todos y cada uno de ellos el fruto de lecciones pronunciadas en la Universidad de Edinburgo. Algo parecido podría decirse, sustancialmente verdadero aunque no gramaticalmente correcto, del más famoso de los tratados jurídicos escoceses, las Institutions de Stair ${ }^{32}$. Lord Stair estudió en Glasgow; no fue nunca profesor, por la sencilla, si no satisfactoria razón, de que ningún puesto de profesor de derecho existía en aquella universidad hasta principios del siglo pasado. Pero las partes filosóficas de las Institutions se remontan ciertamente, según me informa el biógrafo de Lord Stair, a las lecciones que dio en calidad de regente de la Universidad of Glasgow.

$\mathrm{Si}$ alguien sugiriese que los sistemas basados en el derecho romano se prestan a la exposición profesoral mejor que el derecho inglés, la sugerencia puede ser al momento resistida mediante la contrastación con los hechos. En este punto, como en realidad en todo el objeto de esta lección, la experiencia de los Estados Unidos está llena de instrucción. Los ciudadanos de la Unión no son ciertamente ni pedantes ni, en general, teorizadores; pero en este momento el derecho inglés se enseña admirablemente en los colleges de América. Los abogados ejercientes, los tan agudos attorneys de Nueva York, se reirían delante de usted si les sugiriera que nada de valor puede aprenderse de las lecciones del profesor Dwight, del cual la inmensa mayoría de aquéllos son, o han sido alumnos ${ }^{33}$. Y el Consejo de la Abogacía de Massachusetts le

29 David Hume (1757-1838), sobrino del filósofo, catedrático de derecho escocés en la Universidad de Edimburgo (1786) y juez de la Court of Exchequer (1822).

30 John Erskine (1695-1768), profesor de derecho escocés en la Universidad de Edimburgo durante el periodo 1737-1765.

31 George J. Bell (1770-1843), profesor de derecho escocés en la Universidad de Edimburgo durante el periodo $1822-1843$.

32 James Dalrymple (1619-1695), presidente de la Court of Session de Escocia durante los periodos 1671-1681 y 1689-1695.

33 Theodore W. Dwight (1822-1892), decano de la escuela de derecho de Columbia durante el periodo 1858-1891. 
diría sin lugar a dudas que la mejor preparación para la práctica en los tribunales es el estudio en las aulas del Profesor Langdell y de sus colegas de la Universidad de Harvard ${ }^{34}$. Lo anterior, debe ser notado, no es la experiencia de un día o de una única generación. Los eruditos y rigurosos Commentaries de Kent fueron pronunciados en forma de lecciones en el Columbia College de Nueva York ${ }^{35}$. Conflict of Laws de Story, su Equity Jurisprudence, su Law of Agency -la totalidad, de hecho, de una serie de trabajos que son los mejores de su clase en lengua inglesa - fueron pronunciados por él en forma de lecciones en calidad de Dane Professor en la Universidad de Harvard. Nunca ha recibido, debe añadirse, en América, ningún apoyo la idea de que exista alguna inconsistencia entre el conocimiento práctico y la exposición teorética del derecho. Kent abandonó su alto cargo judicial por un puesto de profesor. Sus Commentaries han sido reeditados de tal forma que han sido transformados en una nueva obra de tanto valor como los Commentaries mismos por el más distinguido de los escritores del derecho americanos, quien acaba de dejar su cátedra de Harvard para ejercer en la distinguida Corte Suprema de Massachusetts ${ }^{36}$. Las lecciones de Story fueron pronunciadas en Harvard, cuando era con diferencia el juez más eminente de la Corte Suprema de Washington.

La experiencia de Inglaterra, podría decirse, no ha favorecido la enseñanza académica del derecho. En un país donde durante siglos no ha existido un profesorado, ninguna inferencia podría extraerse del hecho de que nuestros libros de derecho no son, como en otros países, el resultado de lecciones. Pero aquí tenemos, felizmente, una de esas excepciones que precisamente confirman la regla. En esta universidad, y en este college, es imposible olvidar por un momento que el único libro de derecho que puede aspirar a un alto y permanente lugar en la literatura de Inglaterra fue originalmente concebido como un curso de lecciones en la Universidad de Oxford. El gran comentador, debe admitirse con razón, fue un hombre dotado de las más raras combinaciones de dones. Aunó una amplia y práctica experiencia del derecho propia de un eminente asesor que gozaba de influencia en la corte con la facilidad li-

34 Christopher C. Langdell (1826-1906), profesor de la escuela de derecho de Harvard desde 1870, publicó en 1871 A Selection of Cases on the Law of Contracts.

35 James Kent (1763-1847) publicó entre 1826 y 1830 Commentaries on American Law.

36 Oliver W. Holmes Jr. (1841-1935) accedió a tal puesto en enero de 1882. Durante el periodo 1902-1932 fue juez de la Corte Suprema de los Estados Unidos. 
teraria y gracia de estilo propias de un distinguido hombre de letras. Su obra, en cambio, no es precisamente lo que se exige a los maestros actuales. Todo esto es cierto. Blackstone nos ofrece un ejemplo más bien de estímulo que de imitación. Pero la preeminente influencia ejercida por las lecciones profesorales que dieron lugar a los Commentaries de Blackstone es un argumento casi irresistible en favor de la conclusión a la que llegamos desde cualquier lugar del que nos aproximemos a nuestro objeto. Los inmensos méritos y los defectos patentes del actual sistema de enseñanza; las necesidades actuales de los jóvenes estudiantes de derecho, los defectos que han lastrado la literatura jurídica de Inglaterra; el movimiento de reforma por el que estos errores están siendo corregidos o eliminados día tras día; la experiencia de toda Europa continental, de Escocia, América, y, en el único ejemplo al que es posible referirse de la misma Inglaterra - todo ello proporciona la respuesta a nuestra pregunta inicial. No existe una verdadera rivalidad entre las pasantías en bufetes y la enseñanza en las universidades. El derecho inglés puede ser enseñando, y si los docentes son competentes, y perciben claramente los límites y el objetivo de su enseñanza, no puede ser enseñando en otro lugar más que en las universidades inglesas. 



\title{
CAN ENGLISH LAW BE TAUGHT
}

\author{
AT
}

THE UNIVERSITIES?

AN INAUGURAL LECTURE,

Delivered at All Souls College, 21St April, 1883,

BY

\begin{abstract}
A. V. DICEY, B.C.L., Hon. LL.D., BARRISTER-AT-LAW, VINERIAN PROFESSOR OF ENGLISH LAW IN THE UNIVERSITY OF OXFORD, AND FELLOW OF ALL SOULS COLLEGE.
\end{abstract}

London:

MACMILLAN AND CO. 1883.

Price One Shilling. 

If the question whether English law can be taught at the Universities could be submitted in the form of a case to a body of eminent counsel, there is no doubt whatever as to what would be their answer. They would reply with unanimity and without hesitation, that English law must be learned and cannot be taught, and that the only places where it can be learned are the law court or chambers. The barrister who maintains or thinks that the mysteries of his art can be learned by practice only has, it should in fairness be noted, one strong argument in support of his conviction. He can rely on the uniform experience of many generations. Of direct instruction or tuition English lawyers have, till within the last twenty-five years, received nothing whatever, and even now the lectures which are delivered by distinguished professors in the hall of the Temple or of Lincoln's Inn are the ornament rather than any essential part of legal education. essential part of legal education. Knowledge of law is still, as it has been for centuries, acquired by actual practice in the courts, or by the imitative practice miscalled "reading" in chambers. My purpose in this address is to set forth, to the best of my power, and with the utmost impartiality, the marked merits, and the no less patent defects, of the present system of legal study, and to show what is the field which this system leaves open for professorial and academical teaching.

The prevailing method of reading in chambers is so much a part of our customary life that, like many other English institutions, its peculiarity hardly strikes us; yet it is certainly a method of instruction which would strike a foreigner as strange, not to say as unaccountable. Its essential features are exactly hit off by the account which (it is said) an eminent lawyer has left on record of the training which ultimately led him to the woolsack. "The first day I went into chambers I drew a set of pleadings; they were returned to me every word of them altered except the names of the plaintiff and the defendant, with a request from my pleader that I would in future leave a wider space between the lines of my drafts. This injunction was all the teaching in law which I ever received." His lordship of course did not mean to imply that he learned nothing in chambers; what he did mean is, that his instruction consisted solely in seeing how the pleader with whom he read actually pleaded or gave opinions. His lordship's experience was by no means singular. When a student "reading for the bar" enters the chambers of a barrister, the arrangement entered into be- 
tween the so-called pupil and his so-called tutor is rather singular. The pupil does not undertake to learn, the tutor does not in any way undertake to teach. Our student pays a hundred guineas, and the barrister undertakes that his pupil shall see all the work that goes on in chambers, and have an opportunity of trying his own hand at doing it. This is the real and most valuable advantage gained by the student. What teaching (if any) he may obtain is a matter of chance. Many excellent lawyers have no talent as teachers. Many barristers who would make admirable professors have their hands so full of business that they have not the time, even if they had the inclination, to instruct their pupils. Our young man reading for the bar may get, and often does get, immense indirect help from the tutor in whose chambers he works, or from the fellow pupils with whom he talks, but all which he has a right to look to is the seeing and working at the papers which come in day by day. If he is to learn law, he must pick it up for himself. The task is not an easy one. The youth who has acquired the privilege of reading the papers which lie on the table of a pupil-room, finds himself at first engaged in a maze of perplexities. He may, or may not, have read some elementary law books. His reading may, or quite as likely may not, be appropriate to the work which passes before his eyes. $\mathrm{He}$ is, in all probability, ignorant of the very terms of the legal questions which he has to consider. He reads papers, for example, about a charter-party, whilst hunting through Maclachlan to find out what a charter-party is. He attempts to settle whether Brown can sue Jones on a bill of exchange, whilst he tries to gather from Byles the difference between an acceptor and an indorser. He is immersed in the intricacies of marine insurance, whilst perplexed by a vague con fusion between barratry and bottomry, and whilst attempting to master in Arnould the difference between "particular" and "general" average. Several circumstances add greatly to our beginner's perplexities. If he has had the fortune to get into "good chambers," the papers which he studies one day are gone out the next. The set which he begins reading on Monday refers to a bill of exchange; the lot which he takes up on Tuesday turns on covenants running with the land. On Wednesday he attempts to understand a contract of insurance; on Thursday he is immersed in the endeavour to fathom the liability of a railway company for the carriage of goods, to draft a statement of defence or an opinion upon evidence. He is daunted at one moment by difficulties which the slightest legal knowledge would at once remove; he is the next moment plunged over head and ears in a case destined to puzzle the House of Lords. He hardly knows what are the books to which he ought to 
look for guidance, and when he finds the right book he has hardly the ability to use it. Fisher's Digest - a sort of legal dictionary - the inestimable friend of those who have learned how to consult the oracle, is about as useful to the beginner as would be Liddell and Scott to an undergraduate who was not quite at home in the Greek alphabet and knew nothing of Greek grammar. Add to all this, that a case sent in by an attorney looks a very different thing from the same case when divested of all irrelevant matter by a reporter, or when made the subject for comment in a text-book. To our student it is a puzzling and often an ill-digested narrative, of which he does not perceive the point and only half understands the terms. Before he can make up his mind on what may be the very simple question whether A. can sue B., he has to determine what are the facts relevant to the matter in hand, and he is all but certain to fall into one or both of two opposite errors - either he does not see that a lot of details highly interesting to the parties or to their attorneys, transactions which have taken place years before the dispute began, or letters written months after the writ was issued, the ingratitude of the plaintiff, the monstrous dishonesty of the defendant, and the like, have nothing to do with the question for decision, which may ultimately reduce itself to the inquiry whether a particular letter constitutes a proper memorandum of agreement ; or our beginner, because he finds that nine tenths of the circumstances forced on his attention are immaterial, omits to notice the tenth circumstance, on which the whole matter turns. He is put, in short, to make bricks without straw, or rather without having ever been taught how bricks are to be made. The oddity of the thing is, that he after all gets in due time, mainly by the process of imitation, to make pretty tolerable bricks. For this rough, if not exactly ready, method of learning from contact with real business has some inestimable merits. There are at least three things of the highest value which can be learned, if at all, in court or in chambers, and can be learned nowhere else.

First. - The mechanism of legal practice, such as the drafting of deeds, the drawing of claims, the arguing of cases, and the like, must be learned in chambers or in court. Traditions were at one time current of a counsel, better known as a novelist than as a lawyer, who supplemented (it is said) the inadequacy of his practice by the fertility of his imagination. His pupils, it is told, drew sham declarations, answered by fictitious pleas, or giving rise to speculative demurrers. But this example of imaginative practice gained more notoriety than success, and does not commend itself for imitation. In the Law Schools of the United States, and at the Moot Courts, which have been with 
most happy results revived in one at least of the Inns of Court, a great deal is taught and learned by means of arguments carried on by students or young barristers in the presence of experienced lawyers, and with all the solemnity of proceedings in court. But for reasons which easily suggest themselves this mode of instruction could not be practised with advantage either at Oxford or at Cambridge.

Secondly. - In chambers, or from actual business alone, can be acquired the invaluable habit of dis engaging from a crowd of details the relevant facts of a case, and of applying to the occurrences of life the appropriate principles of law. To do this is, as I have already pointed out, the most difficult of the many difficult tasks to be performed by a student in chambers. But though the difficulty is needlessly increased by the defects of the system which encourages beginners to deal with facts before they have mastered principles, there is no part of reading in half as beneficial as the necessity which it imposes upon a young man of considering law in relation to the actual transactions of daily life.

Thirdly. - The capacity for forming sound opinions is a quality which can be acquired by practice alone. A trained lawyer of sufficient learning and industry can generally reduce the possible answers to a given case to one of two plausible opinions. To have brought down a complex and doubtful problem to the narrow choice between two possible views is of itself no small achievement. But the true difficulty lies in determining which of these two competing views is (as the slang of the Bar goes) the "better opinion," or, in other words, which will prove ultimately right when submitted to the true test of legal experiment -the decision of the judges. In the performance of this feat is to be found the criterion of high legal ability. Lawyers of equal knowledge, of equal industry, even in many ways of equal power, differ in nothing so much as in this capacity for forming sound opinions. We all of us know men of profound learning, of infinite ingenuity, of exhaustless subtlety, whose opinions have but one defect, namely, that they never coincide with the judgment of the House of Lords. There are, on the other hand, men whose bare opinions carry infinite weight, because these opinions are known to have the quality of turning out to be right. This characteristic of soundness is of course mainly the result of good sense. But good sense may be cultivated, and good sense itself is not precisely the same thing as the power to estimate what is likely to be the judicial view of good sense. Experience and practice can do a great deal to bring a man's mind into harmony with judicial opinion. This quality of judiciousness is not a fruit to be fostered by lectures. 
The merits, in short, of the present system may be all summed up in the one word "reality." It brings a student in contact with the real actual business, and fosters in him qualities which cannot be produced by any theoretical teaching, however excellent. Readiness, technical skill, sound judgment, the power of disentangling from a mass of bewildering details the essential features of a complicated case, the habit of applying to the actual affairs of men the well established rules of law, are qualities to be acquired, in so far as they are not the gifts of nature, by practice, and by practice alone. And a young man would utterly mistake his interests who, for the sake of hearing the lectures of the most erudite and most eloquent of professors, sacrificed the advantage of that reading in chambers which, with all its singularities, has for generation after generation trained up a succession of great lawyers. But to admit, or rather to proclaim, that from reading in chambers something, and something of great worth, can be gained which no other mode of training can by any possibility replace, is a very different thing from admitting that a hand-to-mouth system of learning under which a young man when reading for the Bar is plunged into details, and left to pick up legal principles haphazard, is a perfect system, or does not exhibit glaring defects which lead to grave evils. It is all very well to be told that a system which has turned out Mansfield, and Eldon, and Campbell, and Westbury, is above criticism. Common sense rejects this appeal ad verecundiam. It is demonstrable that legal education in England has grave defects, and that the circumstances of modem times have rendered these faults of far more importance than they were even as late as fifty years ago.

I have stated without reserve the immense advantages of reading in chambers. The inherent defects of such reading are patent on a bare description of the course of study actually pursued by the pupil of a barrister or of a pleader. These deficiencies are threefold. The knowledge gained in chambers is fragmentary, is unsystematic, is wasteful of time and labour.

First. - The knowledge gained in chambers is fragmentary, for the present system inevitably leads to a most incomplete mastery of legal principles.

A student when his reading has ended may have gained much information about some special department of law in which his teacher excels, say the law of insurance, of patents, or of joint stock companies. He knows nothing of anything else. Of the general principles which pervade the whole field of law he knows probably almost less than nothing, for he has learned to doubt whether such principles exist. Yet no form of scepticism is more baseless in it- 
self or more fatal to the attainment of legal eminence. For whoever will study with intelligence the current numbers of the Law Reports may soon convince himself that matters of principle rather than matters of detail are the real subject of perplexity to lawyers and to judges. Is a marriage contracted in England by a resident in Scotland an English or a Scotch marriage? Can a judgment obtained in a foreign court by fraud be enforced in England? What is the exact liability (if any) of a husband for the contracts made by his wife? What is meant by a "lawful assembly?" What is the bearing on liberty of discussion to be attributed to the dogma that Christianity is part of the law of the land? These and a score more of similar questions have recently perplexed our tribunals. Each of them raises questions of principle; some of them touch the very foundations of law. It were idle to suppose that these inquiries can be dealt with by men who have never been accustomed to trace the applications of general maxims even in the minutiæ of daily practice.

Secondly. - The knowledge gained in chambers is unsystematic, for there is nothing in the mode in which law is learned to induce a student to study law as a whole.

Few are the lawyers who have even tried to obtain command of the elementary doctrines both of common law and of equity, even on one single branch of law. Fewer still are the men who have grasped the canons which pervade and govern the whole law of England. When we have reflected on the nature of reading in chambers, we hardly need inquire for the cause for that narrow conception of legal knowledge which is often found to be the weak side of men who, endowed with great ability, have practised law for years with unwearing assiduity.

Thirdly. - The knowledge gained in chambers is wasteful of time and of labour. The gravest fault of the present system is, that, while it involves untold waste of effort, it robs the learner of half the gains which he ought to derive from the invaluable experience to be gained by the observation of practice.

Here again facts speak for themselves. If a student devotes his attention to the practice before his eyes, he has not time to read books. If he plunges into the perusal of treatises and reports, he has no time to study briefs and pleadings. Nor is reading of much, good to a person unprovided with any scheme of study, and with no guidance as to the books which deserve his attention. Hence the very business which goes on before his eyes loses half its instructiveness, and a pupil when he quits chambers leaves them with a sense of having through misdirected labour wasted a great opportunity. 
Two remarks suggested by a survey of the defects inherent in the established mode of legal education are of special importance.

The first of these observations is that a student however industrious cannot, as things now stand, correct by assiduous study of legal works the deficiencies of reading in chambers. For the literature of the law has, until the beginning of the reform which now dates back some twenty-five or thirty years, reproduced and stereotyped all the most characteristic faults of legal training. Our best works, such as Smith's Leading Cases, are at bottom a mere accumulation of notes on detached points of curious rather than useful learning. They are deficient in all general conceptions, in all grasp of principles, in all idea of method. Authors who have learned their trade by rule of thumb have never even aimed at the accurate analysis or definition of legal ideas. Hence the technical terms of law are as bad as any technicalities can be; they are technical without being precise, or, when apparently popular, are full of latent ambiguity. Attempt to define, in accordance with received authorities, such terms as a "chose in action," "personal property," a "void" contract, an "implied agreement," and you will not only assent to my criticism, but will soon discover the cause of all this hopeless confusion. Generations of practitioners have neither concerned themselves with definition, nor indeed have understood its nature or its necessity. Turn, for example, to a writer whose book was twenty years ago the student's guide to the law of contract. Mr. J. W. Smith opens his treatise with a chapter on the "Nature and Classification of Contracts." Of the nature of a contract he tells his readers nothing. What he does tell them is that agreements consist of contracts of record, contracts under seal, and simple contracts. He first substitutes division for definition, and then gives a division which, for absolute uninstructiveness, may be compared to an attempt to classify animals by dividing them into dodos, lions, and all animals which are not dodos or lions. For the unmeaningness of Mr. Smith's classification can be fully realised by those only who know that the term "simple contract" is a mere negative expression, meaning nothing more than any contract which is not a contract of record and is not a contract under seal. The division, indeed might from many points of view afford a text for lengthy comment. Its most characteristic feature, which ought not to be left unnoticed, is that it thrusts into prominence the anomalous and rare arrangements known as contracts of record, which (if contracts at all) are the last kind of agreements with which it is desirable to perplex the attention of students. As to the true elements of a contract - the offer, the acceptance, the promise- 
our teacher says nothing. If any one will compare the sterile classification of $\mathrm{J}$. W. Smith with the fruitful analysis to be found in the works of my friends the Professor of Jurisprudence and Sir W. Anson, he will perceive at once how great is the confusion introduced into a simple topic by a writer who has learnt law without mastering its principles. A critic will also observe that $\mathrm{J}$. W. Smith, with other such respectable writers as Chitty or Addison, illustrates in every page a fault which has till recently pervaded the whole of our legal literature, and for want of any corrective has infected the intellectual habits of English lawyers. This vice is the tendency to give inordinate attention to exceptions and anomalies, to the neglect of the far more important canons or rules to which these exceptions refer. The original source of this fault is to be found in the fact that English law is built up on cases, and that every reported case at any rate is the record of some exception to a general rule. Hence we are all of us forced to go a good deal on what an eminent lawyer has termed "law taken for granted." This law taken for granted is nothing else than the principles of legal science collected by inference from recorded exceptions. Text-books repeat the exceptions and generally omit to notice the principles.

A second observation is that if a student cannot find in literature the elements of instruction which he misses at chambers, the vices which deform the existing system of legal education are of more con sequence at the present time than they were in the days of our forefathers.

Till the beginning of the present century, or till a considerably later period, it was possible to pursue an exhaustive scheme of legal reading. Students who were able to explore the whole realm of law did not absolutely need a plan in order to master its intricacies. In the time of Coke all the English law committed to writing did not probably exceed in bulk thirty or forty volumes of the present Law Reports. An author writing towards the close of the last century, whose object it was rather to magnify than to understate the difficulty of learning legal principles, states that "the laws of this country including the acts of the legislature and the decisions of the supreme courts of justice are not numbered in fewer than fifty folio volumes." And if Paley, though not likely to have been grossly misinformed, cannot be cited as an authority on legal subjects, we can absolutely rely on the statements of Mr. Wallace, who in his work on the Reporters writes that up to the year 1776, the whole number of reports in England both in law and equity did not much exceed one hundred and fifty volumes. A man therefore of strenuous industry, such as Lord Campbell, could even half a century ago read through something like 
the whole compass of the law. Add to this that at any rate a century ago whole branches of the law, such as the law of partnership, the law of contracts, the law of principal and agent, the rules of so-called private international law, the law of joint stock companies, and the like, were until recent times either imperfectly developed or one might almost say non-existent. Nor can we measure the increased difficulties to be met by a learner who attempts an exhaustive system of study by the increase in the bulk of the reports or by the growing compass of the domain of law. From the accession of George II. (1714) down to say 1830, the principles of English law remained, as far as Parliament was concerned, both unchanged and practically unchangeable. Lord Eldon would as soon have proposed a bill for abolishing the monarchy as have introduced a measure like the Married Woman's Property Act, 1882. All this is now changed. The Reports amount to between 1,300 and 1,500 volumes, the Revised Statutes which come down to 1868 number fifteen hugh volumes; the Reports are yearly increased by ten volumes, the statute-book swells in bulk with each Parliament, and every volume contains important innovations which sometimes shake or appear to shake the very foundations of our legal system. Meanwhile the lawyer is compelled to consult foreign as well as English reports. In 1776, and for some years later, there was not a single American report in existence. The United States are now enriched or oppressed with four thousand volumes of reports, and the library of the Middle Temple contains mass of American reports which far exceeds in amount the whole legal literature of England at a date when America claimed her independence. The exhaustive system of reading has become in the strictest sense an impossibility; it is a tradition of the past. You can no more read law in the mode in which Coke, or Holt, or Blackstone, or even Campbell read it, than you could carry on the trade of England in the ships which sufficed for British commerce in the days of Elizabeth or even in the time of George III.

While the modem student needs educational guidance far more than did his fathers, he has by a strange turn of fortune lost the guides on whose aid his predecessors relied. Pleaders have a bad name; their art is the theme of the best legal satire in the language, but to them law and lawyers owe a heavy debt of gratitude. The science of pleading consisted in the careful discrimination of law from fact. Pupils trained in a pleader's chambers were therefore compelled in pursuing their routine of practice to learn the principles of law from teachers who were never absent in court, and who could not excel in pleading without some comprehension of principles. The Common Law has 
not produced for the last century a single eminent lawyer who was not trained by a special pleader. Pleading is abolished, and the pleaders - the true professors of the Common Law- will soon be a forgotten race.

To recognise the shortcomings and still more the advantages of reading in chambers is almost the same thing as determining how far law can be taught at the Universities. Academical instruction at Oxford ought to form the proper preparation for observation of business in London; the proper sphere of professorial activity is to supply all the defects which flow directly or indirectly from a one-sided system of practical training. It is for professors to set forth the law as a coherent whole -to analyse and define legal conceptionsto reduce the mass of legal rules to an orderly series of principles, and to aid, stimulate, and guide the reform or renovation of legal literature. Let me for a few minutes trace out with some care each of these spheres for academical teaching.

1. At the Universities a student can be taught to regard law as a whole and to consider the relation of one part of English law to another. The revived study of Roman law has already done much to bring the chaotic mass of English law into some sort of form, and to this source must undoubtedly be in great part attributed the advance made by the legal literature of the last twenty years in clearness and in symmetry. But there is no reason in the nature of things why the law of England should not itself be exhibited as a model of the clear and orderly arrangement of legal rules and conceptions. There is not the least reason why students should not be supplied, or still better be taught to supply themselves, with outlines of English law as well marked as those of the only system which can claim to be its rival. He who has obtained such a chart has done much more than merely increase his knowledge. He has gained not only a scheme of study but also a plan into which he can piece, and by piecing retain, the knowledge which he gains from reading or practice. A young man, who begins reading for the Bar with such a general knowledge of his subject as may be obtained in Germany, in France, in Scotland, and in the United States from academical teaching, might easily learn from study in chambers or from attendance in the courts more law than is often possessed by barristers of many years' standing.

2. At the Universities can be taught what from the nature of things can never be learnt in chambers - the habit of analysing and defining legal conceptions. Such analysis is not the work of men wholly occupied in the daily requirements of legal practice, yet its importance can hardly be overrated. No 
competent judge will, I venture to say, dispute that half the difficulties both of legal study and of legal practice arise from the inaccuracy and vagueness of legal terms. We all know how much has been done to clear up the law of contract by a careful analysis of an agreement. Any one who has turned his attention in that direction knows that Savigny's theory of possession has solved many puzzles of English law. It elucidates the rules as to title by prescription; it throws light on matters so apparently technical as the nature of trespass and the principles governing the action of trover, it enables us to reduce to a consistent whole the law of domicil, and oddly enough renders intelligible one perplexity at least in that well-studied enactment -the seventeenth section of the Statute of Frauds. There is indeed no more appropriate or profitable sphere for professorial industry than the explanation, the simplification, and the analysis of legal terminology. It is hardly too much to predict that till the terminology of the law has been reviewed and settled, as it has been in other countries, under the influence of professorial teaching, England will never possess a code at all worthy of the merits of English law.

3. At the Universities can be taught, and can hardly, as things stand, be taught elsewhere, the habit of looking upon law as a series of rules and exceptions, and of carefully marking off the exact limits of ascertained principles. This is the true cure for the fatal tendency to remember exceptions and to forget obvious rules. The first duty of a competent teacher is to impress upon himself and upon his pupils that law can be digested into a set of rules and exceptions, and to make his hearers feel that general, common, normal principles are far more important than what is exceptional, uncommon, or abnormal.

By adequate study and careful thought whole departments of law can thus be reduced to order and exhibited under the form of a few principles which sum up the effect of a hundred cases, and can thus be understood and remembered when no memory could retain even the names of the cases on which these rules depend. Take one example of my meaning. Let any one try to make in the form of rules and exceptions a definite statement (such as would be found in a code) of the different classes of persons who can claim to be British subjects. The task does not present any insuperable difficulty. Three or four short enactments, not more than at most ten or twelve cases, afford the necessary materials. But any one who acts on my suggestion will find that the work is a labour of time and trouble, and also that when it is duly performed he has in his mind a series of propositions as to the acquisition and 
loss of British nationality which makes him permanently master of a difficult topic. He will also discover that on some few points the law of nationality is strictly speaking unsettled. He will know where the true perplexities lie, and when, as recently happened, a case decides one of these moot points, he will easily note the effect of the decision and retain it in his memory. He will further learn that the intricacy of the existing law arises historically from the conflict and ultimate compromise between two rival theories of allegiance. What can be achieved in one narrow department of our subject may by industry and intelligence be gradually accomplished throughout the whole domain of English law. No one professor, no Faculty of professors, could within a limited time reduce the whole law of England to this kind of natural code. But one may confidently assert that nothing can be taught to students of greater value either intellectually or for the purpose of legal practice, than the habit of looking upon law as a series of rules; and further that a school of lawyers imbued with this turn of mind would gradually reduce the whole chaotic mass of legal principles to a clear, logical, and symmetrical form. Here, however, we stand on the confines of the last, the most interesting, and perhaps the most important sphere of professorial energy.

4. At the Universities can be aided, stimulated, and guided as nowhere else the much-needed reform, I had almost said creation, of legal literature.

No country is so rich as our own in the records of judicial decisions. Fifteen hundred volumes and more of Reports are the noblest of monuments to the substantial merits of our law, to the sound sense, to the justice, to the acumen, to the intellectual power, to the literary ability, of our judges. One shelf of the library at the Temple would be amply sufficient to contain every volume which does credit to our legal literature. We have no history of English law as a whole deserving the name, we have not twenty treatises worthy to stand side by side with the productions of great jurists in other countries. If our wealth in reports is the standing memorial to the greatness of our judges, the poverty of our legal literature is surely one result of the non-existence till recent years of any legal professoriate. On academical teachers, at any rate, naturally falls the task, as full of importance as it is of interest, of aiding that reform or revival of legal literature which is one of the most remarkable phenomena of the last thirty years. If we look to the needs of our students, it is clearly of primary importance to supply them with works which may enable them to see that law is a rational study, and can be treated like other sciences in a clear, rational, and interesting manner. More than one of my colleagues 
has already taken a hand in this task with preeminent and acknowledged success. If youthful learners are capable of gratitude, there must surely be a large class of students who render daily thanks to Sir William Anson and Professor Pollock for having delivered them from the burden of Addison's ponderous confusion, and from the useless toil imposed by the attempt to understand the futile subtleties of J. W. Smith. But though the absolute necessity of the case must suggest to all teachers the need for creating treatises worthy of the law of which they treat, another motive may well direct energetic teachers towards the path of legal authorship. By teaching and by literature they can influence far more than is generally believed not the form only but the substance of the law. The rules of law which are supposed to be so inflexible are, for the most part, in fact enactments of judicial legislation, and nothing is more remarkable or more intelligible than the ease with which judicial legislation is swayed by the pressure of authoritative opinion. Busy magistrates, dealing with cases as they occur, take their principles from text-writers. Particular authors have notoriously, even in recent times, modelled, one might almost say brought into existence, whole departments of law. Pleading was fifty years ago systematised into an art by one lawyer of consummate logical ability; the law of damages has grown up, it is said, under the influence of a writer still living. The vast field of so-called private international law has been mapped out in England by three or four rules derived from Huber, and by the doctrines expounded in Story's Conflict of Laws. But in England, as elsewhere, the effect produced by single writers is nothing to the effect which may be produced by a school of teachers.

Throughout this lecture, it will be observed, no contrast has been drawn between the functions of a professor as a teacher, and his duties by way of investigation, research, or authorship. No contrast has been drawn because there exists no opposition. The process indeed of teaching and re-teaching elementary doctrines to a necessarily ignorant class involves some waste of labour. Exposition (it may be said with truth) is not erudition. But the waste of labour, such as it is, is or ought to be more than repaid by two advantages in the position of a lecturer. He will soon find that he cannot explain that which he does not understand; easy and lucid lectures are the fruit of hard reading and long if not painful meditation. The need again of making one's thoughts clear to one's self and clear to others is the most admirable corrective to the pedantry, the crotchetiness, the unreality, which certainly are the vices of socalled "paper lawyers," and which I venture to conjecture are faults which 
occasionally may infest the studies of professors and jurists. At any rate the qualities which ought to distinguish academical teaching of law -the habit of looking at our subject as a whole, the desire to define and (with a constant eye however to received authorities and to actual facts) simplify legal ideas and conceptions, the effort to reduce law to a series of propositions which are both intelligible and in correspondence with the decisions of the court and the opinions of practising lawyers - these qualities are all fostered by the necessity for clear and effective exposition of actual law, and are also characteristics which ought to be found in authors who wish to produce monumental works of legal literature. It is difficult to imagine that if law books had in England been composed as in other lands by jurists who wrote with a constant eye to an audience of students, we should have witnessed the growth of such literary monstrosities as Smith's Leading Cases, in which pile after pile of notes is kid so to speak in layer after layer on the top of some case, worthless in itself, and entirely crushed under the weight of superincumbent comment ; that we should all of us have racked our brains over the crabbed learning of Lord St. Leonards; or that successive generations should have seen one province of law after another fall a prey to the calamitous energy of authors as conspicuous by their lack of insight as by their portentous and multifarious industry. But the immense influence on law of writers and teachers - the two need not for our present purpose be distinguished - may be proved by far stronger arguments than general considerations as to the effect of exposition. On this matter we may consult the lessons of large and various experience. The very demand for a reform in our legal literature is merely one side of what may fairly be called a most remarkable intellectual movement or revolution. During the last thirty years, three men of genius have given a new impulse to the study of law. Macaulay has created a new type of codification. As an historian he is certainly not the head of a school; as a reformer, as a codifier of the law he is the parent not only of legislative codes which may possibly survive the memory of his history, but of all the unauthorised though invaluable digests of English law such as Mr. Chalmers's Law of Bills of Exchange or Sir James Stephen's Digest of Criminal Law, of which the one has received and the other is probably destined to receive legislative authority. Austin has given a new impulse to legal speculation, and has influenced far more than they perceive writers who do not share his views, and who do not avowedly adopt his system of logical analysis. Sir Henry Maine has opened a new field of historical research, and with Austin has rekindled public interest in the law of 
Rome. Of these men two were professors, and Macaulay, with his intense love of explanation and his passion for illustration, approached far more nearly to the professorial type than to that of the barrister who shines at quarter sessions, on circuit, at nisi prius or even in the House of Lords. If, however, it be said that the influence of these three men but indirectly illustrates the effect of professorial teaching, we must extend our gaze so as to take in a wider view. The names of Pothier, of Savigny, of Wangerow, of Mancini, of Bluntschli, are sufficient to remind us that the great works of foreign jurists, the treatises or the codes which have been the result and the embodiment of their teaching, were in many instances the more or less immediate growth of lectures. But we may look nearer home and examine the legal condition of a country of which the law certainly receives in England far less attention than it deserves.

Scotland is, as regards reports, less richly endowed than England, but even cursory observation shows that Scotland possesses at least three or four institutional writers whom it would be hard to match with English authors of the same merit. On inquiry I am informed by the greatest living authority on the legal history of his country that the best Scotch institutional works are in effect the product of lectures. Baron Hume's Commentaries on the Definition and Punishment of Crime, John Erskine's Principles of the Law of Scotland, George Joseph Bell's Principles of the Law of Scotland, are each and all of them the fruit of lectures delivered in the University of Edinburgh. Something the same may be said with substantial truth though not with verbal correctness of the most famous among Scotch legal treatises, Stair's Institutions. Lord Stair studied at Glasgow; he was never a professor, for the sufficient if not satisfactory reason that no law professorship existed at that university until the beginning of the last century. But the philosophical parts of the Institutions may, as I am informed by Lord Stair's biographer, be traced back with certainty to the lectures which he gave as Regent in the University of Glasgow.

If any one should suggest that systems based on the law of Rome lend themselves to professorial exposition better than does the law of England, the suggestion can be at once met by an appeal to facts. On this point, as in fact on the whole subject of this lecture, the experience of the United States is full of instruction. The citizens of the Union are certainly neither pedants nor, in general, theorists; but at the present moment English law is taught, and admirably taught, in the colleges of America. The practising lawyers, the very sharp attorneys of New York, would laugh in your face if you suggested 
that nothing could be learnt worth knowing from the lectures of Professor Dwight, of whom the vast majority of them are, or have been, pupils. And the practising counsel of Massachusetts would undoubtedly tell you that the best preparation for practice in court is study in the lecture rooms of Professor Langdell and his colleagues of Harvard University. This, be it noted, is not the experience of a day or of a single generation. The learned and accurate Commentaries of Kent were delivered as lectures in Columbia College, New York. Story's Conflict of Laws, his Equity Jurisprudence, his Law of Agency -the whole, in fact, of a series of works which are the best of their kind in the English language- were delivered by him as Dane Professor in the University of Harvard. There has never too, we must add, in America, been any encouragement given to the idea that there was an inconsistency between practical knowledge and the theoretical exposition of the law. Kent retired to his professorship from high judicial office. Kent's Commentaries have been so re-edited as to be transformed into a new work of as high worth as the Commentaries themselves by the most distinguished among American writers on law, who has himself just passed from a professor's chair at Harvard to a seat on the honoured Bench of Massachusetts. Story's lectures were delivered at Harvard, while Story himself was by far the most eminent among the Judges of the Supreme Court at Washington.

The experience of England has not, it may be said, favoured the academical teaching of law. In a country where there has for centuries existed no professorial class, no certain inference can be drawn from the fact that our law books are not, like those of other countries, the result of lectures. But here we have, happily, one of those exceptions which precisely prove the rule. In this University, and in this College, it is impossible to forget for a moment that the one book of law which can claim a high and permanent place in the literature of England was originally produced as lectures to the University of Oxford. The great commentator, it may be urged with truth, was a man endowed with the rarest combination of gifts. He united the wide and practical experience of law belonging to an eminent counsel who commanded the ear of the court with the literary facility and graces of style to be expected in a distinguished man of letters. His work, again, was not precisely the work which is required from the teachers of to-day. All this is true. Blackstone affords us rather an example for encouragement than a model for imitation. But the preeminent influence exerted by the professorial lectures which make up Blackstone's Commentaries is an almost irresistible argument in favour of the conclusion 
at which we arrive from whatever side we approach our subject. The immense merits and the patent defects of the present system of teaching; the actual wants of young men studying the law; the faults which have marred the legal literature of England; the movement of reform by which these faults are being day by day corrected or removed; the experience of the whole of continental Europe, of Scotland, of America, and, in the single instance to which it is possible to refer, of England itself -all supply the answer to our original question. There is no real rivalry between reading in chambers and teaching at the Universities. The law of England can be taught, and if only the teachers are competent, and clearly perceive the limits and aim of their teaching, can be taught as it can nowhere else, at the English Universities. 

APÉNDICES 



\section{APÉNDICE 1}

\section{PRINCIPALES SEDES DE LA ENSEÑANZA JURÍDICA}

(1847-1914)

Chichele Professorship of International Law and Diplomacy, Oxford: Mountague Bernard (1859-1870); Thomas E. Holland (1874-1911).

Corpus Professorship of Jurisprudence, Oxford: Henry S. Maine (18691877); Frederick Pollock (1883-1903).

Downing Professorship of the Laws of England, Cambridge: Thomas Starkie (1823-); Andrew Amos (1849-1860), Frederic W. Maitland (1888-1906).

Professorship of Jurisprudence, International Law and Constitutional Law, Council of Legal Education: James Bryce (1877-?).

Reader at the Inns of Court: Henry S. Maine (1852-?); James F. Stephen (1875-1879); Frederick Pollock (1884-1890).

Reader en derecho indio, Oxford: William Markby (1878-1900).

Regius Professorship of Civil Law, Cambridge: James W. Geldart (18141847); Henry S. Maine (1847-1854).

Regius Professorship of Civil Law, Oxford: Joseph Phillimore (1775-1855); James Bryce (1870-1893).

Vinerian Professorship of English Law, Oxford: John R. Kenyon (18441880); Albert V. Dicey (1882-1909).

Warden of All Souls, Oxford: William R. Anson (1881-1914).

Whewell Professorship of International Law, Cambridge: Henry S. Maine (1887); John Westlake (1888-1908). 


\section{APÉNDICE 2}

\section{CRONOLOGÍA DE A. V. DICEY (1835-1922)}

1835, 4 de febrero. Nació en Claybrook Hall, Leicestershire. Su padre, Thomas E. Dicey, era director de la Midway Railway Company y propietario del periódico Northampton Mercury. Su madre fue Anne Mary Stephen. 1852-54. Estudios en la King's College School de Londres.

1854-58. Estudios universitarios en el Balliol College, Universidad de Oxford. Su tutor fue el catedrático de griego Benjamin Jowet. Obtuvo la calificación First Class en la examinación en Classical Moderations

1858. Se graduó, nuevamente con First Class, en la examinación de Literae Humaniores.

1858, 8 de noviembre. Solicitó la admisión en el londinense Inner Temple. Posteriormente realizó pasantías en los despachos de W. H. Butterworth, I. H. Christie y W. C. Beasley.

1860. Obtuvo una pensión en el Trinity College de la Universidad de Oxford, tras superar la correspondiente examinación. Fue tutor de James Bryce, entre otros.

1860. Publicó el estudio histórico The Privy Council, ganador del premio Arnold de ese año.

1863, 26 de enero. Fue admitido en el Inner Temple, comenzó su escasa práctica forense en el Northern Circuit.

1865. Se integró en el Jamaica Committee contra el gobernador Eyre y su represión en la colonia, al igual que sus primos James F. Stephen y Leslie Stephen.

1866. Fue nombrado profesor de lógica en el Working Men's College de Londres, institución educativa para adultos vinculada a movimientos socialistas cristianos.

1869. Fue contratado por John Coleridge, Solicitor General. Trabajó con él hasta que Coleridge fue nombrado Chief Justice of Common Pleas en 1874. 1870, 16 de agosto. Emprendió su primer viaje a Estados Unidos junto a James Bryce. 
1870, octubre. Publicó su primer tratado legal, Rules for the Selection of the Parties to an Action.

1871. Fue nombrado lecturer del Council of the Incorporated Law Association.

1872. Contrajo matrimonio con Elinor Mary Bonham-Carter, hija del miembro del Parlamento John Bonham-Carter.

1872-73. Ejerció el cargo de lecturer en derecho en el Owens College de Mánchester.

1874. Fue contratado por John Holker, Solicitor General.

1876. Fue nombrado Junior Counsel to the Commissioners of Inland Revenue, puesto que ocupó hasta 1890.

1879. Publicó The Law of the Domicil.

1882. Fue nombrado catedrático de la Vinerian Chair of English Law del All Souls College, Universidad de Oxford. Se retiró en 1909.

1883, 21 de abril. Pronuncia su lección inaugural: ¿Puede enseñarse el derecho inglés en las universidades?

1884. Fundó la revista Law Quarterly Review junto a otros profesores de Oxford.

1885. Publicó Lectures Introductory to the Study of the Law of the Constitution. La octava y última edición editada por él se publicó en 1915.

1886, octubre. Publicó England's Case Against Home Rule, firme crítica al proyecto de Home Rule o Government of Ireland Bill, presentado por Gladstone en abril. Apoyó al Unionist Liberal Party tras su escisión del Partido Liberal.

1890, 27 de enero. Fue nombrado Queen's Counsel, miembro del Consejo Privado (Gaceta de Londres del 28 de enero).

1896. Publicó A Digest of the Law of England with Reference to the Conflict of Laws.

1898, septiembre. Partió a los Estados Unidos invitado por la Universidad de Harvard para pronunciar una serie de conferencias sobre la historia del derecho inglés.

1899, 16 de febrero. Fue nombrado director del Working Men's College. Dimitió en 1912. 
1902. Fue miembro fundador de la Academia Británica, junto con colegas juristas como Bryce, Anson o Holland, entre otros.

1905. Publicó Lectures on the Relation between Law and Public Opinion in England during the Nineteenth Century.

1907, junio. Recibió el doctorado honorífico de la Universidad de Oxford.

1909. Miembro fundador de la Society of Public Teachers of Law.

1909. Se posiciona contra el sufragio femenino en la compilación de artículos titulada Letters to a Friend on Votes for Women.

1910. Fue nombrado reader en derecho internacional privado en el All Souls College. Dimitió en 1913.

1922, 7 de abril. Falleció en Oxford a los 87 años de edad. 


\author{
APÉNDICE 3 \\ COMPARECENCIA DE A. V. DICEY \\ ANTE LA GRESHAM UNIVERSITY COMMISSION \\ 9 DE DICIEMBRE, 1892
}

17.118. (Presidente). Creo que es Vd. profesor de derecho en Oxford. - Soy Vinerian Professor de derecho inglés.

17.119. ¿Fue Vd. lecturer en la Incorporated Law Society? - Sí. Hace unos veinte años, no tengo pues experiencia reciente en ello. También he enseñado en Mánchester y Liverpool para las Law Associations locales.

17.120. ¿Está familiarizado con las universidades estadounidenses? - Las conozco algo. También de hace bastante tiempo, pero he mantenido la conexión con profesores estadounidenses. Creo conocer el plan de enseñanza de Massachusetts.

17.121. Le preguntaré primero sobre su puesto de profesor en Oxford. ¿El grado en derecho se demanda bastante ahora, no es así? - Sí, bastante. Sin duda sabrán que existen dos cosas diferentes. Por un lado, la examinación en la School of Jurisprudence que corresponde a la clásica examinación para el grado de B. A. [Bachelor of Arts], y por el otro el grado de B. C. L. [Bachelor of Civil Law], en cierto modo bastante demandado actualmente. Alguien que haya obtenido el grado de B. A. o de M. A en cualquier universidad puede acceder a él.

17.122. ¿El grado de B. C. L. supone un conocimiento general del derecho, no es así? - Es una profunda examinación en derecho. Cubre tanto el derecho romano como el derecho inglés.

17.123. ¿Asiste a sus lecciones mucha gente que no persigue ejercer en la abogacía? - No mucha que yo sepa. Diría que por lo menos tres cuartos buscan acceder a la abogacía o a despachos de solicitors - a algún tipo de ejercicio del derecho.

17.124. ¿Cree que un grado conferido por una hipotética universidad en Londres sería demandado por las mismas personas que lo hacen en Oxford? - No lo creo, porque un buen número de personas que en Oxford escogen derecho lo hacen simplemente porque creen que en general es uno de los itinerarios más fáciles por el que pueden optar. Los jóvenes piensan que la examinación en la Honour School of Literae Humaniores exige más trabajo 
del que están dispuestos a aceptar, y prefieren entrar en la Escuela de Derecho o de Historia.

17.125. ¿Es un estudio útil, no es así? - Sí.

17.126. ¿Es por tanto positivo fomentar su estudio por parte de los jóvenes? - Creemos sufrir la situación de personas que estudian derecho sin una idea de dedicación enérgica al mismo. No me atrevería a decir que prefiera un aumento del número de estudiantes. Debe decirse que los mejores estudiantes de Oxford entran acertadamente en las Classical Schools, i.e., School of Literae Humaniores. No hay duda de que el trabajo es más duro, hay mayor cantidad de profesores, etc. - mayor cantidad de becas también.

17.127. ¿Debe el grado diseñarse para que aporte considerables ventajas a los hombres de negocios, y a las personas que esperan hacer carrera política? - Sería una gran ventaja, y lo es también, creo, para todos aquéllos que deseen acceder a la abogacía o a despachos de Solicitors. La examinación del B. C. L. es una de las mejores preparaciones que alguien puede obtener para realizar un trabajo efectivo en los bufetes.

17.128. ¿Cree que el estudio del derecho puede ampliarse y dividirse en diferentes disciplinas, algunas de las cuales podrían ser más útil para personas ajenas a la profesión jurídica, que no persiguen ejercer de abogados? - No he considerado la cuestión suficientemente para dar una opinión al respecto. Mi visión ha estado reducida en la práctica a personas que de una u otra manera ejercerán la abogacía.

17.129. ¿Sería útil y demandado un grado de calidad conferido por una universidad en Londres? - Sin duda sería ventajoso contar con una universidad en Londres donde pudiese estudiarse el derecho como materia separada. La valía de los grados depende de diferentes consideraciones. Es una cuestión sobre la que no tengo una opinión formada.

17.130. ¿Ha dirigido su atención al hecho de que, en el supuesto establecimiento de una facultad de derecho en Londres, deberíamos contar con las Inns of Court, que participarían en el proyecto? - Sin duda no podrán crear con éxito tal facultad a menos que de una manera u otra colaboren las Inns of Court, pero al mismo tiempo es muy improbable que se consiga tal colaboración sin la presión parlamentaria. Ningún órgano en Inglaterra ha sido jamás reformado sin una presión de ese tipo.

17.131. ¿Defenderán firmemente su derecho de otorgar la cualificación para ejercer el derecho? - Me agradaría que de una manera u otra pudiesen colaborar con las Inns of Court para integrarlas en el grado, y así, convertir- 
lo en la cualificación para el ejercicio. Conozco propuestas que mantienen separadas las dos vías. Si merece la pena tener un grado creo que debería ser suficientemente bueno como para cualificar para la práctica. Hasta tiempos recientes no existía ninguna garantía de que una persona admitida en la abogacía supiese algo de derecho.

17.132. ¿La única objeción que ve es que las Inns of Court nunca aceptarían la propuesta? -Quizás lo hagan bajo presión moral.

17.133. Aparte de eso y suponiendo que mantengan la defensa de su monopolio y que el grado sea simplemente ornamental, algo que otorga prestigio sin ofrecer cualificación, aun así, ¿daría peso al grado el apoyo de las Inns of Court? - Si las Inns of Court cooperan, creo que el grado sería en la práctica un medio de aproximarse a la abogacía. Sería pronto una condición sine qua non para acceder a la abogacía.

17.134. ¿Sería entonces el mayor asunto conseguir el apoyo de las Inns of Court? -Añadiría que en Oxford estaríamos muy satisfechos si las Inns of Court aceptasen el grado de B. C. L., por ejemplo, como cualificación para el acceso a la abogacía, y estaríamos dispuestos a garantizar que la examinación fuese suficiente. En verdad es una examinación más consistente que la requerida para el acceso a la abogacía. Creo que las Inns of Court deberían tener algún medio de nombrar miembros de nuestra facultad para comprobar que la formación ofrecida en Oxford constituye buena enseñanza jurídica.

17.135. ¿Deberían Cooperar las Inns of Court en una examinación que otorgase tal cualificación? - Sí. Creo que deberían cooperar.

17.136. ¿Y también en el caso de la Universidad de Victoria y de otras? Sí, en el caso de cualquier universidad con cuya enseñanza jurídica estuvieran satisfechos.

17.137. ¿Cree que en el supuesto de una nueva universidad en Londres las Inns of Court deberían formar parte de la facultad? - Es probable que fuese recomendable que pertenecieran a la facultad. A propósito del tema me gustaría decir que pienso que es extremadamente importante para la enseñanza jurídica que si se otorgase un grado en Londres que permitiese al acceso a la abogacía, un grado en derecho de cualquier universidad donde exista una escuela sistemática de derecho debería conferir también acceso a la abogacía; de otra manera la existencia de una universidad jurídica en Londres, en sí un gran beneficio, podría producir un efecto muy pernicioso para la enseñanza jurídica de Oxford. Si hubiese una universidad jurídica en Londres cuyos gra- 
dos diesen la cualificación para la abogacía, los grados en derecho de otras universidades debería tener el mismo efecto.

17.138. ¿Está hablando como representante de Oxford? - Sí, hablo de parte de Oxford; y de cualquier otra universidad que cuente con una facultad de derecho establecida equiparable.

17.139. Se ha interesado también por la Incorporated Law Society. ¿Quizás sean más favorables que las Inns of Court a la creación de la nueva universidad y en la transferencia de sus poderes? - Creo que, si se pudiese convencerlos de ello, sería una ganancia para ambas partes.

17.140. ¿Es partidario entonces de que la cualificación para la profesión de solicitor sea también otorgada por las universidades consolidadas y de calidad? - Sería partidario con las restricciones que sean necesarias para garantizar el tipo de instrucción que es necesario.

17.141. Algunos miembros de la Incorporated Law Society prefieren restringirlo a las universidades en las que tienen representación en el Senado y en las facultades, y no con relación a otras. - Consideraría entonces razonable permitir a la Incorporated Law Society una representación de algún tipo en el órgano examinador de Oxford. Creo que, si en Oxford tuviéramos el derecho de otorgar acceso a la profesión de solicitor tras la obtención del grado, sería razonable que la Incorporated Law Society tuviese cierta cantidad de representantes en la facultad. No creo que existan reparos en Oxford para llevar a cabo un esquema de este tipo. De hecho, una de las ventajas que advierto en el plan de esta universidad de Londres sería el hecho de que la examinación conjunta puede ser adoptada por cualquier otra universidad. Por los intereses de Oxford debería seguirse tal esquema.

17.142. ¿Ha pensado sobre la cuestión del establecimiento de una institución de enseñanza en Londres? - Únicamente tengo nociones generales sobre el asunto, no puedo pronunciarme en detalle; creo que sería una gran ventaja tener una Escuela de Derecho en Londres, porque no creo que pueda existir ninguna gran escuela en ningún otro sitio de Inglaterra, y también porque la combinación de enseñanza, con la observación de la práctica, o con la práctica misma, sería de gran ventaja. La dificultad de la enseñanza jurídica en Oxford es aportar algún tipo de sentido de la realidad. Puede hablarse a un estudiante de una demanda o de una letra de cambio. Pero nunca ha redactado una demanda ni sabe lo que es una letra de cambio, por lo que el estudiante adquiere una idea demasiado abstracta. Si pudiese haber jóvenes que estuviesen en los bufetes o en tribunales, la enseñanza mejoraría nota- 
blemente. Sería una gran ganancia tanto para los profesores como para los pasantes.

17.143. ¿Podrían prepararse para el grado universitario mientras realizan sus pasantías? - Parte del trabajo necesario para el grado podría realizarse en los bufetes. Ciertamente un estudiante obtendría el doble de beneficio al realizar la pasantía si hubiese aprendido los elementos del derecho antes.

17.144. ¿Cree que el grado debería tener lugar antes de las pasantías? Creo que una parte de la enseñanza podría coincidir con la pasantía.

17.145. ¿Y en el caso de los solicitors? - Creo que igualmente sería beneficioso para los solicitors, pero sólo puedo hablar con seguridad en el caso de los bufetes de barristers, porque son en los que yo me he formado.

17.146. ¿Conoce mucho el sistema estadounidense? - Hace unos 20 años estuve en los Estados Unidos, donde presté mucha atención al carácter de la enseñanza jurídica del país. Desde entonces he mantenido relaciones de amistad con muchos profesores estadounidenses.

17.147. En los Estados Unidos dan mucha importancia al grado, ¿no es así? - Dan mucha importancia al grado, o por lo menos al éxito en las escuelas de derecho, porque otorga grandes ventajas en lo profesional. Así, pueden darse a conocer entre personas que serán solicitors en los diferentes Estados. Me han informado de que en Nueva York, si un despacho de solicitors quiere contratar a un joven socio suelen enviar a un distinguido profesor a la escuela, al que piden que recomiende a su mejor estudiante. Buena parte de la enseñanza se realiza en los Moot Courts, mediante los cuales un joven adquiere su reputación. Los solicitors pueden conocer si el joven argumenta bien, si está llamado a ser un buen orador, etc.

17.148. ¿Ha surgido ello espontáneamente sin la interferencia del Estado? - Ha surgido espontáneamente, pero en verdad, no sin la ayuda del Estado. Me refiero a ayuda del Estado en el sentido de ayuda de la universidad. Estoy pensando en la Escuela de Derecho de Harvard.

17.149. ¿Reciben financiación? - Tienen el patrimonio universitario, creo, pero no hablo con conocimiento directo del asunto.

17.150. ¿Es la cualificación es algo meramente formal? - La cualificación es formal. No concibo que pueda existir ninguna duda sobre una persona que haya tenido éxito en las Escuelas de Harvard. Hace un tiempo tuve un estudiante que, a pesar de su juventud, poseía mayores conocimientos que los que posee generalmente un pasante en un bufete de un barrister. 
17.151. La razón por la cual se estima tanto en los Estados Unidos es que la gente prospera gracias a ella. - Creo que es la explicación.

17.152. Surgió de manera espontánea supongo. Nadie puede crear una cosa así. - Creo que así fue. El único punto que me hace dudar es que tuvieron profesores muy eminentes hace un siglo o 60 años. En esa época dieron sus lecciones Story y Kent. Por eso la escuela de derecho de los Estado Unidos tienen una reputación que no tiene ninguna de aquí.

17.153. ¿Estuvieron en Harvard? - Story fue profesor de Harvard, creo que tras abandonar la magistratura, y Kent dio lecciones en Nueva York. Por lo tanto debió de existir previamente una demanda de enseñanza jurídica que no existía en Inglaterra.

17.154. ¿Consideraban valioso el grado? - Sí; recordemos que las lecciones de Blackstone fueron ofrecidas unos 50 años antes. En cualquiera de los casos el profesor mejoró la reputación de la enseñanza.

17.155. ¿ंSu experiencia de los Estados Unidos confirma por tanto que un hombre que comience allí ejerciendo de barrister tiene mayor conocimiento real que el que tiene un barrister inglés en promedio? - Diría que tiene mayor conocimiento del derecho. No tengo duda de que un estudiante que haya acabado su carrera en Harvard conoce más el derecho que los estudiantes de aquí.

17.156. ¿̇Es resultado de la enseñanza? - Sí, creo que es más la enseñanza que la examinación según he oído. Me pregunto si el grado (me refiero al resultado de la examinación, e.g., en Harvard) cuenta tanto como el hecho de asistir a las clases, ser bien conocido entre futuros solicitors, así como haber recibido enseñanza de eminentes profesores.

17.157. Suponiendo que un hombre buscase un socio, ¿no escoge necesariamente al hombre que tiene la nota más alta, sino al que es tenido en mayor consideración? - Recientemente me informaron de que el juez Gray, el juez de Massachusetts en la Corte Suprema de los Estados Unidos, tiene cada año o cada dos un nuevo secretario, a quien escoge entre los hombres con la mejor carrera en Harvard, con lo cual da en la práctica un premio a la eminencia en Harvard. No creo que la elección dependa de la examinación, sino de la recomendación del profesor.

17.158. ¿Si pudiésemos hacer que nuestros jueces seleccionasen a sus secretarios de esta manera desde la universidad, se incentivaría a los estudiantes de derecho? - Creo que sí. Incluso en la actual situación, la Escuela de Derecho de Oxford ya produce efectos prácticos similares. Conozco casos en los 
que podría haber recomendado a un barrister algunos estudiantes por su conocimiento del derecho al llegar a la universidad.

17.159. ¿Podría aportar información de utilidad sobre algún otro punto? - No, excepto la siguiente. Advertí en un artículo de Mr. Crackanthorpe en la Nineteenth Century ${ }^{1}$, que el autor traza una división entre derecho especulativo, y lo que podría llamarse derecho practico. Él divide la enseñanza jurídica en cuatro secciones, de las cuales dos corresponden a la enseñanza especulativa, y otros dos más o menos a la enseñanza de carácter práctico, que sólo es posible aprender por la práctica. No creo que se pueda separar la enseñanza práctica de la teórica de esta manera. En verdad, cuando se trabaja en la práctica, la instrucción jurídica no permite este tipo de división. Por ejemplo, con el derecho de los contratos, se advierte que hay cierta cantidad de principios que se deducen de los casos, y creo que la labor del profesor es aclarar tales principios. Pero no se puede distinguir entre enseñanza teórica y práctica, porque los principios que se enseñan están basados en casos reales, e ilustran el resultado de casos reales. Me gustaría incluso protestar contra lo que me parece un error, porque creo que tiende a una división insatisfactoria del estudio. Es cierto que ninguna enseñanza profesoral puede sustituir lo que se aprende en un bufete. Se puede intentar enseñar medicina sin que el estudiante visite un hospital igual que se puede enseñar derecho sin ninguna relación con la práctica. Creo que teoría y práctica no se pueden dividir de la manera que se hace en el artículo de Mr. Crackanthorpe.

17.160. Si tuviese que instruir a un hombre para una vida de utilidad general y a otro para la profesión de abogado, ¿no le enseñaría prácticamente las mismas ramas del derecho? - Yo enseñaría a ambos casi de la misma manera, porque creo que lo que se puede aprender del profesor con ventaja son los principios generales del derecho, y estos principios explicados acertadamente serían igualmente útiles para ambos. Puede ser que no tenga talento para la enseñanza teorética abstracta. Lo que realmente confirma mi visión es que los mejores libros de derecho que he leído tienen este carácter, son todos de tipo profesoral, i. e., son exposiciones profesorales de los principios jurídicos. Los libros de Story son perfectos modelos de exposición del derecho inglés en lenguaje popular.

17.161. ¿Cree que es la mejor obra existente? - Sí, creo que es la mejor. El único libro de celebridad literaria que tenemos son los Commentaries de Blackstone. Tienen gran mérito, pero no creo que igualen a las obras de Story.

1 32, Nineteenth Century, pp. 773, 786. 
17.162. ¿Cree que no hemos tenido buenas obras desde entonces? - No, y fueron pronunciadas como lecciones. Este es realmente el resultado.

17.163. Creo que algún informe del Standing Committee of the American Bar Association de los Estados Unidos ha encontrado defectos en la enseñanza jurídica, por ser demasiado práctica y técnica. - Eso he oído. No conozco el informe personalmente, pero lo creo posible, porque en Harvard, institución que da el tono de la enseñanza estadounidense, han tomado para la enseñanza casi exclusivamente lo que ellos llaman discusión de casos. El profesor ofrece a su clase digamos veinte casos sobre algún punto del derecho. Posteriormente discuten, argumentan y trazan inferencias a partir de esos casos. Sin duda esta enseñanza es valiosa. Pero en Harvard defienden que este es el único método verdadero de enseñanza jurídica. Lo que nosotros llamamos lecciones ellos piensan que es un error. Creo no estar mal informado sobre ello, porque recientemente coincidí con uno de sus más eminentes estudiantes, con el que hablé sobre el particular.

17.164. ¿Esas discusiones son prácticamente desconocidas en Inglaterra? - Son casi desconocidas. En los Estados Unidos las valoran mucho. Yo he tenido pequeñas clases en las que he probado tal sistema. Funciona bastante bien en clases pequeñas, pero he comprobado que en las clases grandes de Oxford los estudiantes no hacen preguntas.

17.165. ¿Consigue dividir Harvard a los estudiantes en clases pequeñas? No, en Harvard las clases son grandes. Nunca he visto el sistema en la práctica, pero creo que los jóvenes estadounidenses motivados hacia el trabajo práctico hacen preguntas más fácilmente que los ingleses. Pero incluso allí hay menos dificultades en provocar en la clase la discusión. Eso he oído. Pero estoy ansioso por conocer cómo funciona realmente el sistema.

17.166. ¿Está intentando introducir ese modelo? - Lo he intentado una o dos veces con clases pequeñas. Lo encuentro muy exitoso cuando se tienen cinco o seis personas alrededor de la mesa, pero no lo es tanto si se intenta con un número mayor.

17.167. (Mr. Anstie). Hay un punto que ha tocado antes que me gustaría que considerase más detenidamente. Vd. sugirió que el grado debería ser el único y suficiente acceso a la abogacía y a la profesión de solicitor. ¿Desearía desposeer a los órganos actualmente responsables de sus potestades disciplinarias? - Estoy hablando principalmente del acceso a la abogacía. No conozco suficientemente la práctica de los solicitor para hablar con seguridad sobre el asunto. No conozco realmente ninguna potestad disciplinaria ejercida por los Benchers [presidentes 
de las Inns of Court]. Lo que sucede es lo siguiente: toda la disciplina que he visto son las 12 cenas en la sala de Inner Temple por cierta cantidad de tiempo y dinero, y la asistencia a dos sesiones de lecciones. Por supuesto ahora hay examinaciones más serias que en mi tiempo, pero en lo que se refiere a la disciplina, dudo que exista alguna con relación al acceso a la abogacía.

17.168. ¿̇ero Vd. no duda de que ha habido ciertos casos tanto en la abogacía como con la profesión de solicitor, en los que se ha negado el acceso a algunas personas por ciertos motivos? - No dudo que los haya habido, pero han sido casos muy raros.

17.169. ¿Hay entonces casos de expulsión de la abogacía? - Creo que se debería distinguir entre aquéllos y los casos sobre los que estamos hablando. No dudo de que algún órgano debe tener la potestad de expulsión, y de que quizás deben ejercitarla más frecuentemente que en la actualidad. No niego a las Inns of Court el ejercicio de esta potestad, pero no veo ninguna razón particular por la que deban ejercerla. Los jueces, por ejemplo, podrían ejercerla. Pero no me opongo a que las Inns of Court puedan ejercer esta potestad.

17.170. ¿Alguien debe ejercer esta potestad? - Sí.

17.171. ¿La ejercen actualmente las Inns of Court? - Sí; y por tanto, preferiría dejarla en sus manos. ¿Pero es realmente una cuestión práctica? Simplemente como conjetura, supongo que la cantidad de personas expulsada es muy reducida, y que las expulsiones han sido por casos de flagrante falta en la conducta.

17.172. ¿Su interés reside en la parte docente de la cuestión? - Sí, mi interés reside en la parte docente del asunto. Sobre ello estaba pensando. $\mathrm{Su}$ tuviese que hacer una sugerencia, pediría que el poder disciplinario de la abogacía se incrementase.

17.173. ¿Se confundiría el asunto si mezcláramos cuestiones disciplinarias y educacionales? ¿No sería partidario de que lo hiciéramos? - No; creo que con relación a la admisión a la abogacía, la disciplina, excepto una cierta cantidad de formación, no existe. Esto no se aplica a los solicitors.

17.174. Por lo que ha dicho sobre los Estados Unidos, ¿̇creo poder asumir que el grado no lo obtienen ni mucho menos todos los ejercientes? - No lo creo, pero no puedo hablar con seguridad. Personalmente creo que asisten cierto tiempo a Harvard o a escuelas de derecho en Nueva York, o similares. No pienso que el grado tenga por sí mismo, por lo que he escuchado a los estadounidenses, tanta repercusión como el haber asistido a clases de derecho y ser conocido por haberlo hecho. 
17.175. ¿Varía mucho la situación entre los diferente Estados? - Sí; pero no puedo hablar de otros Estados que no sean Massachusetts, del cual conozco algo.

17.176. (Presidente). ¿Harvard se reduce enteramente a personas de Massachusetts? - Creo que no. Las personas van allí desde todas las partes de los Estados Unidos. Las personas de Massachusetts serán mayoría, pero seguramente nada evita que estudiantes de otros lugares acudan allí.

17.177. (Mr. Anstie). ¿Ofrecen todavía los jueces lecciones? - Desconozco si todavía lo hacen. Seguramente hay antiguos jueces que todavía ofrecen lecciones en Harvard y en otros lugares. No sé si alguna persona ofrece lecciones siendo todavía juez. Creo recordar que Story ofreció algunas de sus lecciones cuando todavía era juez de la Corte Suprema.

17.178. ¿Y Kent? - Recientemente me sorprendí al conocer que las lecciones de Kent fueron pronunciadas después de que fuese obligado a retirarse de la magistratura de Nueva York por haber alcanzado la edad legal.

17.179. El Profesor Emmot de la John Hopkins University, nos ha asegurado que un juez actualmente en el cargo ofrece lecciones cada cierto tiempo. - Me lo puedo imaginar. No conozco ningún dato que pueda contradecir tal afirmación. Confirma lo que suponía, pero no dispongo de información para asegurarlo.

17.180. ¿Provoca ello una tendencia a elevar el tono? - Sí. Creo que sería una gran ventaja, si fuera posible, implementarlo en Inglaterra.

17.181. Vd. niega la supuesta distinción entre lo especulativo y lo práctico. Sin impugnar sus puntos de vista sobre el particular, ¿̇no sería una ventaja tener ciertos cursos para personas que no persiguen el ejercicio profesional, como los casos de la diplomacia o el derecho público? - Le agradezco que me plante esta pregunta. Me expresé antes precipitadamente. Cursos de tal índole serían muy beneficioso. Por ejemplo, hay cierta cantidad de derecho que un caballero de provincias estaría interesado en conocer como magistrado, etc. Se pueden, por supuesto, diseñar cursos con finalidades específicas o dirigidos a carreras particulares con ventaja. Es cierto.

17.182. El derecho internacional no sería muy demandado por ejercientes ordinarios, pero, ¿́podría ofrecer grandes servicios a las personas envueltas en tareas diplomáticas? - Por supuesto es cierto que la enseñanza puede adaptarse a las necesidades de diferentes clases o carreras como la que ha comentado del diplomático.

17.183. Hay otra clase de materias que pertenecen más propiamente a 
la ciencia pura, como la historical jurisprudence. ¿No podría esta materia elevarse a un grado considerable de perfeccionamiento e investigación con resultados beneficiosos? - Sí, podría sin duda.

17.184. Sin esperar que aquéllos que optan por el grado ordinario, o incluso por el grado con honores, sean capaces de seguirlas completamente, ¿no sería conveniente establecer cátedras que pudieran investigar tales materias? - No estoy seguro de que sea ventajoso separar ciertas materias. Creo haber advertido el hecho de que los más eminentes profesores de derecho han sido aquellos que, al enseñar alguna disciplina jurídica, han optado por perseguir su propio método. Dudo que procure gran ventaja en este momento separar estas materias de la enseñanza jurídica ordinaria.

17.185. Pongamos el caso de Sir Henry Maine. Fue uno de los más distinguidos escritores como es sabido, y al mismo tiempo fue un hombre alejado de la práctica. - Creo que habría mejorado notablemente, incluso como autor, si hubiese estado algo más en contacto con la práctica. Pienso que si se comparan sus obras con los escritos de Savigny, incluso con lo poco que conozco de éste, puede verse una tendencia en Sir Henry Maine a extenderse en torno a ideas no suficientemente basadas en el conocimiento real del derecho. En todo caso Sir Henry Maine se hubiese dirigido hacia la parte especulativa de la enseñanza jurídica, pero creo que hubiese ganado la cátedra si hubiese estado más conectado con alguna disciplina jurídica; hubiese enseñado cualquiera admirablemente bien, y sus escritos hubiesen ganado si hubiesen sido compuestos en conexión con tal enseñanza.

17.186. Lo ha comparado con Savigny, quien escribió sus mejores obras sobre el derecho vigente. ¿No quiso Sir Henry Maine escribir sobre el derecho vigente? - No, me parece una pena que no lo hiciese, porque estoy seguro de que lo habría hecho con gran habilidad.

17.187. ¿No es beneficioso incluir dentro de los estudios materias de investigación histórica y especulativas, que difícilmente tienen relación con el derecho vigente? - Creo que ello puede lograrse con el establecimiento de una cátedra jurídica, cuya finalidad fuese específicamente el tratamiento histórico de la materia.

17.188. ¿Esa es la idea? - Sí. Pero debo decir que personalmente no concedo tanta importancia al método de enseñanza histórico como es frecuente en el caso de personas que están más informadas. Puede que me equivoque, pero no le concedo tanta importancia a la enseñanza histórica como sí hacen ciertos juzgadores muy competentes. Aunque conozco eminentes juris- 
tas que profesan la opinión opuesta, creo que el derecho no siempre se conoce mejor cuando se mira históricamente que cuando es visto con la intención de entender el derecho inglés tal y como existe actualmente. Me inclino a pensar que los beneficios del sistema histórico se exageran.

17.189. ¿En todo caso Vd. desearía ver una obra histórica o especulativa de tal tipo, que pudiera dentro de los posible, ponerse en relación con el derecho vigente para de alguna manera interpretar uno mediante el otro? - Sí, quizá sea la mejor manera de decirlo. O dicho de otro modo, en ocasiones he pensado que sería una ventaja que los profesores de universidades fuesen profesores de derecho inglés o de derecho romano. Se pueden separar hasta este punto, y después permitir que el genio de cada profesor particular, y las necesidades del lugar determinen la línea particular de enseñanza escogida por el profesor. No creo, por ejemplo, que Sir Henry Maine, hubiese sufrido ningún perjuicio si hubiese sido nombrado simplemente profesor de derecho. Por supuesto, hubiese tendido hacia la línea que mejor se adaptaba a su intelecto o genio. Se puede crear un cuerpo de profesores de derecho y después dejar que se distribuyan las disciplinas según los talentos de los concretos profesores.

17.190. ¿Debe haber profesores que no formen parte del cuerpo de catedráticos - un cuerpo bien organizado de readers? - Sí.

17.191. Respecto a estos últimos, ¿̇propondría Vd. una división más estricta? - Sí.

17.192. Según su visión, ċlos profesores responsables de estas materias deberían tener el poder de distribuir las diferentes partes entre sus asistentes? - No he considerado la materia lo suficiente como para discutir el asunto. Creo que si me dieran el caso de una universidad que conociera, podría juzgar hasta cierto punto en qué medida son capaces los profesores de distribuir convenientemente el objeto de su enseñanza. Prefiero no responder la cuestión de manera general.

17.193. ¿Son éstas cuestiones de detalles que deben dejarse por el momento a un lado? - Si estuviéramos diseñando la organización, dejaría la mayor cantidad de materias sin definir, porque creo que los asuntos que estamos tratando se organizan de la mejor manera cuando se dejan en manos de los profesores. Teniendo profesores eminentes, organizarían entre ellos estos asuntos y sería mejor que no sufriesen injerencias en cuanto al modo de organizarlos.

17.194. (Mr. Palmer). ¿Entiendo por lo que Vd. dice que es partidario de 
que la misma enseñanza y examinación se apliquen tanto a solicitors como a barristers? - Nunca he podido encontrar una razón para que no sea así.

17.195. ¿Y sería partidario de que la universidad y no las Inns of Court confiriese el grado por lo menos a los barristers? Corporaciones como las Inns of Court, si continuasen siendo competentes para la admisión de abogados, ¿deberían aceptar la examinación de la universidad? - Considero que no sería muy deseable que una hipotética universidad asumiese cualquier actitud que pueda considerarse hostil hacia una corporación de tan alta posición histórica, y que ha hecho tanto recientemente por la enseñanza. Sacrificaría mucho para mantener desde el comienzo la armonía entre la universidad y las Inns of Court. Aparte de eso, estaría de acuerdo con lo que se ha dicho.

17.196. Hay otra corporación muy sensible -la profesión de la medicina. Se ha recibido favorablemente la sugerencia, según la cual debería haber lo que se llamó una examinación conjunta entre el Royal College of Physicians and Surgeons y la universidad, por la que se requiriese a ésta una examinación adecuada para la obtención del grado, y a los Royal Colleges el establecimiento de otra examinación adecuada para la admisión a la práctica. No estoy proponiendo una estricta analogía, pero, ¿̇pondría alguna objeción a que un órgano aceptase los resultados de una examinación organizada por otro o a que existiese alguna forma de organización conjunta entre la universidad y las corporaciones que conceden la admisión? - No tendría nada que objetar si se asumiese que ambas partes implantarían bona fide el nuevo sistema. Pero siempre que se trata con un órgano consolidado se advierte que éste nunca quiere, y quizás en su naturaleza nunca pueda querer establecer un nuevo sistema. Es extremadamente difícil conseguir que una institución antigua y otra nueva actúen conjuntamente. Hay más verdad de lo que se cree en el viejo refrán que dice nunca cosas a la vez con telas antiguas y nuevas. En Inglaterra siempre intentamos hacerlo y sobrevienen choques. Si pudiese hacerse, creo que una combinación entre la universidad y las Inns of Court tendría buenos efectos. Si puede conseguirse que eminentes juristas prácticos o jueces tengan un papel activo en la universidad, sacrificaría otras cosas de menor entidad para realizarlo, porque creo que mejoraría mucho el carácter de la enseñanza.

17.197. Para todas las facultades deber haber una distinción entre lo que se podría llamar lo interno y lo externo del grado. En relación con lo que ha respondido a Mr. Anstie, entiendo que la enseñanza de los principios y el ejercicio del derecho constituyen lo que he llamado interno, que aunque 
sin diferir de lo que podría llamarse externo, tendría que desarrollarse en la organización ordinaria de la enseñanza, mientras que en el caso de lo externo al grado se tendría que recurrir a investigación ulterior e instrucción de postgrado. Las cátedras dedicadas a disciplinas jurídicas que no se enseñan normalmente en el ámbito del Common Law o la Equity, como las de general jurisprudence o derecho internacional, ¿̇podrían establecerse de manera que la distinción entre práctica interna y externa condujese a que esta última fuese tratada por cátedras específicamente dotadas para tal fin? - No estoy seguro de haber entendido por completo lo que se entiende por práctica interna y externa.

17.198. Me refiero a que en el resto de facultades hay algo específico más allá de la primera obtención del grado universitario ofrecido por cátedras especializadas y específicamente dotadas, que es algo valioso y distinto de la enseñanza que finaliza con el grado. - Creo que seguramente es así.

17.199. (Mr. Rendall). ¿Me podría indicar de manera general cuál es la organización de la facultad de derecho de Oxford? - Lo que llamamos la Board of the Faculty consiste básicamente en los profesores universitarios y readers pertenecientes a la facultad y en los profesores de derecho contratados por los colleges. Hay también miembros cooptados. Lord Justice Bowen es uno de ellos, creo. Para los detalles debo dirigirles a los Commissioners to the University Statutes. (Véase Statuta Universitalis Oxoniensis, Tit. V. Sect. i-viii.)

17.200. Hay entonces profesores universitarios, lecturers de los colleges, readers, y uno o dos miembros cooptados. ¿Hay también examinadores? Un examinador no es propiamente un miembro de la Board. Son en principio profesores universitarios, y readers de derecho (miembros ex-officio) y personas elegidas por los profesores de derecho de los colleges. Los estatutos exigen que los miembros elegidos no pueden exceder la cantidad de miembros ex-officio.

17.201. ¿Son básicamente profesores? - Sí.

17.202. ¿No existe apenas un elemento de juristas ejercientes? - Creo que ninguno. Puede que haya uno o dos. Pero debe decir que todos los profesores de derecho son de hecho juristas, y algunos de ellos, como Sir F. Pollock, todavía ejercen la abogacía.

17.203. Entiendo que la relación entre la facultad de derecho y la universidad es exactamente igual que la de otras facultades. ¿No existe ningún monopolio específico en los asuntos de la universidad? - No; el caso de la facultad de derecho es igual que el del resto de facultades. 
17.204. Hemos recibido una propuesta para dejar prácticamente toda la organización de la facultad de derecho a las Inns of Court, en la cual la universidad debería aceptar el currículo, las examinaciones y las condiciones. - ¿ ¿Se refiere a la nueva universidad de Londres?

17.205. Sí, a la universidad planeada. ¿Entiendo que concedería mucha importancia a que los profesores, readers, o lecturers de la nueva universidad tuvieran una participación en la facultad? - Creo ciertamente que deben tener una participación en la facultad.

17.206. ¿La presencia de los profesores es mucho más importante en la facultad que la de miembros directivos sin participación en la enseñanza, aunque sean miembros distinguidos de la profesión? - Prefiero no hablar de modo dogmático, pero creo que los profesores deben constituir una parte considerable de la facultad. Aunque si se contase realmente con eminentes juristas, especialmente jueces, sería una pena restringir su influencia.

17.207. ¿Su posición es que para garantizar la armonía al principio sería conveniente realizar sacrificios razonables? - Sí.

17.208. ¿Una manera sería conceder una representación amplia y generosa al actual Council of Legal Education o a los líderes de la abogacía en el órgano de gobierno de la universidad, y quizás de la Facultad? - Es un asunto meramente de prudencia y no de conocimiento jurídico. Mi dificultad sobre el asunto es que no creo que se deba conceder al Council of Legal Education o a los líderes de la profesión una representación demasiado alta, que permita que las personas no especialmente favorables a la reforma puedan obstruirla. Determinar cuál debe ser la exacta cantidad de influencia que deba darse a los juristas prácticos es un problema de difícil solución.

Asumiendo que no se dé un poder de bloqueo a los oponentes del nuevo sistema, me gustaría que se hiciese lo posible para conseguir el apoyo de la profesión, pues sería beneficioso para los profesores tener contacto con eminentes juristas prácticos.

17.209. Dice que debemos sacrificar lo necesario, y que casi cualquier sacrificio merecería la pena. Me gustaría conocer su opinión sobre los puntos que no pueden sacrificarse. Me refiero a las potestades que es esencial reservar a la universidad. - Difícilmente puedo responder a esta pregunta porque es necesaria mucha reflexión, y no he pensado detenidamente en ello. Diría que una cosa está clara -el nombramiento de buenos profesores es el asunto vital. Cualquier sistema funcionará si se consiguen buenos profesores, y a menos que se cuente con éstos, ningún sistema merece la pena. Eso está bastante claro. 
17.210. ¿Y este extremo debe estar en manos de alguna autoridad de la universidad? - Sí, en manos de alguna autoridad de la universidad, como eminentes juristas que estén realmente comprometidos con los fines de la universidad - en resumen, de los mejores hombres que puedan conseguirse. - Lo que temo es que se deje la selección del profesorado en manos de hombres que, con o sin razón, piensan que no hay ninguna ventaja en la enseñanza profesoral. Todos sabemos que la habitual visión del jurista inglés es que ha aprendido el derecho de manera excelente sin escuchar a ningún profesor, por lo que no cree que haya ningún beneficio en el profesorado. Estoy seguro de que si se preguntase al conjunto de los abogados prácticos (algunos me han expresado su opinión de manera más o menos abierta) dirían que el derecho ha funcionado bien durante siglos sin enseñanza profesoral y que puede seguir perfectamente bien sin ella unos siglos más. Si esta visión es correcta, es un argumento contra el establecimiento de una facultad jurídica; pero no fundemos una facultad jurídica y después dejemos que esté controlada por personas que piensan que tal facultad no debería existir. Cómo alcanzar el fin de asegurar buenos nombramientos es una dificultad, pero creo que sería fatal contar con electores de cátedras que realmente piensan que éstas no deberían existir, porque ello conduciría a lo siguiente: nombrarían a personas meritorias, pero no pensarían que la capacidad de enseñar fuese una cualificación necesaria en un profesor. La mayoría de abogados ingleses piensan que el derecho no se puede enseñar, sino que únicamente puede ser aprendido mediante la práctica. Naturalmente la dificultad de conseguir la participación de abogados prácticos y al mismo tiempo evitar el peligro de dejar el nombramiento de profesores en manos de personas que no creen en el valor de la enseñanza profesoral puede parecer muy grande, pero no creo que lo sea tanto, porque estoy convencido de que si la universidad tuviese el poder de elegir distinguidos miembros jurídicos de la facultad de derecho, sería fácil obtener cierta cantidad de abogados cuya ayuda como electores sería de gran beneficio. Pongamos el ejemplo del Lord Justice Lindley o del Lord Justice Bowen; todo el mundo reconoce que serían exactamente los hombres apropiados para designar buenos profesores. Creo que el modo en que se solucionaría la dificultad mencionada sería ofrecer a la universidad la opción de determinar qué abogados nombraría miembros de la facultad o del órgano elector.

17.211. ¿Entonces indirecta o directamente mediante un órgano elector la universidad debe tener el control en última instancia? - Eso creo, pero no he meditado el asunto. 
17.212. El currículo del grado en derecho, o la examinación, ¿debe ser competencia del Senado? - Creo que debería ser competencia del Senado, pero debería restringirse tanto como fuese posible a los límites recomendados por los abogados prácticos relativos a un plan estudios de calidad. No me gustaría que el currículo, al menos para la mayoría, se alejase de materias útiles para la práctica del derecho. No creo que los estudiantes ganen nada con un currículo de carácter abstracto o teórico, estoy convencido de que la universidad sufriría un perjuicio.

17.213. En relación con el control de la asistencia y con la demanda de asistencia, tengo entendido que una de las dificultades es que actualmente las Inns of Court practican bajo su sistema estrictamente la norma que restringe la asistencia a aquéllos que preparan su acceso a la abogacía. ¿Cree que la universidad debería insistir en tener derecho a controlar la materia, en concreto la necesidad de abrir tales cursos organizados por la universidad o aceptados por ella a todos los estudiantes de derecho, tanto aspirantes a barrister o a attorney, como a estudiantes de índole más general? - Nunca he sido capaz de ver ninguna razón por que la deba restringirse la asistencia a las lecciones. La dificultad práctica es conseguir tantos asistentes como se desean. Ninguna experiencia me ha hecho pensar que se deba restringir la asistencia. Diría que no hay realmente ninguna razón para restringir la asistencia.

17.214. ¿Sería bajo su punto de vista una reivindicación razonable por parte de la universidad tener alguna potestad de regular o restringir la asistencia? - Eso pienso. No tengo dudas sobre este asunto, aunque no lo he considerado detenidamente. Tomemos el ejemplo de las únicas lecciones con tendencia a estar llenas a las que he asistido: las lecciones de Sir Henry Maine, a las que solía asistir en 1861, eran realmente cautivadoras. Es posible que cierta cantidad de externos pudiese haber entrado, pero no puedo entender qué perjuicio me hubiese podido provocar a mí, que me preparaba para el acceso a la abogacía, el hecho de tener sentados junto a mí a un hombre o incluso a una mujer sin intenciones de entrar en la abogacía. Supongo que hay algo más en el asunto que lo que conozco, porque no puedo ver por qué las Inns of Court podrían objetar a una asistencia irrestricta. Supongo que tiene que ver con la conexión entre las dos ramas de la profesión.

17.215. ¿Se afirma simplemente como un hecho, y por consiguiente no se discute su bondad o conveniencia? - Creo que la verdadera razón es la cuestión de la conexión entre las dos ramas de la profesión. Es la única cosa que se me ocurre. Propondría que se abriesen las clases tanto como fuera posible. 
17.216. (Lord Reay). Permítame leer algunos pasajes del Report of the Committee of the American Bar Association, me gustaría escuchar su opinión con relación a algunas opiniones vertidas en el mismo. Son de valor, por provenir de abogados prácticos: "el trabajo del abogado deber estar siempre en concordancia con los hechos jurídicos o concepciones de las relaciones jurídicas en que consiste el derecho. Todo asesoramiento al cliente, toda selección de un remedio, toda afirmación en un proceso, y en resumen, todo trabajo que tenga un valor para otros debe depender de una delicada concepción de estos hechos últimos y del sistema de derechos y deberes que constituye el derecho. En este respecto, el derecho no difiere de otras ciencias, pues todas tratan sólo de nociones y verdades generales. ¿Qué le suscita? - No es el lenguaje que yo hubiese empleado, pero no puedo negar su verdad. Es cierto que en cualquier caso hay dos cosas que hacer; aprehender los hechos - descubrir cuáles son los hechos materiales del caso-y aplicar después la regla jurídica. Quizás diría que el pasaje infravalora la habilidad, que casi podría llamarse innata, que tienen algunas personas de encontrar los hechos materiales. Nadie puede llevar un caso sin advertir que la determinación de los hechos es la mitad de la batalla. Por supuesto, saber qué hechos son materiales implica algún tipo de conocimiento sobre los principios jurídicos que deben aplicarse al asunto concreto. Pienso que está claro que el derecho consiste en principios y en su aplicación a los hechos.

17.217. Sobre el siguiente punto, creo que ya ha manifiesto su acuerdo: "en relación con el método de estudio, siempre depende de las circunstancias de cada escuela y de los profesores". - Estoy totalmente de acuerdo.

17.218. "Pero el Comité recomienda encarecidamente que todo profesor de una escuela de derecho deba presentar un programa de su materia impreso que los estudiantes deben dominar tanto como sea posible"? - Sobre este asunto tengo alguna experiencia. Siempre o casi siempre, de hecho, presento un programa de mis lecciones impreso para que los estudiantes puedan seguirlas. No sé si le concedo tanta importancia como el autor del pasaje parece hacer, pero si se refiere a que un lecturer debe ofrecer un esquema general de su materia de una forma u otra, creo que tiene toda la razón.

17.219. Supongo que estará de acuerdo con lo que sigue: "y debería ocupar el tiempo de clase en esas referencias e ilustraciones que pueden ayudarlos en la clara comprensión de estos principios fundamentales, y en examinaciones suficientes para convencerse de que lo han comprendido". - Sí; estoy de acuerdo, pero añadiría lo siguiente. Parece sencillo, pero no lo es. Parece 
muy sencillo, pero es algo muy difícil de lograr. Muy pocas personas pueden hacerlo con éxito.

17.220. El informe continúa: "el empleo de casos como ilustración de estos principios legales tiene ventajas incuestionables y aporta precisión al conocimiento del estudiante que difícilmente podría obtener de otra manera, pero no valoramos el mero empleo de casos sin referencias a los principios fundamentales del derecho, de los que en nuestra opinión todos los casos son aplicaciones". - Concuerdo con el pasaje. Supongo que se refiere al sistema estadounidense de enseñanza exclusivamente mediante casos. Me inclinaría, si nos estuviéramos dirigiendo a un cuerpo de profesores ingleses, por apremiarlos sobre la urgente necesidad de mostrar que los casos son ilustraciones de principios, y acentuaría más enfáticamente de lo que lo hacemos la importancia de los casos.

17.221. Con el siguiente pasaje, por lo que ha mencionado, creo que difícilmente estará de acuerdo: "la evolución histórica del derecho puede sin dudas trazarse de manera más exacta en las decisiones de los tribunales que de otra manera, pero la unidad lógica del sistema y la armonía entre las diferentes decisiones constituyen otros modos de estudio diferente, que no sería sabio descuidar. El único test de una norma del Common Law debe ser su consistencia con el resto de las normas, o la armonía del entero sistema. Si dos normas conducen a resultados diferentes en algún momento, alguna de ellas no pertenece al Common Law; y se si deja que ambas continúen teniendo autoridad y se enseñan como tales, el único resultado será la discrepancia de las decisiones que se deriven de ellas. Por esta razón urgimos a que los dos métodos de enseñanza sean empleados en su correcta relación con los tribunales; el método histórico con el objeto de mostrar cómo nuestro actual concepto del Common Law ha llegado a ser lo que es, el método lógico con el de mostrar la relación entre las normas jurídicas y el modo en que todas ellas se derivan de ciertos principios fundamentales". - Como afirmación genérica, no tengo ninguna objeción. El único punto que me gustaría enfatizar es que personalmente insistiría en la mayor importancia del método lógico que del histórico por la siguiente razón: el método histórico comienza tan atrás y continúa tan atrás respecto al derecho vigente con el que ahora tenemos que tratar que sus ventajas son menores que lo que cabría esperar de él.

17.222. ¿Coincidiría entonces con esta visión?: "pero no queremos que se entienda que proponemos una idea según la cual la instrucción en la Escuela de Derecho deba impartirse exclusivamente por aquéllos que no participan activamente en la práctica de la profesión. Consideramos muy poco sabio no 
contar entre los órganos de instrucción con algunas personas que estén activamente implicadas en la práctica de la profesión. Recomendamos una combinación de las dos". - Estoy de acuerdo con esta combinación de las dos; con ello entiendo que los autores del informe se referían a que los instructores deben ser tanto abogados ejercientes que esté dispuestos a enseñar, como profesores que no se encuentran activamente implicados en el ejercicio del derecho. Con ello estoy enteramente de acuerdo.

17.223. ¿La mejor persona que podría conseguirse sería aquella que hubiese sido ejerciente y por alguna razón hubiese abandonado el ejercicio? - Sí, sería la mejor persona, asumiendo que tenga capacidad para enseñar.

17.224. Como ha afirmado, la práctica real, el arte que garantiza el éxito en la abogacía, obviamente no puede ser enseñado. Ninguna facultad puede intentar enseñar cómo interrogar a un testigo o cómo dirigirse a un jurado Solo hay una parte de la práctica que se puede enseñar en los Estados Unidos y que realmente se enseña allí. Se puede hasta cierto punto enseñar el arte de argumentar ante un tribunal. He visto por ejemplo, una discusión desarrollada ante el Profesor Dwight en Nueva York tan preparada y elaborada como si hubiese ocurrido en un tribunal. Dwight fue un abogado eminente. Frecuentemente ocupó la magistratura. Le fue ofrecido el puesto de manera temporal. Además, hay cuestiones técnicas que se pueden enseñar, por ejemplo, cómo preparar notas sobre las demandas, etc. Con frecuencia un joven en sus comienzos comete errores y estropea el resultado de su argumentación por ignorancia de insignificantes detalles. Este riesgo es descartado por los Moot Courts en los Estados Unidos.

17.225. ¿Está a favor de esos Moot Courts? - Sí, soy muy partidario de ellos si están bien dirigidos.

17.226. Con relación al derecho penal, ¿̇supongo que no se opondrá la enseñanza de su teoría y su lado filosófico? - No me opongo, pero creo que no supone una gran ventaja para el abogado. Quizás me equivoque. Personas de gran eminencia discrepan conmigo sobre el particular. Personalmente encuentro tantas dificultades en enseñar a los jóvenes lo que es el derecho vigente, que no me inclino por enseñarles cómo podría ser mejorado.

17.227. ¿Se opondría a una cátedra que se ocupase de la materia? - No me opondría, pero la dificultad de disponer de un cuerpo completo de profesores de derecho, aunque redujéramos la materia a la enseñanza a los aspectos básicos, es muy considerable. No me opongo a dicha cátedra, pero no tengo especial entusiasmo por ella. 
17.228. Tornando del lado especulativo al práctico, Vd. es consciente del buen trabajo realizado por M. Boutmy en Francia en la Ecole des Politique Sciences [sic]. ¿La considera una buena institución? - Constituye una institución de extraordinario éxito.

17.229. Dejando a un lado la cuestión de si una escuela como ésa debiese formar parte de la facultad de derecho o de si la nueva universidad debería crear un departamento especializado (lo cual son cuestiones de detalle) están son las materias que se enseñan: la historia diplomática de Europa desde 1789; la historia constitucional de Europa desde 1789; la historia de las ideas políticas y el desenvolvimiento de la opinión pública en los últimos dos siglos, la organización militar comparada. Otra materia que no es menos importante para nosotros que para los franceses, el sistema colonial y la historia de las relaciones de los Estados occidentales con los orientales. ¿Serían apropiadas estas materias? - Creo que existe una gran necesidad de enseñanza de estas materias, aunque algunas de las que ha citado no me parecen muy estrechamente ligadas con la enseñanza del derecho

17.230. Por eso deje abierto un interrogante antes. ¿̇Reconoce Vd. que existe una gran necesidad de alguna instrucción en materias de este tipo? - Sí. Me gustaría tener la oportunidad de conocer el funcionamiento de la Ecole des Libres Sciences politiques [sic]. No tengo dudas sobre el valor de la enseñanza ofrecida allí.

17.231. Dado que existe una demanda espontánea por tal institución en Francia, la cual es voluntaria, no faltarían estudiantes aquí, incluso creo que algunos ingleses han sido estudiantes de la misma - Sí. Creo que sería estupendo que la universidad impulsase esta línea de enseñanza si es posible. Aunque supongo que los comisionados intentaran conseguir evidencias más directas sobre la Ecole des Libres Sciences politiques. Es un fenómeno destacable. Me gustaría que tuviéramos más información en Inglaterra sobre ello. Es un extraordinario ejemplo de enseñanza de alta calidad implantada por esfuerzos voluntarios, y supongo que se habrá creado gracias a Monsr. Boutmy, su fundador, aunque tenga distinguidos colegas.

17.232. Eso parece; ¿y no es constituye un ejemplo, especialmente cuando se quiere establecer una nueva universidad, de que todo depende de conseguir las mejores personas? - Sí, es realmente el punto vital. Está claro que puede encontrarse en Inglaterra un buen número de buenos profesores. Mantenerlos es realmente el problema práctico. No veo el motivo por el que no se puedan contratar a los profesores que se necesitan. Pero creo que sería difícil 
organizar el modo adecuado de seleccionarlos y también conseguir que las cátedras sean reguladas de tal forma que se incentive a las personas correctas a mantenerse en ellas.

17.233. ¿En caso de que se hubiesen seleccionado debería ofrecerse un puesto fijo? - Un puesto fijo con alguna forma de jubilación. En Oxford no tenemos una regulación muy acertada de las jubilaciones y asuntos de esta clase, lo que podría producir grandes daños bajo ciertas circunstancias.

17.234. (Lord Playfair). ¿Otorga la escuela de ciencias políticas grados? (Lord Reay.) No, otorga diplomas; no tiene ninguna conexión con la facultad de derecho de la universidad. (Lord Playfair). Creo que estamos muy lejos de exigir tal diploma a los miembros del Parlamento - No veo esa tendencia para nada. Quizás deba volver al asunto de los grados ya que se ha mencionado. Si se consiguen buenos diplomas, no le concedo mucha importancia a los grados en derecho otorgados mediante una examinación competitiva. Una escuela de derecho de una universidad al uso se encuentra en una posición diferente que la de una escuela de derecho en la que estudian personas que van a acceder a la abogacía. Si la enseñanza jurídica de la nueva universidad fuese tan buen como la de la Ecole des Libres Sciences politiques no tendría dudas de su valía ni de que ésta se reconociese. Sería una pena que en la época de sus vidas en la que los estudiantes preparan su acceso a la abogacía tengan que rendir otra examinación competitiva. No me opongo a las examinaciones tanto como lo hacen algunos amigos míos, pero no me gustaría que la universidad fuera fundamentalmente un centro de examinaciones. Estoy convencido de que la buena enseñanza triunfaría por ella misma. Pienso que el ejemplo de M. Boutmy lo corrobora. No quiero que la Comisión piense que tengo ninguna intención en incentivar los grados competitivos. Nadie contrataría a una persona por el simple hecho de haber obtenido una alta calificación en una examinación de derecho. Dense diplomas de asistencia y nada o poco más.

17.235. ¿Se aplica a la mayoría de las materias el hecho de que las examinaciones si pueden evitarse son más bien un mal, o que los grados constituyen simplemente una prueba de que los alumnos han estudiado? - No querría comprometerme en toda su extensión con la afirmación porque, aunque conllevan grandes perjuicios, creo que las examinaciones de la universidad tienen grandes ventajas. Los jóvenes se benefician mucho de tener un plan de estudios establecido para ellos. Por cada persona que estaría mejor con un plan fijado por él mismo en vez de con uno fijado por otros, diez personas 
estarían peor. Agradezco mucho que cuando era estudiante de grado me hubiesen obligado a leer libros que de otra manera no habría leído. Establecería una distinción entre educación universitaria, y educación para adultos que estudian derecho.

17.236. (Presidente). Dice Vd. que lo más importante es contar con los profesores más capaces, y las mejores personas son aquéllas que han sido ejercientes. No es un tipo de persona difícil de encontrar - ¿̇una persona capaz? - Quizás debería haber dicho personas capaces que han intentado ejercer. Asumiendo que las cátedras estuvieran adecuadamente remuneradas, aunque no de modo extravagante, y que el puesto fuera fijo, no creo que la selección de las personas fuese muy complicada. Hay personas que creen que la práctica se adquiere lentamente, y otras que tienen un gusto natural por la enseñanza y la especulación. Ése sería el tipo de personas que yo escogería. Sospecho que hay una o dos personas en la magistratura que en algún momento de su carrera habrían aceptado una cátedra como la que se quiere establecer - personas que han tenido un enorme éxito desde entonces, pero que hubiesen optado por una cátedra hace 10 años.

17.237. ¿Hay personas con una mentalidad dirigida a impartir conocimientos, más que hacia los negocios cotidianos de la vida? - Sí. Éstas serían las personas en las que habría que confiar principalmente. Pero creo que ocasionalmente se podría contratar a personas con experiencia en la abogacía.

17.238. ¿Cómo deberían ser nombrados? ¿Por el Senado a propuesta de los profesores? - Creo que sí. Nunca he encontrado un modo de selección perfectamente satisfactorio. Por otro lado, creo que la dificultad en el diseño de un buen sistema de nombramientos no es en la práctica insuperable.

17.239. (Lord Playfair). No estoy seguro de haber entendido la cautela que con razón avanza sobre la composición de la facultad o el Senado. ¿̇Teme Vd. que distinguidos abogados que no estén interesados por la mejora de la enseñanza jurídica sean nombrados, y que más bien obstruyan al avance? Pero eso me preocupa.

17.240. ¿Y no ha existido una tendencia similar en otras profesiones? Fijémonos en la profesión de los ingenieros. En ese caso, especialmente aquéllos que más se han distinguido que no han recibido formación, con la excepción de Stephenson, que asistió a la Universidad de Edimburgo y siempre ha reconocido la ventaja de haberlo hecho, ¿no ha advertido Vd. que creían que la ingeniería se enseñaba mejor en sus propios establecimientos que en 
los universitarios, y después han abandonado progresivamente tal opinión? - Creo que tal sentimiento será progresivamente abandonado porque, y lo creo ciertamente, una parte del derecho se enseña mejor en la universidad que en otros lugares. Supongan que tenemos una universidad de teología, sugeriría que no tuviese un cuerpo de electores formado por clérigos muy amplio. En realidad, no sabrían exactamente qué se espera de un profesor. He oído afirmaciones por parte de abogados sobre lo que sería deseable en un profesor que me han hecho dudar de su competencia para elegir profesores de derecho. Pero al fin y al cabo todo es cuestión de la cantidad de abogados ejercientes que formarían el órgano elector.

17.241. ¿Daría entonces una preeminencia considerable en la facultad a los profesores? - Sí, y nombraría eminentes abogados. No es con estos últimos con los que pueden surgir dificultades, sino con la persona que hace bien su trabajo y nunca ha comprendido por qué lo hace bien. No sabe lo que se requiere de él. Si se nombran electores a un cierto número de personas eminentes, creo que en general, todo irá bien.

17.242. Pensemos en la profesión médica. En cierto momento una gran parte de la profesión consistía en pasantías con reconocidos médicos ejercientes. Actualmente no es así, y el público ha aprendido a apreciar la instrucción en una escuela de medicina para el ejercicio de la profesión. ¿Cree que este reconocimiento llegará gradualmente al derecho como lo ha hecho en otras profesiones? - Creo que sí; pero el peligro al que me quería referir era el de crear un órgano poco competente para seleccionar a los primeros profesores de derecho. Si estos primeros profesores no ejercen sus cargos tan bien como se espera será mucho más difícil después conseguir que el derecho se enseñe bien en la nueva universidad. Este peligro al que me refería es el de que los primeros nombramientos no sean buenos debido al tipo de órgano de elección que se establezca. Pero debo decir que he exagerado tal riesgo.

Fuente: Gresham University Commission, Minutes of evidence taken by the Royal Commissioners Appointed to Consider the Draft Charter for the Proposed Gresham University in London; together with Tables of Witnesses and of Institutions Represented, Londres, Eyre and Spottiswoode, printed for her Majesty's Stationery Office, 1892, pp. 742-750. 


\section{BIBLIOGRAFÍA}

AA.VV., Law Quarterly Review 1 (1885). Disponible en: https://archive.org/details/lawquarterlyrevo5unkngoog/page/n6.

AA.VV., Report of the Royal Commission Appointed to Consider the Law relating to Indictable Offences: with an Appendix containing a Draft Bill embodying the Suggestions of the Commissioners, Londres, G. E. Ayre y W. Spottiswoode, 1879. Disponible en: http://www.lareau-legal.ca/EnglishDraftCodeONE.pdf.

[Anon], "Professor Dicey", Journal of the Society of Comparative Legislation (new series) 17, 1 (1917), pp. 1-4.

William R. Anson, Principles of the English Law of Contract, Oxford, Clarendon Press, 1879. Disponible en: https://archive.org/details/principlesengliooansogoog/page/n9.

John Austin, Lectures on Jurisprudence. Or the Philosophy of Positive Law (ed. Sarah Austin), Londres, John Murray, 1861-1863, 3 vols. Disponible en: https://archive.org/details/provincejurispro1austgoog. Existe edición española del vol. 1, John Austin, El Objeto de la jurisprudencia, Madrid, Centro de Estudios Políticos y Constitucionales, 2002, traducción de Juan Ramón de Páramo Argüelles.

Del mismo, "The Uses of the Study of Jurisprudence", en John Austin, Lectures on Jurisprudence. Or the Philosophy of Positive Law (ed. Sarah Austin), Londres, John Murray, 1863, vol. 3, pp. 345-388. Disponible en: https://archive. org/details/provincejurispro6austgoog. Felipe González Vicén la tradujo en 1951: John Austin, Sobre la utilidad del estudio de la jurisprudencia, Madrid, Instituto de Estudios Políticos, 1951, $2^{\text {a }}$ ed. Centro de Estudios Constitucionales, 1981. La última edición española es: John Austin, Sobre la utilidad del estudio de la jurisprudencia (Carlos Antonio Agurto, Sonia Lidia Quequejana y Benigno Choque eds.), Santiago (Chile), Olejnik, 2018.

Gumersindo Azcárate y Santiago Innerárity, "Al lector", nota a Lord [Thomas] Mackenzie, Estudios de derecho romano comparado en algunos puntos con el francés, el inglés y el escocés, Madrid, Francisco Góngora, 1876 [1862]. Disponible en: http://www.cervantesvirtual.com/obras/autor/innerarity-santiago-72010.

Walter Bagehot, The English Constitution, $2^{\mathrm{a}}$ ed., Boston, Little, Brown, and Company, 1873 [1867]. Disponible en: https://archive.org/details/englishconstituoobagegoog/page/n3. La primera edición española fue Walter Ba- 
gehot, La constitución inglesa, Madrid, 1902, traducción de Adolfo Posada. Disponible en: https://archive.org/details/BReso81340.

"Barrister", Encyclopædia Britannica, 1911, vol. 3. Disponible en: https:// en.wikisource.org/wiki/1911_Encyclop\%C3\%A6dia_Britannica/Barrister.

Montague Bernard, A Letter to the Right Hon. W. E. Gladstone on the Statutes of the University of Oxford Commission, Londres, Rivingtons, 1882. Disponible en: https://archive.org/details/lettertorighthonoobern.

William Blackstone, Commentaries on the Laws of England, Oxford, Clarendon Press, 1765-1770, 4 vols.

James Bryce, “A Few Words on the Universities Bill”, Fortnightly Review 25 (1876), pp. 771-776.

Del mismo, "The Academical Study of the Civil Law. An Inaugural Lecture", en James Bryce, Studies in History and Jurisprudence, Oxford, Clarendon Press, 1901, vol. 1, pp. 860-886. Disponible en: https://archive.org/details/studiesinhistoryo2brycuoft.

Del mismo, Constituciones flexibles y rígidas (ed. Pablo Lucas Verdú), Madrid, Centro de Estudios Constitucionales, 1988.

Del mismo, Constituciones flexibles y rígidas (ed. Pablo Lucas Murillo de la Cueva), Madrid, Centro de Estudios Políticos y Constitucionales, 2015.

Fiona R. Burns, "Lord Westbury, Law Reform and Fusion", The Journal of Legal History 29 (2008), pp. 1-37. Disponible en: https://www.tandfonline.com/ doi/abs/10.1080/01440360801903554.

John B. Byles, A Practical Compendium on the Laws of Bills of Exchange, Londres, S. Sweet, 1829. Disponible la 4 a edición de 1843 en: https://archive.org/ details/practicaltreatisoobyleuoft/page/n4.

Mackenzie D. Chalmers, A Digest of the Law of Bills of Exchange, Promissory Notes and Cheques, Londres, Stevens and Sons, 1878. Disponible en: https:// archive.org/details/adigestlawbillsoounkngoog/page/n5

Bartolomé Clavero, "Imperio de la ley y rule of law: léxico jurídico y tópica constitucional”, Quaderni Fiorentini per la Storia del Pensiero Giuridico Moderno 25 (1996), pp. 287-346. Disponible en: http://www.centropgm.unifi.it/cache/ quaderni/25/0286.pdf.

Raymond Cocks, Foundations of the Modern Bar, Londres, Sweet \& Maxwell, 1983.

Stefan Collini, Public Moralists. Political Thought and Intellectual Life in Britain, 1850-1930, Oxford, Clarendon Press, 1991.

Stefan Collini, Donald Winch y John W. Burrow, That Noble Science of Politics. 
A Study in Nineteenth-Century Intellectual History, Cambridge, Cambridge University Press, 1983.

Richard A. Cosgrove, The Rule of Law. Albert Venn Dicey, Victorian Jurist, Chapel Hill, The University of North Carolina Press, 1980.

Del mismo, Our Lady the Common Law. An Anglo-American Legal Community, 1870-1930, Nueva York, New York University Press, 1987.

Ramón Cotarelo, "Introducción”, en Henry S. Maine, El derecho antiguo. Su conexión con la historia temprana de la sociedad y su relación con las ideas modernas, Valencia, Tirant, 2014, pp. 9-46.

Ignacio Cremades Ugarte, “Introducción”, en Frederic W. Maitland, Las formas de acción en el Common Law, Madrid, Marcial Pons, 2005, pp. 9-30.

Albert Venn Dicey, "Legal Etiquette", The Fortnightly Review 7 (1867), pp. 169179.

Del mismo, "Suggestions on Academical Organization", Fraser's Magazine 80 (1869), pp. 407-430.

Del mismo, A Treatise on the Rules for the Selection of the Parties to an Action, Londres, William Maxwell \& Son, 1870. Disponible en: https://archive.org/ details/atreatiseonruleoodicegoog/page/n7.

Del mismo, “Legal Education”, Macmillan's Magazine 24 (1871), pp. 115-127.

Del mismo, "Judicial Policy in England" [abril, 1874], Macmillan's Magazine 29 (1873-1874), pp. 473-487.

[A. V. Dicey], "Maine's Early History of Institutions”, The Nation, 1875, 1 de abril, pp. 225-226.

[A. V. Dicey], “Modern English Law”, The Nation, 1876, 2 de noviembre, pp. 273274.

Del mismo, The Law of Domicil as a Branch of the Law of England Stated in the Form of Rules, Londres, Stevens and Sons, 1879. Disponible en: https:// archive.org/details/lawdomicileasaboodicegoog/page/n5.

Del mismo, "The Study of Jurisprudence", The Law Magazine and Review (fourth series) 5 (1880), pp. 382-401.

Del mismo, "Sir George Bramwell and the English Bench", The Nation, 15 de diciembre, 1881 , pp. 468-470.

Del mismo, Can English Law be Taught at the Universities?, Londres, Macmillan and Co., 1883. Disponible en: https://archive.org/details/canenglishlawbeoodicegoog.

Del mismo, Lectures Introductory to the Study of the Law of the Constitution, Londres, Macmillan and Co., 1885. Disponible en: https://archive.org/details/ 
lecturesintroduo3dicegoog/page/n15. La edición francesa es A. V. Dicey, Introduction a l'étude du droit de la constitution (ed. André Batut y Gaston Jèze), París, V. Giard \& E. Brière, 1902; la española A. V. Dicey, El derecho de la constitución, Valencia, Tirant lo Blanch, 2019, traducción de Héctor Domínguez Benito. Del mismo, England's Case Against Home Rule, Londres, John Murray, 1886.

Del mismo, "A Common Citizenship for the English Race", Contemporary Review 71 (1897), pp. 457-476.

Del mismo, "The Teaching of English Law at Harvard", Contemporary Review 76 (1899), pp. 742-760.

Del mismo, Lectures on the Relation between Law \& Public Opinion in England during the Nineteenth Century, Londres, Macmillan and Co., 1905. Disponible en: https://archive.org/details/lecturesonrelatoounkngoog/page/n9. La edición española es A. V. Dicey, Lecciones sobre la relación entre derecho y opinión pública en Inglaterra durante el siglo XIX, Albolote (Granada), Comares, 2007.

Del mismo, "Blackstone's Commentaries", National Review, 54 (1909), pp. 653675. Reimpresa en The Cambridge Law Journal 4, 3 (1932), pp. 286-307.

Del mismo, "Law-Teaching, Oral and Written", en Herbert H. Henson (ed.), A Memoir of the Right Honourable Sir William Anson, Oxford, Clarendon Press, 1920, pp. 84-101.

Del mismo, The Law of the Constitution (ed. John W. F. Allison), Oxford, Oxford University Press, 2013.

Héctor Domínguez Benito, "Frederick Pollock en París, o la naturaleza conflictiva del derecho comparado", Revista de Historia del Derecho 55 (2018), pp. 91126. Disponible en: http://www.scielo.org.ar/pdf/rhd/n55/n55a03.pdf.

Del mismo, "Historia de un manifiesto. Una introducción al derecho de la constitución de Albert Venn Dicey", en A. V. Dicey, El derecho de la constitución, Valencia, Tirant lo Blanch, 2019, pp. 9-77.

Roland Epstein, Fernando Picchi y Bruna Di Sabato, West's Law \& Commercial Dictionary. Dizionario giuridico e commerciale inglese-italiano, francese, spagnolo, tedesco, italiano-inglese, Bologna/St. Paul (Minnesota), Zanichelli/West, 1988.

H. A. L. Fisher, James Bryce. Viscount Bryce of Dechmont, O. M, Londres, Macmillan, 1927, 2 vols. Disponible en: https://archive.org/details/in.ernet. dli.2015.178411.

Trowbridge H. Ford, Albert Venn Dicey. The Man and His Times, Chichester, Barry Rose Publishers Ltd., 1985. 
Gresham University Commission, Minutes of evidence taken by the Royal Commissioners Appointed to Consider the Draft Charter for the Proposed Gresham University in London; together with Tables of Witnesses and of Institutions Represented, Londres, Eyre and Spottiswoode, printed for her Majesty's Stationery Office, 1892.

Harold G. Hanbury, The Vinerian Chair and Legal Education, Oxford, Basil Blackwell, 1958.

H. L. A. Hart, "Introducción" [1954], en John Austin, El objeto de la jurisprudencia (ed. Juan Ramón de Páramo), Madrid, Centro de Estudios Políticos y Constitucionales, 2002, pp. 5-15.

Del mismo, "Analytical Jurisprudence in Mid-Twentieth Century: A Reply to Professor Bodenheimer”, University of Pennsylvania Law Review 105 (1957), pp. 953-975.

Christopher Harvie, "From the Cleveland Commission to the Statutes of 1882", en Michael G. Brock (ed.), The History of the University of Oxford, Oxford, 2000, vol. 7, pp. 67-96.

William S. Holdsworth, Charles Viner and the Abridgments of English Law, Londres, Stevens \& Sons, 1923.

Thomas E. Holland, “Codification”, Edinburgh Review 127 (1867), pp. 347-376.

Del mismo, The Elements of Jurisprudence, Oxford, Clarendon Press, 1880. Disponible la $2^{\text {a }}$ ed. en: https://archive.org/details/cu31924017837968/page/ n8.

House of Commons, Report from the Select Committee on Legal Education. Together with the Minutes of Evidence, Appendix and Index, Londres, 1846. Disponible en: https://archive.org/details/op1246300-1001.

Del mismo, Report of the Commissioners Appointed to Inquire into the Arrangements in the Inns of Court and Inns of Chancery, for Promoting the Study of the Law and Jurisprudence. Together with Appendices, Londres, 1855. Disponible en: https://archive.org/details/reportcommissiooojurigoog/page/ n7.

Edward Jenks (ed.), A Digest of English Civil Law, Londres, Butterworth, 19051917. Disponible el libro 1 en: https://archive.org/details/adigestenglishco2geldgoog/page/n6.

James Kent, Commentaries on American Law, Nueva York, O. Halsted, 1826-1830, 4 vols. Disponible en: https://catalog.hathitrust.org/Record/ oo8593272?type\%5B\%5D=author\&lookfor\%5B\%5D=\%22Kent\%2C\%20 James\%2C\%201763-1847\%22\&ft= 
Harry Kirk, Portrait of a Profession. A History of the Solicitor's Profession, 1100 to the Present Day, Londres, Oyez Publishing, 1976.

Christopher C. Langdell, Selection of Cases on the Law of Contracts, Boston, Little, Brown and Company, 1871. Disponible la $2^{\mathrm{a}}$ ed. en: https://archive.org/ details/cu31924018826713/page/n9.

Frederick H. Lawson, The Oxford Law School, 1850-1965, Oxford, Clarendon Press, 1968.

Dylan Lino, "Albert Venn Dicey and the Constitutional Theory of Empire”, Oxford Journal of Legal Studies 36, 4 (2016), pp. 751-780. Disponible en: https://papers.ssrn.com/sol3/papers.cfm?abstract_id=2719376.

Michael Lobban, "Was There a Nineteenth Century 'English School of Jurisprudence’?”, The Journal of Legal History 16 (1995), pp. 34-62.

David Maclachlan, A Treatise on the Law of Merchant Shipping, Londres, William Maxwell, 1862. Disponible en: https://archive.org/details/atreatiseonlawmoomaclgoog/page/n4.

Henry S. Maine, "Roman Law and Legal Education” [1856], en Henry S. Maine, Village Communities of the East and West, $3^{\mathrm{a}}$ ed., Londres, John Murray, 1876, pp. 330-386. Disponible en: https://archive.org/details/villagecommunoomain/page/n8.

Del mismo, Ancient Law. Its Connection with the Early History of Society and its Relation to Modern Ideas, Londres, John Murray, 1861. Disponible en: https://archive.org/details/ancientlawitsco18maingoog. Hubo doble edición española, Henry S. Maine, El derecho antiguo. Considerado en sus relaciones con la historia de la sociedad primitiva y con las instituciones modernas. Parte general. Historia del derecho y de la organización social, Madrid, Tipográfica del Hospicio, 1893, con un prólogo-artículo de Gumersindo de Azcárate. Disponible en: http://bdh-rd.bne.es/viewer.vm?id=0000146947\&page=1. Henry S. Maine, El derecho antiguo. Parte especial, Madrid, Librería de Victoriano Suárez, 1894, traducción de A. Guerra. Existe nueva traducción directamente del inglés, Henry S. Maine, El derecho antiguo. Su conexión con la historia temprana de la sociedad y su relación con las ideas modernas, Valencia, Tirant, 2014, traducción de Ramón Cotarelo.

Henry S. Maine, Lectures on the Early History of Institutions, Londres, John Murray, 1875. Disponible en: https://ia800306.us.archive.org/9/items/ lecturesonearlyo3maingoog/lecturesonearlyo3maingoog.pdf. La edición española es Henry S. Maine, Las instituciones primitivas, Madrid, La España Moderna, [1895]. Disponible en: http://datos.bne.es/obra/XX5515913.html. 
Del mismo, Dissertations on Early Law and Custom. Chiefly Selected from Lectures Delivered at Oxford, Londres, John Murray, 1883. Disponible en: https://archive.org/details/in.ernet.dli.2015.216448.

Frederic W. Maitland, Why the History of English Law is Not Written, Londres, Cambridge University Press, 1888. Disponible en: https://archive.org/details/whyhistoryenglioomaitgoog/page/n11.

Del mismo, Equity. Also the Forms of Action at Common Law. Two Courses of Lectures (A. H. Chaytor y W. J. Whittaker eds.), Londres, Cambridge University Press, 1909. Disponible la $2^{\text {a }}$ ed. en: https://archive.org/details/equityalsoformsooomait/page/n7/mode/2up. La edición española de la segunda lección es Frederic W. Maitland, Las formas de acción en el Common Law, Madrid, Marcial Pons, 2005, traducción de Ignacio Cremades Ugarte.

William Markby, Elements of Law. Considered with Reference to Principles of General Jurisprudence, Oxford, Clarendon Press, 1871. Disponible en: https://archive.org/details/elementsoflawcooomarkuoft.

John S. Mill, On Liberty, Londres, John W. Parker and Son, 1859. Disponible en: https://archive.org/details/onlibertyxerooomilluoft.

Del mismo, "Austin on Jurisprudence", Edinburgh Review 118 (1863, July-October), pp. 439-482.

W. Morgan y A. G. Macpherson (eds.), The Indian Penal Code (Act XLV of 186o). With Notes, Calcutta, G. C. Hay \& Co, Londres, Crescent Place, Blackfriars, 1863. Disponible en: https://archive.org/details/indianpenalcodeoomacpgoog/page/n4.

Roger K. Newman, The Yale Biographical Dictionary of American Law, New Haven, Yale University Press, 2009.

Mark Pattison, Suggestions on Academical Organisation with Especial Reference to Oxford, Edimburgo, Edmonston and Douglas, 1868. Disponible en: https://catalog.hathitrust.org/Record/o01733748.

Carlos Petit, "California y el Derecho Romano", nota de lectura a Max Radin, Cartas Romanísticas (1923-1950), Nápoles, Jovene, 2001, pp. xi-cxxiv.

Frederick Pollock, Principles of Contract at Law and in Equity, Londres, Stevens and Sons, 1876. Disponible en: https://archive.org/details/principlescontro3pollgoog/page/n6.

Del mismo, A Digest of the Law of Partnership, Londres, Stevens \& Sons, 1877. Disponible en: https://archive.org/details/adigestlawpartnoobritgoog.

Del mismo, Essays in Jurisprudence and Ethics, Londres, Macmillan and Co., 1882. Disponible en: https://archive.org/details/essaysinjurisprudeoopoll/page/n6. 
Del mismo, "English Opportunities and Duties in the Historical and Comparative Study of Law. An Inaugural Lecture", en Frederick Pollock, Oxford Lectures and other Discourses, Londres, Macmillan and Co., 1890. Disponible en: https://archive.org/details/rsoxfordlecturesoopolluoft/page/n8.

Adolfo Posada, Tratado de derecho político, Madrid, Librería de Victoriano Suárez, 1893-1894, 3 vols.

Del mismo, El régimen municipal de la ciudad moderna, $3^{\text {a }}$ ed., Madrid, Librería General de Victoriano Suárez, 1927.

Robert S. Rait, Memorials of Albert Venn Dicey. Being chiefly Letters and Diaries, Londres, Macmillan, 1925.

Wilfrid E. Rumble, Doing Austin Justice. The Reception of John Austin's Philosophy of Law in Nineteenth-Century England, Londres/Nueva York, Continuum, 2005.

José Sánchez Osés, “La codificación del Derecho penal en Inglaterra”, Anuario de Derecho Penal y Ciencias Penales, t. 9, fasc. 2 (1956), pp. 267-295.

Víctor Saucedo, "La doble vida de la conspiración inglesa", Indret. Revista para el Análisis del Derecho 1 (2019), pp. 1-23. Disponible en: http://agora.edu.es/ ejemplar/511488.

Friedrick Charles von Savigny, Of the Vocation of Our Age for Legislation and Jurisprudence, Londres, Littlewood \& Co, 1831. Traducción de Abraham Hayward de la $2^{\text {a }}$ edición de 1828. Disponible en: https://catalog.hathitrust.org/ Record/010448970.

Del mismo, Private International Law. A Treatise on the Conflict of Laws, and the Limits of their Operation in Respect of Place and Time, translated, with notes, by W. Guthrie, Edinburgo/Londres, 1869. Disponible en: https://archive.org/details/privateinternatooguthgoog/page/n7.

Del mismo, De la vocación de nuestra época para la legislación y la ciencia del Derecho, Madrid, Universidad Carlos III de Madrid, 2015. Traducción de José Díaz García. Disponible en: https://e-archivo.uc3m.es/handle/10016/21520.

A. B. Schofield, Dictionary of Legal Biography, 1845-1945, Chichester, Barry Rose Law Publishers, 1998.

A. W. B. Simpson, Biographical Dictionary of the Common Law, Londres, Barry Rose Law Publishers, 1984.

John W. Smith, A Selection of Leading Cases on Various Branches of the Law, Londres, A. Maxwell, 2 vols., 1837-1840. Disponible en: https://babel.hathitrust.org/cgi/pt?id=uc2.ark:/13960/t1mg7r37z\&view=1up\&seq=10.

Statutes made for the University of Oxford, and for the Colleges and Halls there- 
in, by the University of Oxford Commissioners, etc, Oxford, Clarendon Press, 1882. Disponible en: https://babel.hathitrust.org/cgi/pt?id=nyp.334330674 $05328 \&$ view $=1$ up\&seq $=7$.

Henry J. Stephen, New Commentaries of the Laws of England. Partly Founded in Blackstone, Londres, Henry Butterworth, 1841-45, 4 vols.

James F. Stephen, "English Jurisprudence”, Edinburgh Review 114 (1861), pp. 456-486. Disponible en:https://babel.hathitrust.org/cgi/pt?id=njp.3210107 $6379260 \&$ view $=1$ up\&seq $=12$.

Del mismo, "Codification in India and in England", The Law Magazine and Review (new series) 1 (1872), pp. 963-990. Disponible en: https://babel.hathitrust.org/cgi/pt?id=inu.30000093208803\&view=1up\&seq=654.

Del mismo, Liberty, Equality, Fraternity, Nueva York, Holt \& Williams, 1873. Disponible en: https://archive.org/details/libertyequalityoostepgoog/page/ n5.

Del mismo, A Digest of the Law of Evidence, Londres, Macmillan \& Co., 1876.

Del mismo, "Improvement of the Law by Private Enterprise", The Nineteenth Century 4 (1877), pp. 198-218. Disponible en: https://archive.org/stream/ twentiethcentur24unkngoog\#page/n208/mode/2up.

Del mismo, A Digest of the Criminal Law. Crimes and Punishments, Londres, Macmillan and Co., 1877.

Del mismo, A History of the Criminal Law of England, Londres, Macmillan and Co., 1883, 3 vols. Disponible el vol. 3 en: https://ia8oo20o.us.archive.org/5/ items/cu31924069587230/cu31924069587230.pdf.

James F. Stephen y Herbert Stephen, A Digest of the Law of Criminal Procedure in Indictable Offences, Londres, Macmillan \& Co., 1883.

Joseph Story, Commentaries on the Constitution of the United States. With a Preliminary Review of the Constitutional History of the Colonies and States before the Adoption of the Constitution, Boston, Hilliard, Gray and Company, 1833, 3 vols. Disponible en: https://catalog.hathitrust.org/Record/o11532173. Del mismo, Commentaries on the Conflict of Laws, Foreign and Domestic, in Regard to Contracts, Rights, and Remedies, and especially in Regard to Marriages, Divorces, Wills, Successions, and Judgments, Boston, Hilliard, Gray, and Company 1834. Disponible en: https://archive.org/details/commentariesonc17storgoog/page/n9. La edición española es Comentarios sobre el conflicto de las leyes, Buenos Aires, Félix Lajouane Editor, 1891, traducción de Clodomiro Quiroga de la 8a ed. Disponible en: http://www.bibliotecadigital.gob.ar/items/show/1114. 
David Sugarman, "Legal Theory, the Common Law Mind and the Making of the Text-Book Tradition”, en William Twining (ed.), Legal Theory and Common Law, Oxford, Blackwell, 1986, pp. 26-61.

Del mismo, "A Special Relationship? American Influences on English Legal Education, c. 1870-1965”, International Journal of the Legal Profession 18 (2011), pp. 7-57. Disponible en: https://www.researchgate.net/ publication/228204415_A_Special_Relationship_American_Influences_ on_English_Legal_Education_c_1870-1965.

Del mismo, "Making Respected Gentlemen out of Law Professors. A Commentary on Albert Venn Dicey, Can English Law Be Taught at the Universities (1883)", en Isabella Löhr, Matthias Middell y Hannes Siegrist (eds.), Kultur und Beruf in Europa, Stuttgart, Franz Steiner Verlag, 2011, vol. 2, pp. 161-168. Disponible en: https://www.europa.clio-online.de/essay/id/fdae-1592.

Isabel Turégano Mansilla, Derecho y moral en John Austin, Madrid, Centro de Estudios Políticos y Constitucionales, 2001.

Charles Viner, A General Abridgment of Law and Equity. Alphabetically Digested under Proper Titles, with Notes and References to the Whole, Aldershot, 1742-53, 23 vols.

John W. Wallace, The Reporters. Chronologically Arranged. With Occasional Remarks upon their respective Merits, Filadelfia, I. R. Bailey, 1844.

Ian Ward, Writing the Victorian Constitution, Cham, Springer International Publishing, 2018.

John Westlake, A Treatise on Private International Law, or the Conflict of Laws, with Principal Reference to its Practice in the English and other Cognate Systems of Jurisprudence, Londres, W. Maxwell, 1858. Disponible en: https:// archive.org/details/atreatiseonprivoowestgoog. 


\section{PROGRAMA HISTORIA DEL DERECHO PUBLICACIONES \\ ISSN: 2255-5137}

1. Luis Grau, Origenes del constitucionalismo americano. Corpus documental bilingüe / Selected Documents Illustrative of the American Constitutionalism. Bilingual edition, 3 vols., Madrid 2009, 653+671+607 pp.

http://hdl.handle.net/10016/5669

2. Luis Grau, Nosotros el pueblo de los Estados Unidos. La Constitución de los Estados Unidos y sus enmiendas. 1787-1992. Edición bilingüe / We the People of the United States. The U.S. Constitution and its Amendments. 1787-1992. Bilingual edition, Madrid 2010, $338 \mathrm{pp}$.

http://hdl.handle.net/10016/8517

3. Carlos Petit, Fiesta y contrato. Negocios taurinos en protocolos sevillanos (1777-1847), Madrid 2011, 182 pp.

http://hdl.handle.net/10016/10145

4. Pablo Mijangos y González, El nuevo pasado jurídico mexicano. Una revisión de la historiografía jurídica mexicana durante los últimos 20 años, Madrid 2011, 110 pp. http://hdl.handle.net/10016/10488

5. Luis Grau, El constitucionalismo americano. Materiales para un curso de historia de las constituciones, Madrid 2011, xxii+282 pp.

http://hdl.handle.net/10016/11865

6. Víctor Tau Anzoátegui, El taller del jurista. Sobre la Colección Documental de Benito de la Mata Linares, oidor, regente y consejero de Indias, Madrid 2011, 175 pp.

http://hdl.handle.net/10016/12735

7. Ramon Llull, Arte de Derecho, estudio preliminar de Rafael Ramis Barceló, traducción y notas de Pedro Ramis Serra y Rafael Ramis Barceló, Madrid 2011, 178 pp.

http://hdl.handle.net/10016/12762

8. Consuelo Carrasco García, ¿Legado de deuda? A vueltas con la Pandectística, Madrid 2011, 158 pp.

http://hdl.handle.net/10016/12823

9. Pio Caroni, Escritos sobre la codificación, traducción de Adela Mora Cañada y Manuel Martínez Neira, Madrid 2012, xxvi + 374 pp.

http://hdl.handle.net/10016/13028

10. Esteban Conde Naranjo (ed.), Vidas por el Derecho, Madrid 2012, 569 pp.

http://hdl.handle.net/10016/13565

11. Pierangelo Schiera, El constitucionalismo como discurso político, Madrid 2012, 144 pp. http://hdl.handle.net/10016/13962 
12. Rafael Ramis Barceló, Derecho natural, historia y razones para actuar. La contribución de Alasdair MacIntyre al pensamiento jurídico, Madrid 2012, 480 pp.

http://hdl.handle.net/10016/13983

13. Paola Miceli, Derecho consuetudinario y memoria. Práctica jurídica y costumbre en Castilla y León (siglos XI-XIV), Madrid 2012, 298 pp.

http://hdl.handle.net/10016/14294

14. Ricardo Marcelo Fonseca, Introducción teórica a la historia del derecho, prefacio de Paolo Cappellini, Madrid 2012, 168 pp.

http://hdl.handle.net/10016/14913

15. Alessandra Giuliani, Derecho dominical y tanteo comunal en la Castilla moderna, Madrid 2012, 134 pp.

http://hdl.handle.net/10016/15436

16. Luis Grau, An American Constitutional History Course for Non-American Students, Madrid 2012, xx + 318 pp.

http://hdl.handle.net/10016/16023

17. Antonio Ruiz Ballón, Pedro Gómez de la Serna (1806-1871). Apuntes para una biografía jurídica, Madrid 2013, 353 pp.

http://hdl.handle.net/10016/16392

18. Tamara El Khoury, Constitución mixta y modernización en Líbano, prólogo de Maurizio Fioravanti, Madrid 2013, 377 pp.

http://hdl.handle.net/10016/16543

19. María Paz Alonso Romero/Carlos Garriga Acosta, El régimen jurídico de la abogacía en Castilla (siglos XIII-XVIII), Madrid 2013, 337 pp.

http://hdl.handle.net/10016/16884

20. Pio Caroni, Lecciones de historia de la codificación, traducción de Adela Mora Cañada y Manuel Martínez Neira, Madrid 2013, 213 pp.

http://hdl.handle.net/10016/17310

21. Julián Gómez de Maya, Culebras de cascabel. Restricciones penales de la libertad ambulatoria en el derecho codificado español, Madrid 2013, 821 pp.

http://hdl.handle.net/10016/17322

22. François Hotman, Antitriboniano, o discurso sobre el estudio de las leyes, estudio preliminar de Manuel Martínez Neira, traducción de Adela Mora Cañada, Madrid 2013, 211 pp. http://hdl.handle.net/10016/17855

23. Jesús Vallejo, Maneras y motivos en Historia del Derecho, Madrid 2014, 184 pp.

http://hdl.handle.net/10016/18090

24. María José María e Izquierdo, Los proyectos recopiladores castellanos del siglo XVI en los códices del Monasterio de El Escorial, Madrid 2014, 248 pp.

http://hdl.handle.net/10016/18295 
25. Regina Polo Martín, Centralización, descentralización y autonomía en la España constitucional. Su gestación y evolución conceptual entre 1808 y 1936, Madrid 2014, 393 pp. http://hdl.handle.net/10016/18340

26. Massimo Meccarelli/Paolo Palchetti/Carlo Sotis (eds.), Il lato oscuro dei Diritti umani: esigenze emancipatorie e logiche di dominio nella tutela giuridica dell'individuo, Madrid 2014, 390 pp.

http://hdl.handle.net/10016/18380

27. María López de Ramón, La construcción histórica de la libertad de prensa: Ley de policía de imprenta de 1883, Madrid 2014, 143 pp.

http://hdl.handle.net/10016/19296

28. José María Coma Fort, Codex Theodosianus: historia de un texto, Madrid 2014, $536 \mathrm{pp}$.

http://hdl.handle.net/10016/19297

29. Jorge Alberto Núñez, Fernando Cadalso y la reforma penitenciaria en España (18831939), Madrid 2014, 487 pp.

http://hdl.handle.net/10016/19662

30. Carlos Petit, Discurso sobre el discurso. Oralidad y escritura en la cultura jurídica de la España liberal, Madrid 2014, 185 pp.

http://hdl.handle.net/10016/19670

31. Jean-Étienne-Marie Portalis, Discurso preliminar sobre el proyecto de Código civil, Madrid 2014, 53 pp.

http://hdl.handle.net/10016/19797

32. Cesare Beccaria, Tratado de los delitos y de las penas, Madrid 2015, 87 pp.

http://hdl.handle.net/10016/20199

33. Massimo Meccarelli/Paolo Palchetti (eds.), Derecho en movimiento: personas, derechos y derecho en la dinámica global, Madrid 2015, 256 pp.

http://hdl.handle.net/10016/20251

34. Alessandro Somma, Introducción al derecho comparado, traducción de Esteban Conde Naranjo, Madrid 2015, 193 pp.

http://hdl.handle.net/10016/20259

35. A. F. J. Thibaut, Sobre la necesidad de un derecho civil general para Alemania, Madrid 2015, 42 pp.

http://hdl.handle.net/10016/21166

36. J.-J.-R. de Cambacérès, Discursos sobre el Código civil, Madrid 2015, 61 pp.

http://hdl.handle.net/10016/21254

37. Ramon Llull, Arte breve de la invención del derecho, estudio preliminar de Rafael Ramis Barceló, traducción de Pedro Ramis Serra y Rafael Ramis Barceló, Madrid 2015, 233 pp. http://hdl.handle.net/10016/21406 
38. F. C. von Savigny, De la vocación de nuestra época para la legislación y la ciencia del Derecho, Madrid 2015, 130 pp.

http://hdl.handle.net/10016/21520

39. Joaquín Marín y Mendoza, Historia del derecho natural y de gentes, Madrid 2015, 40 pp. http://hdl.handle.net/10016/22079

40. Rafael Ramis Barceló, Petrus Ramus y el Derecho. Los juristas ramistas del siglo XVI, Madrid 2016, $250 \mathrm{pp}$.

http://hdl.handle.net/10016/22197

41. Emanuele Conte, La fuerza del texto. Casuística y categorías del derecho medieval, edición de Marta Madero, Madrid 2016, 194 pp.

http://hdl.handle.net/10016/22261

42. Constituciones españolas: 1808-1978, edición de Javier Carlos Díaz Rico, Madrid 2016, $259 \mathrm{pp}$.

http://hdl.handle.net/10016/22905

43. Giacomo Demarchi, Provincia y Territorio en la Constituyente española de 1931. Las raíces europeas del Estado integral, Madrid 2016, 362 pp.

http://hdl.handle.net/10016/22906

44. Miguel Ángel Ladero Quesada/César Olivera Serrano (dirs.), Documentos sobre Enrique IV de Castilla y su tiempo, Madrid 2016, $\mathrm{xx}+1446$ pp.

http://hdl.handle.net/10016/23015

45. Gustavo César Machado Cabral/Francesco Di Chiara/Óscar Hernández Santiago/Belinda Rodríguez Arrocha, El derecho penal en la edad moderna: Nuevas aproximaciones a la doctrina y a la práctica judicial, Madrid 2016, 217 pp.

http://hdl.handle.net/10016/23021

46. Lope de Deza, Juicio de las leyes civiles, estudio preliminar de Víctor Tau Anzoátegui, edición de María José María e Izquierdo, Madrid 2016, 136 pp.

http://hdl.handle.net/10016/23228

47. Henrik Brenkman, Historia de las Pandectas, estudio preliminar, traducción y notas de Juan Lorenzo, Madrid 2016, 426 pp.

http://hdl.handle.net/10016/23317

48. Massimo Meccarelli (a cura di), Diversità e discorso giuridico. Temi per un dialogo interdisciplinare su diritti e giustizia in tempo di transizione, Madrid 2016, 287 pp. http://hdl.handle.net/10016/23792

49. Beatrice Pasciuta, El diablo en el Paraíso. Derecho, teología y literatura en el Processus Satane (s. XIV), Madrid 2017, 264 pp.

http://hdl.handle.net/10016/24439

50. Maximiliano Hernández Marcos, Tras la luz de la ley: legislación y justicia en Prusia a finales del siglo XVIII. Un modelo de Ilustración jurídica, Madrid 2017, 184 pp.

http://hdl.handle.net/10016/24488 
51. Eleonora Dell'Elicine/Paola Miceli/Alejandro Morin (comps.), Artificios pasados. Nociones del derecho medieval, Madrid 2017, 307 pp.

http://hdl.handle.net/10016/24514

52. Eva Elizabeth Martínez Chavéz, Redes en el exilio. Francisco Ayala y el Fondo de Cultura Económica, Madrid 2017, 145 pp.

http://hdl.handle.net/10016/24715

53. Pierre de Jean Olivi, Tratado de los contratos, estudio preliminar de Rafael Ramis Barceló, traducción de Pedro Ramis Serra y Rafael Ramis Barceló, Madrid 2017, 171 pp. http://hdl.handle.net/10016/25200

54. Daniel Panateri, El discurso del rey. El discurso jurídico alfonsí y sus implicaciones políticas, Madrid 2017, 284 pp.

http://hdl.handle.net/10016/25377

55. Joaquín Costa, El problema de la ignorancia del derecho y sus relaciones con el estatus individual, el referéndum y la costumbre, Madrid 2017, 85 pp.

http://hdl.handle.net/10016/25578

56. Massimo Meccarelli (ed.), Reading the Crisis: Legal, Philosophical and Literary Perspectives, Madrid 2017, $224 \mathrm{pp}$.

http://hdl.handle.net/10016/25705

57. Pablo Ramírez Jerez/Manuel Martínez Neira, La historia del derecho en la Real Academia de Ciencias Morales y Políticas. Los concursos de derecho consuetudinario, Madrid 2017, 322 pp.

http://hdl.handle.net/10016/25809

58. Thomas Duve (coord.), Actas del XIX Congreso del Instituto Internacional de Historia del Derecho Indiano, 2 vols., Madrid 2017, 1681 pp.

http://hdl.handle.net/10016/25729

59. Víctor Saucedo, Conspiracy. A Conceptual Genealogy (Thirteenth to Early Eighteenth Century), Madrid 2017, 350 pp.

http://hdl.handle.net/10016/26095

60. Aurora Miguel Alonso (dir.), Doctores en derecho por la Universidad Central. Catálogo de tesis doctorales 1847-1914, Madrid 2017, 571 pp.

http://hdl.handle.net/10016/26198

61. François Hotman, Francogallia, o la Galia francesa, estudio preliminar y traducción de Tamara El Khoury, Madrid 2017.

http://hdl.handle.net/10016/26321

62. Rafael Altamira, Spain. Sources and Development of Law, estudio preliminar y edición de Carlos Petit, Madrid 2018, lxxxvi + 126 pp.

http://hdl.handle.net/10016/26322 
63. Jesús Delgado Echeverría, Joaquín Costa, jurista y sociólogo. Derecho consuetudinario e ignorancia de la ley, Madrid 2018, 174 pp.

http://hdl.handle.net/10016/26335

64. Rubén Pérez Trujillano, Creación de constitución, destrucción de Estado: la defensa extraordinaria de la II República española (1931-1936), Madrid 2018, 367 pp.

http://hdl.handle.net/10016/27108

65. Eugenia Torijano Pérez, Los estudios jurídicos en la universidad salmantina del siglo XIX, Madrid 2018, 625 pp. + apéndices complementarios.

http://hdl.handle.net/10016/27392

66. Laura Beck Varela/María Julia Solla Sastre (coordinadoras), Estudios Luso-Hispanos de Historia del Derecho. Estudos Luso-Hispanos de História do Direito, Madrid 2018, 543 pp.

http://hdl.handle.net/10016/27751

67. Manuel Martínez Neira/Pablo Ramírez Jerez, Hinojosa en la Real Academia de Ciencias Morales y Políticas, Madrid 2018, 279 pp.

http://hdl.handle.net/10016/27810

68. Rudolf von Jhering, La lucha por el derecho, estudio preliminar y edición de Luis Lloredo Alix, Madrid 2018, 137 pp.

http://hdl.handle.net/10016/27845

69. Enrique Roldán Cañizares, Luis Jiménez de Asúa: Derecho penal, República, Exilio, Madrid 2019, 406 pp.

http://hdl.handle.net/10016/28236

70. José María Puyol Montero, Enseñar derecho en la República. La Facultad de Madrid (1931-1939), Madrid 2019, 486 pp.

http://hdl.handle.net/10016/28286

71. Pedro L. López Herraiz, Formar al hombre de Estado. Génesis y desarrollo de la École libre des sciences politiques (1871-1900), Madrid 2019, 333 pp.

http://hdl.handle.net/10016/28313

72. Emiliano J. Buis, El juego de la ley. La poética cómica del derecho en las obras tempranas de Aristófanes (427-414 a.C.), Madrid 2019, 442 pp.

http://hdl.handle.net/10016/28358

73. Virginia Amorosi/Valerio Massimo Minale (ed.), History of Law and Other Humanities: Views of the Legal World Across the Time, Madrid 2019, 588 pp.

http://hdl.handle.net/10016/28459

74. Carlos Petit, Un Código civil perfecto y bien calculado. El proyecto de 1821 en la historia de la codificación, Madrid 2019, 409 pp.

http://hdl.handle.net/10016/28678 
75. Eduardo de Hinojosa, El elemento germánico en el derecho español, Madrid 2019, 82 pp. http://hdl.handle.net/10016/28877

76. Carlos Petit (ed.), Derecho ex cathedra. 1847-1936. Diccionario de catedráticos, Madrid 2019, 491 pp.

http://hdl.handle.net/10016/28916

77. Manuel Ángel Bermejo Castrillo (ed.), La memoria del jurista español. Estudios, Madrid 2019, 416 pp.

http://hdl.handle.net/10016/29108

78. Elisabetta Fiocchi Malaspina/Simona Tarozzi (ed.), Historical Perspectives on Property and Land Law. An Interdisciplinary Dialogue on Methods and Research Approaches, Madrid 2019, 236 pp.

http://hdl.handle.net/10016/29290

79. Daniel J. García López, La máquina teo-antropo-legal. La persona en la teoría jurídica franquista, Madrid 2020, $121 \mathrm{pp}$.

http://hdl.handle.net/10016/29463

80. Concepción Arenal, Las colonias penales de la Australia y la pena de deportación, Madrid 2020, 99 pp.

http://hdl.handle.net/10016/29667

81. Cristina Morales Segura, Galeotes de mercurio. El caso de Mateo Alemán: la interacción entre el derecho y la literatura en el informe de la mina de mercurio de Almadén y $\mathrm{El}$ Guzmán de Alfarache, Madrid 2020, 276 pp.

http://hdl.handle.net/10016/29888

82. Eduardo de Hinojosa, La condición civil de la mujer en el derecho español antiguo y moderno, Madrid 2020, 50 pp.

http://hdl.handle.net/10016/30043

83. Eduardo de Hinojosa, Influencia que tuvieron en el derecho público de su patria y singularmente en el derecho penal los filósofos y teólogos españoles anteriores a nuestro siglo, Madrid 2020, 146 pp.

http://hdl.handle.net/10016/30052

84. Eva Elizabeth Martínez Chávez, España en el recuerdo, México en la esperanza. Juristas republicanos del exilio, Madrid 2020, $343 \mathrm{pp}$.

http://hdl.handle.net/10016/30520

85. Rafael de Ureña y Smenjaud, Una tradición jurídica española: La autoridad paterna como el poder conjunto y solidario del padre y de la madre, estudio preliminar y edición de Carlos Petit, Madrid 2020, 174 pp.

http://hdl.handle.net/10016/30550

86. Carlos Petit, Derecho por entregas. Estudios sobre prensa y revistas en la España liberal, Madrid 2020, 311 pp.

http://hdl.handle.net/10016/30841 
87. Massimo Meccarelli/Cristiano Paixão/Claudia Roesler (ed.), Innovation and Transition in Law: Experiences and Theoretical Settings, Madrid 2020, 352 pp.

http://hdl.handle.net/10016/31394

88. Fernando Martínez-Pérez, Posesión, dominio y Registro. Constitución de la propiedad contemporánea en España (1861-1944), Madrid 2020, 286 pp.

http://hdl.handle.net/10016/31430

89. Fernando Liendo Tagle, Prensa jurídica española. Avance de un repertorio (1834-1936), Madrid 2020, 235 pp.

http://hdl.handle.net/10016/31583

90. Rafael Ramis Barceló, El nacimiento de la Filosofía del derecho. De la Philosophia iuris a la Rechtsphilosophie, Madrid 2021, 248 pp.

http://hdl.handle.net/10016/31704

91. Eugenia Torijano Pérez, Ser (de nuevo) doctor por Salamanca. Las tesis doctorales de la Facultad de Derecho en el Sexenio Revolucionario (1868-1874), Madrid 2021, 441 pp. http://hdl.handle.net/10016/31694

92. Víctor Saucedo, The Poulterers' Case (1611): A Landmark in the History of Criminal Conspiracy, Madrid 2021, 302 pp. http://hdl.handle.net/10016/31790

93. Albert Venn Dicey, ¿Puede enseñarse el derecho inglés en las universidades?, Madrid 2021, $122 \mathrm{pp}$.

http://hdl.handle.net/10016/31912 